\title{
Conductive MOFs with Photophysical Properties: Applications and Thin-Film Fabrication
}

Cite as

Nano-Micro Lett.

(2020) 12:132

Received: 21 March 2020

Accepted: 29 May 2020

Published online: 19 June 2020

(C) The Author(s) 2020

\author{
Zeyu Zhuang ${ }^{1}$, Dingxin Liu ${ }^{1} \bowtie$ \\ $\triangle$ Dingxin Liu, liudx9@mail.sysu.edu.cn \\ 1 Skate Key Laboratory of Optoelectronic Materials and Technologies, Nanotechnology Research \\ Center, School of Materials Science and Engineering, Sun Yat-Sen University, Guangzhou 510275, \\ People's Republic of China
}

\section{HIGHLIGHTS}

- An overview on photophysical properties of conductive metal-organic frameworks (MOFs) including photoconductivity and photoluminescence is provided.

- Miscellaneous applications of MOFs with photophysical properties are discussed.

- Recent advances in integration of photoactive MOFs with practical devices are summarized.

\begin{abstract}
Metal-organic frameworks (MOFs) are a class of hybrid materials with many promising applications. In recent years, lots of investigations have been oriented toward applications of MOFs in electronic and photoelectronic devices. While many high-quality reviews have focused on synthesis and mechanisms of electrically conductive MOFs, few of them focus on their photophysical properties. Herein, we provide an in-depth review on photoconductive and photoluminescent properties of conductive MOFs together with their corresponding applications in solar cells, luminescent sensing, light emitting, and so forth. For integration of MOFs with practical devices, recent advances in fabrication of photoactive MOF thin films are also summarized.
\end{abstract}

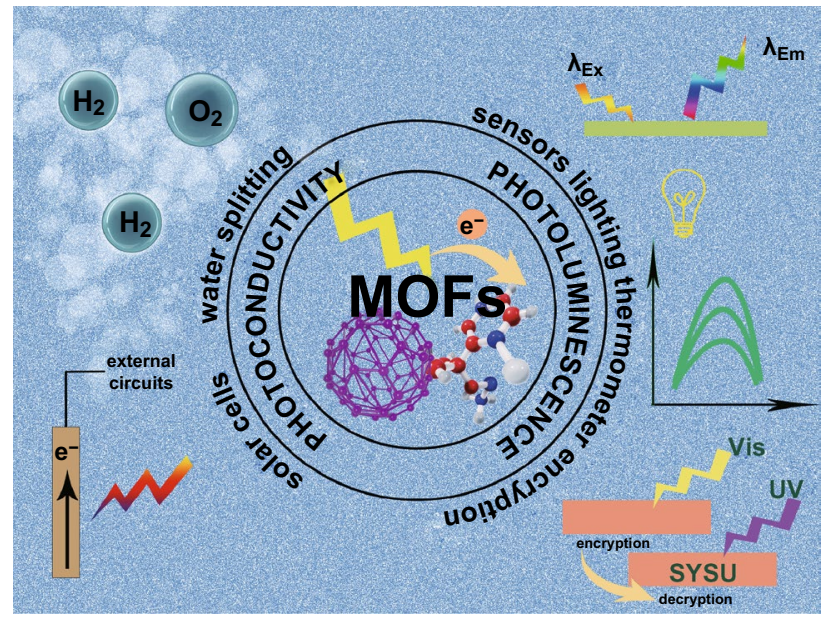

KEYWORDS Metal-organic frameworks; Photoconductivity; Photoluminescence; Thin films

\section{Introduction}

As a collective class of crystalline materials containing metal nodes connected by organic ligands, metal-organic frameworks (MOFs) have attracted much attention [1]. The high porosity, stability and exceptional topological and compositional tunability make MOFs applicable in many fields such as gas storage, separation [2], catalysis [3] and ionic transport [4]. In recent years, more and more conductive MOFs have been designed and synthesized with their electrical conduction nature widely discussed. Conductive MOFs have been demonstrated as promising materials to improve technologies such as energy conversion and storage, electrochemical capture and release, battery systems, chemical sensing, and catalysis [5]. Especially, under irradiation of laser, conductive MOFs generally exhibit surprising 
reactions such as the change of electrical conductivity and light emission effect [6]. As is known to all, light energy has played a more and more significant role in modern society due to its renewability and eco-friendliness. The effective utilization of light energy will help alleviate energy crisis. These laser-induced photophysical properties of conductive MOFs expand their applications in light harvesting, analyte sensing and so on and provide another possible way to utilize the light energy [7]. Furthermore, with the help of advances in fabrication of MOF thin films, it is enabled to integrate functional MOFs with electronic and optoelectronic devices.

While many excellent reviews have focused on the synthesis, mechanisms, and miscellaneous applications of conductive MOFs [8-11], few of them focus on their photophysical properties (i.e., their responses under irradiation of laser). Therefore, in this review, we will discuss in detail the photophysical properties of conductive MOFs. Specifically, we provide an in-depth review on the photoconductive and photoluminescent properties of MOFs as well as their corresponding applications in solar cells, luminescent sensors, lighting devices, and so forth. In addition, for integration in practical devices, MOFs need to be prepared in forms of thin films, so in the last section we will discuss recent advances in deposition of MOF thin films that exhibit exceptional photophysical properties and hold a bright prospect in electronic and optoelectronic fields.

\section{Photoconductivity}

\subsection{Photoconductive MOFs}

The band gap theory accounts for conductive or insulating properties of many MOFs. For MOFs with large band gap between the valence band (VB) and conduction band (CB), it is usually hard to realize charge transfer and hence electrical conductivity. Upon irradiation at wavelengths exceeding the band gap, electrons can be excited from the VB to CB, which arouse electron-hole separation with positive holes created in the VB and negative electrons in the CB. Based on the above band gap mechanism, lowering the band gap is a promising strategy for synthesis of photoconductive MOFs, which exhibit increased electrical current under illumination and can possibly function as photoactive electrodes for many optoelectrical applications such as water splitting and solar cells. In general, the band gap of MOFs with electron donor-acceptor pairs is relatively narrow. In MOFs of donor-acceptor architecture, electrons are released by the electron donor and the electron acceptor further promotes the charge transfer by enhancing electron-hole separation and inhibiting electron-hole recombination. Therefore, it is a promising strategy to synthesize photoconductive MOFs through donor-acceptor architecture, which usually involves photoactive organic compounds. Besides photoconductivity based on the organic moieties, attempts have also been made to explore the effects of inorganic building unit on photoconductive properties of MOFs.

\subsubsection{Photoconductivity Based on Organic Moieties}

Electron-accepting ligands As metal centers in MOFs tend to emit electrons due to their reduction property, they usually serve as electron donors. Therefore, electron-accepting organic ligands are typically involved in construction of donor-acceptor architecture for photoluminescent MOFs. With suitable band gap, electrons will be generated and transferred from the metal center to ligand upon irradiation at some wavelengths.

1,4,5,8-Naphthalene diimides (NDIs) are a class of organic compounds with excellent semiconductive and optical properties. On basis of this, the photoactive response of MOF-CoNDI-py-2, featuring Co(II), $N, N^{\prime}$-bis(4-pyridyl)1,4,5,8-naphthalene diimide (NDI-py) and terephthalic acid (TpA), was observed [12]. Upon irradiation, a charge transfer from the metal center to the $\pi$-acceptor NDI-py occurred, which promoted hole transport through the Co-TpA direction and electron transport through the NDI-py direction. As shown in Fig. 1, the as-synthesized MOF exhibited anisotropic photoconductivity and the highest photoresponse intensities $\left(J_{\mathrm{ph}}\right)$ obtained coincided with the charge transfer band. Interestingly, in this case, a photoresistive-photoresponsive dual behavior was observed. While mostly the current increased upon illumination, at negative bias sometimes the current decreased under illumination at some wavelengths. This special photoresistance phenomenon could be ascribed to the metal centers as charge trap sites in their oxidation state which may impede the charge transfer.

Another typical example is the 3D framework $\left\{\left[\mathrm{Cu}^{\mathrm{I}} \mathrm{Cu}_{2}^{\mathrm{II}}(\mathrm{DCTP})_{2}\right] \mathrm{NO}_{3} \cdot 1.5 \mathrm{DMF}\right\}_{\mathrm{n}}$ (DCTP $=4^{\prime}$-(3,5-dicarboxyphenyl)-4,2':6',4'-terpyridine) with a narrow band gap of $2.1 \mathrm{eV}$ [13]. Upon irradiation, 
electrons jumped into the $\mathrm{CB}$ and holes were generated in the VB. Local density of states (LDOS) and partial density of sates (PDOS) analysis revealed that the valance-band maximum (VBM) was dominated by $\mathrm{Cu} 3 \mathrm{~d}$ orbitals and the conduction-band minimum (CBM) mainly consisted of $2 p$ orbitals of $\mathrm{C}$ and $\mathrm{N}$ of the ligand. Thereby, the excited electrons transferred from $\mathrm{Cu}$ to neighboring $\mathrm{C}$ and $\mathrm{N}$ atoms. Notably, for this photoconductive MOF, the CBM was higher than $\mathrm{H}^{+} / \mathrm{H}_{2}$ energy level and the VBM was lower than $\mathrm{O}_{2} / \mathrm{H}_{2} \mathrm{O}$ level, enabling the production of $\mathrm{H}_{2}$ and $\mathrm{O}_{2}$ with this MOF under irradiation.

Electron-donating ligands Not all ligands serve as electron acceptors in photoconductive MOFs. For some electron-donating ligands, guest molecules are usually required to form donor-acceptor pairs. Porphyrins, for example, are excellent electron donors with delocalized

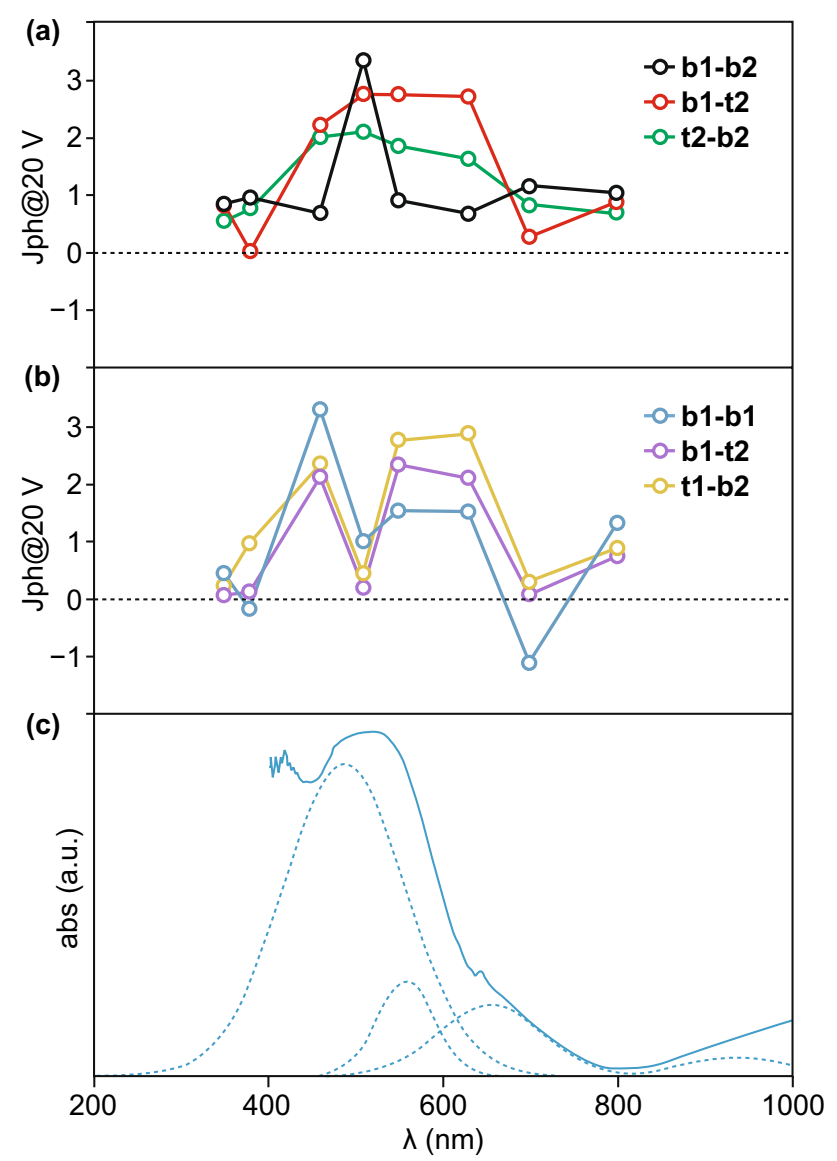

Fig. 1 a, b Photoresponse intensities at $20 \mathrm{~V}$ (different combinations of $\mathrm{b} 1, \mathrm{~b} 2$ and $\mathrm{t} 1, \mathrm{t} 2$ stand for different crystal orientations). c Electronic absorption spectrum of MOF-CoNDI-py-2. Reprinted with permission from Ref. [12]. Copyright 2017, Springer Nature $\pi$-systems. Recently, Liu et al. have conducted research to compare the photoconductivity of $\mathrm{Cu}(\mathrm{BDPC})$ and $\mathrm{Zn}(\mathrm{TPP})$ SURMOFs with embedded $\mathrm{C}_{60}$ fullerene and found that the physical properties of both SURMOFs were considerably distinct although they shared the very similar lattice constants and pore sizes [14]. While $\mathrm{C}_{60}$-loaded $\mathrm{Cu}(\mathrm{BDPC})$ responded to light irradiation slightly with their conductivity almost unaffected by irradiation of light of various wavelengths, the opposite was true for $\mathrm{C}_{60}$ @ $\mathrm{Zn}$ (TPP), which was ascribed to the different linkers in them as $\mathrm{Cu}$ (BDPC) possessed phenyl-based linkers and $\mathrm{Zn}$ (TPP) porphyrinic linkers. As shown in Fig. 2a, applying $2 \mathrm{~V}$ to the $\mathrm{C}_{60} @ \mathrm{Zn}(\mathrm{TPP})$ sample, the current increased from 0.11 in the dark to $9 \mathrm{nA}$ upon irradiation of photon wavelength at $455 \mathrm{~nm}$ (blue light). Figure $2 \mathrm{~b}$ shows that the current increased with voltage roughly exponentially in the dark, whereas for light of $455 \mathrm{~nm}$, the current was proportional to the voltage, revealing almost ideal ohmic conduction behavior with a conductivity of $1.3 \times 10^{-7} \mathrm{~S} \mathrm{~cm}^{-1}$, corresponding to a conductivity increase upon illumination by 2 orders of magnitude. The photoconductivity of $\mathrm{C}_{60} @ \mathrm{Zn}(\mathrm{TPP})$ was attributed to the interaction of electrondonor porphyrin linkers and electron-acceptor $\mathrm{C}_{60}$ guest molecules. Upon irradiation, the Soret band of porphyrin was activated, enabling the generation of electron-hole pairs, and at the same time, $\mathrm{C}_{60}$ significantly improved the separation and transfer of electron-hole pairs, restraining their recombination and the electron back-transfer. Furthermore, it is possible to modify the active components, porphyrin and fullerene, without changing the crystal structure. $\mathrm{C}_{60}-\mathrm{COOH} @ \mathrm{Zn}(\mathrm{DAP})$ with a different porphyrin linker $(\mathrm{DAP}=[10,20$-bis $(4$-carboxyphenyl $) 5,15$ diazaporphyrinato]zinc(II)) was thus synthesized and showed similar photoconductance properties.

It has been revealed that the delocalized $\pi$ electrons can effectively decrease the band gap of MOFs and hence promote photoconductive properties. A research on 4-(4-oxopyridin-1 $(4 \mathrm{H})$-yl)phthalic acid $\left(\mathrm{H}_{2} \mathrm{~L}\right)$ and three $\mathrm{H}_{2}$ L-based MOFs $\mathrm{ZnL}(\mathrm{DPE})\left(\mathrm{H}_{2} \mathrm{O}\right) \cdot \mathrm{H}_{2} \mathrm{O}(\mathrm{DPE}=(\mathrm{E})$ 1,2-di(pyridine-4-yl)ethene), $\mathrm{CdL}\left(\mathrm{H}_{2} \mathrm{O}\right)_{2}$ and $\mathrm{CdL}$ was conducted [15]. Even though the three as-synthesized MOFs shared the same $\mathrm{L}^{2-}$ ligand, the band gap of the first MOF was much lower than that of either the other two or the free $\mathrm{H}_{2} \mathrm{~L}$ ligand, which was ascribed to the presence of DPE ligand in the first MOF. DPE ligand as N-donor was a planar molecule full of $\pi$ electrons over the large 

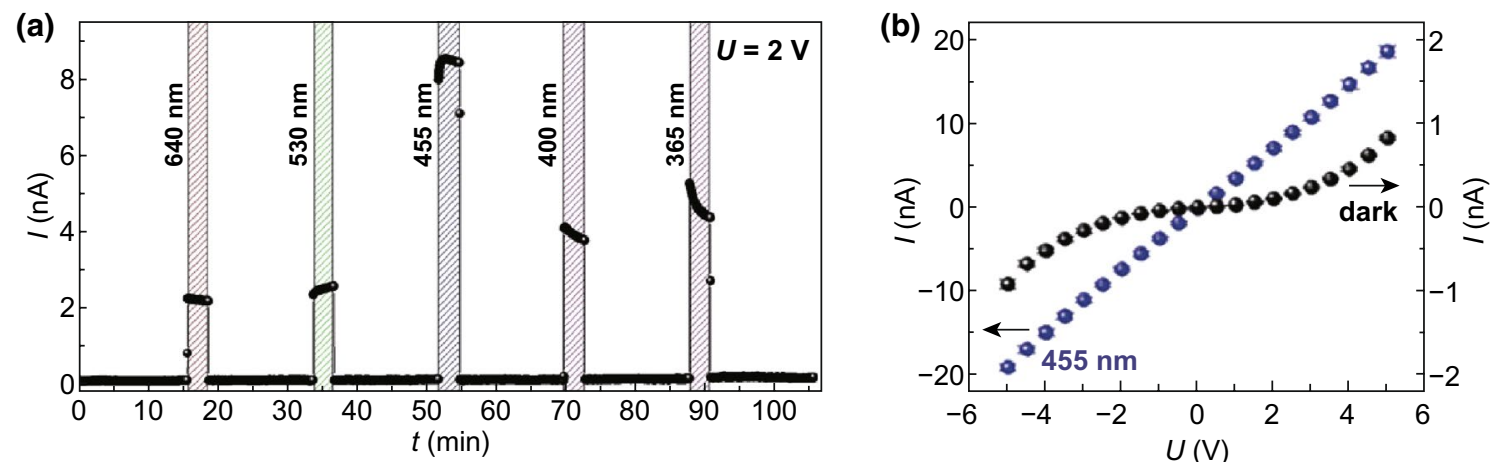

Fig. 2 a DC current $I$ at a voltage of 2 V under irradiations with light of 640, 530, 455, 400, and 365 nm wavelength. b Current-voltage curve of the sample in the dark (black spheres) and under irradiation with $455 \mathrm{~nm}$ (blue spheres). Reprinted with permission from Ref. [14]. Copyright 2019, Wiley. (Color figure online)

conjugated system, which decreased the conduction-band minimum (CBM) of the first MOF and therefore its band gap. The decrease in the band gap considerably improved the photoconductivity of the MOF. The photocurrent response of the MOF and $\mathrm{H}_{2} \mathrm{~L}$ is shown in Fig. 3. The largest photocurrent density of the MOF was approximately $8 \times 10^{-5} \mathrm{~mA} \mathrm{~cm}^{-2}$, much larger than that of $\mathrm{H}_{2} \mathrm{~L}$ $\left(3 \times 10^{-5} \mathrm{~mA} \mathrm{~cm}^{-2}\right)$.

Organic guest molecules Besides the above researches where organic compounds directly serve as the ligands in photoconductive MOFs, donor-acceptor architecture can also be constructed completely with two different guest molecules with one as electron acceptor and the other as electron-donor. In this case, MOFs usually function as not only a host but also a photon antenna. Taking advantages of the highly ordered structure and permanent porosity of MOFs, a typical electron-accepting organic compound $\alpha, \omega$-dihexylsexithiophene (DH6T) and a typical electrondonating organic compound [6] -phenyl- $\mathrm{C}_{61}$-butyric acid methyl ester (PCBM) were infiltrated into the channel and cavity of MOF-177 $\left(\mathrm{ZnO}_{4}(\mathrm{BTB})_{2}\right.$; BTB $=1,3,5$-benzenetribenzoate) [16]. The MOF in this MOF-donor-acceptor hybrid served as a host which confined and stabilized guest molecules, preventing their phase segregation, as well as a photon antenna which harvested light and transferred it to the guest acceptor molecules. This MOF-donor-acceptor hybrid provides another promising strategy that photoconductivity can be realized by carefully and appropriately designing the guest@MOF system.

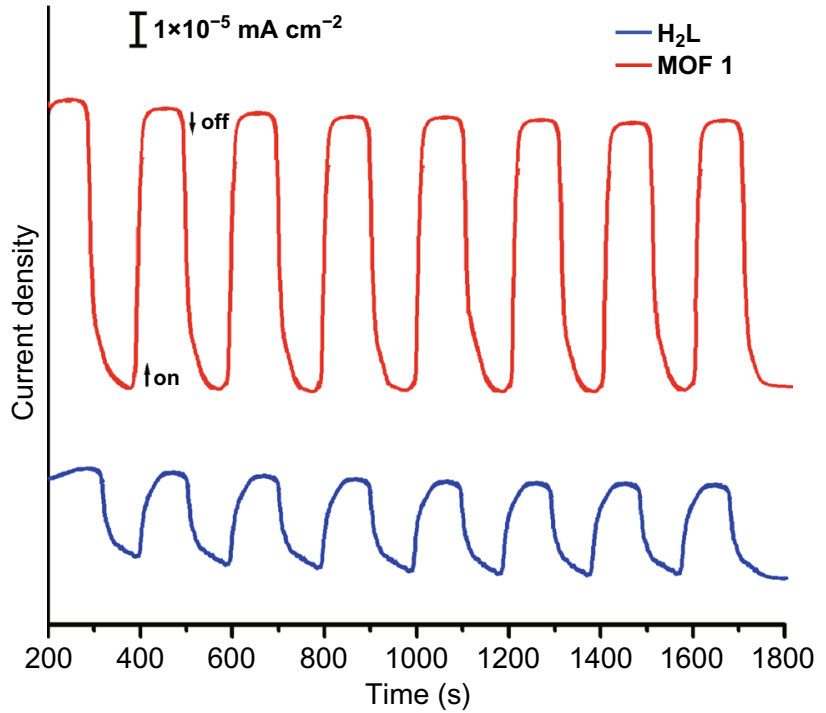

Fig. 3 Comparison of photocurrent time plots of $\mathrm{ZnL}(\mathrm{DPE})$ $\left(\mathrm{H}_{2} \mathrm{O}\right) \cdot \mathrm{H}_{2} \mathrm{O}$ and free $\mathrm{H}_{2} \mathrm{~L}$ ligand. Reprinted with permission from Ref. [15]. Copyright 2016, Elsevier

\subsubsection{Photoconductivity Based on Inorganic Moieties}

Although most reported photoconductive MOFs are based on the photoactive organic ligands, photoconductivity originated from inorganic building unit of MOFs has also been demonstrated. A mdip-based Ti-MOF with the formula $\mathrm{Ti}_{12} \mathrm{O}_{15}$ (mdip) ${ }_{3}$ (formate) ${ }_{6}$ (mdip $=3,3^{\prime}, 5,5^{\prime}$-tetracarboxydiphenylmethane), namely MIL-177-LT (LT stands for low temperature and HT below for high temperature), underwent 
an irreversible phase transformation into MIL-177-HT upon heating at $280{ }^{\circ} \mathrm{C}$ for $12 \mathrm{~h}$, as shown in Fig. 4 [17]. The dimensionality change of the inorganic secondary building units in MIL-177 (LT: 0D; HT: 1D) had a significant impact on the photophysical properties. In contrast to MIL-177-LT which generated extremely weak photoconductivity signals upon ultraviolet (UV) laser irradiation due to the lack of conduction pathways in their frameworks, MIL-177-HT exhibited exceptional photoconductive response with the carrier mobility calculated to be at least $4 \times 10^{-4} \mathrm{~cm}^{2} \mathrm{~s}^{-1} \mathrm{~V}^{-1}$, comparable to nano-sized $\mathrm{TiO}_{2}$ materials [18]. After phase transformation, MIL-177-HT exhibited a narrow band gap of $3.67 \mathrm{eV}$. This revealed that the band gap of MOFs could be lowered and photoconductivity could be increased by increasing the dimensionality of the inorganic building unit. MIL-177-HT was the first reported photoconductive MOFs whose photoconductivity mainly came from the inorganic Ti-O building unit. Further research on the conduction mechanism and the possible functions of inorganic building unit for photoconductivity is still under way.

\subsection{Applications}

\subsubsection{Solar Cells}

As a kind of clean and reproducible energy, solar energy is expected to alleviate the energy crisis and reduce environment pollution induced by conventional fuels. Solar cells with high light harvesting and conversion efficiency are thus desired to optimize the energy structure. By converting light

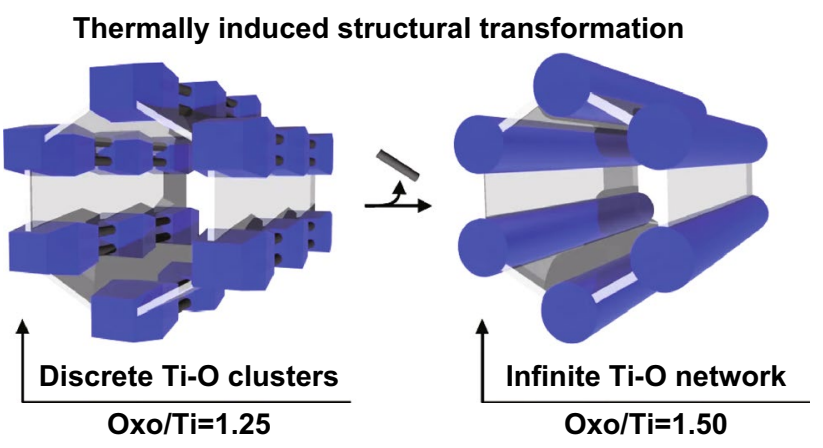

Fig. 4 Thermally induced phase transformation of MIL-177. Reprinted with permission from Ref. [17]. Copyright 2018, Springer Nature energy into electrical energy, photoconductive MOFs are promising for the construction of photoanodes in solar cells with higher efficiency, stability, and lower cost. Typically, a photoanode consists of a thin film of photosensitizer coated on porous metal oxide supported by a conductive and transparent substrate. The substrate widely used in photoanode is FTO glass. $\mathrm{TiO}_{2}$ and $\mathrm{ZnO}$ are the most commonly adopted metal oxides. And MOFs and derivatives have attracted much attention as photosensitizer in photoanodes.

It should be noted that while many MOFs have been reported to serve as functional additives or interlayers to modify the electrodes or electrolytes and improve charge generation and electrical conductivity in dye-sensitized solar cells, hybrid perovskite solar cells and organic solar cells, which has been summarized and discussed in an excellent review [19], investigations on photoconductive MOFs that directly serve as photoactive sensitizers in photoanodes are rare and limited. Most reported researches in this field focus on guest@MOFs systems, where the guest molecules like QDs, POM and dyes serve as photosensitizer to absorb photons and generate electrons and the MOF hosts better improve adsorption property and suppress charge recombination, which will be illustrated in detail as the following.

QDs are prominent photoactive materials with broad adsorption band and effective exciton generation and present a bright prospect for solar cells with relatively lower cost compared to silicon. A research innovatively combined CdTe QDs with MOF NTU-9, whose band gap is comparable to that of semiconductive $\mathrm{TiO}_{2}$ [20]. The CdTe/NTU-9 composite was used as photosensitizer in photoanode of a dye-sensitized solar cell and yielded a photoelectric conversion efficiency (PCE) up to $3.20 \%$, much higher than $1.67 \%$ obtained with CdTe alone. The improved PCE was mainly ascribed to the enhanced adsorption capacity and lower charge recombination rate due to the ordered porous structure of NTU-9. Furthermore, polyoxometalate (POM), a kind of metal-oxide cluster compound, is an excellent electron acceptor with light-absorbing properties. POM@ MOF hybrid is another effective system as photosensitizer for modification of photoanodes in solar cells. POM@ $\mathrm{MOF}(\mathrm{Fe})$ hybrids were synthesized solvothermally by Zhang et al. and coated on $\mathrm{ZnO}$ photoanode [21]. As shown in Fig. 5a, compared to bare $\mathrm{ZnO}$ photoanode, the POM@ $\mathrm{MOF}(\mathrm{Fe})$-modified $\mathrm{ZnO}$ photoanode exhibited an increase in photoelectric conversion efficiency from 0.057 to $0.073 \%$. Figure $5 \mathrm{~b}$ illustrates the mechanism of charge transfer of 
POM@MOF(Fe). Upon irradiation, electrons were excited and transferred from the ligand of $\mathrm{POM}$ to the $\mathrm{MOF}(\mathrm{Fe})$ and then injected into the conduction band of $\mathrm{ZnO}$. This process could enhance electron injection and electron-hole separation as well as photon capture, leading to higher photoelectric conversion efficiency.

Despite most researches on guest@MOFs systems with guest molecules as the photoactive sensitizer, some investigations on photoactive MOFs as the direct photosensitizer have been conducted as well. A graphene-doped Eu-MOF was synthesized to construct graphene- $\mathrm{MOF} / \mathrm{TiO}_{2} / \mathrm{FTO}$ photoanode [22]. In this case, the photoactive Eu-MOF served as photosensitizer that adsorbed photons and generated electrons, and graphene facilitated charge transfer. Upon irradiation, electrons were generated from the LUMO level of the Eu-MOF and transferred through graphene to the conduction band of $\mathrm{TiO}_{2}$. The synergy of Eu-MOF and graphene accounted for the excellent photoconductivity of this fabricated photoanode, which presented a photoelectric conversion efficiency of $2.2 \%$. Solar cells based on Pd-porphyrin Zn-SURMOFs 2 thin films grown through lay-bylayer method were fabricated and exhibited an efficiency of $0.45 \%$ [23]. As discussed above, porphyrin ligands are effective photoactive donors and in this solar cell, electrons were excited and injected from porphyrin ligand to the FTO substrate. An indirect band gap was observed in Pd-porphyrin Zn-SURMOFs 2, which strongly suppressed the electron-hole recombination, improving the photovoltaic device performance. However, in general, the photoelectric conversion efficiencies of photoanodes made from photoconductive MOFs in available researches are still relatively low. Further researches in future to obtain higher efficiency are needed.

\subsubsection{Water Splitting}

Water splitting consists of two half-cell reactions, namely hydrogen evolution reaction (HER) at cathode and oxygen evolution reaction (OER) at anode. To date, it is the major way to produce $\mathrm{H}_{2}$, which is a kind of renewable and ecofriendly energy helpful for environment protection and sustainable development. Conventionally, water splitting is realized through noble metal-based electrochemical catalysts like $\mathrm{Pt}, \mathrm{Ru}$, Ir and their oxides. However, the rareness in nature and high cost of noble metals limit their wide commercial applications. Photoelectrochemical (PEC) water splitting, which converts solar energy into chemical energy through photoactive electrodes, has attracted much attention due to a wide range of sources for the electrodes. Over the last few years, many MOFs have been utilized as cocatalysts [24-26] or interlayers at the semiconductor/ electrolyte interface $[27,28]$ to improve photogenerated charge transfer or promote efficient charge injection at the semiconductor/electrolyte interface. In addition to MOFs as cocatalysts or interlayers, photoconductive MOFs have also investigated as photoanodes in photoelectrochemical water splitting.

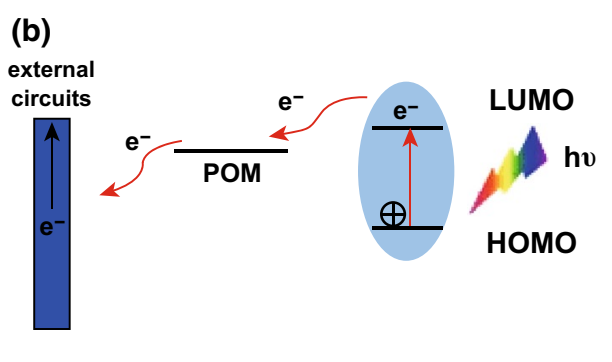

Fig. 5 a $J-V$ curve of cell with pure ZnO and POM@MOF(Fe)-modified ZnO photoanode. b Mechanism of charge transfer of POM@ $\mathrm{MOF}(\mathrm{Fe})$. Reprinted with permission from Ref. [21]. Copyright 2017, Springer Nature 
For better PEC performance, the photoanode used in water splitting should possess outstanding light adsorption capacity, efficient charge separation and transfer properties and high stabilities. In general, photoanodes for photoelectrochemical water splitting fabricated from photoconductive MOFs possess several advantages: (i) a wide range of adsorption band in the Vis/near-IR range, which the wavelengths of solar light are mainly located within; (ii) the interface between MOF layer and the semiconducting substrate allows for effective charge injection from the MOF into the substrate and suppresses charge recombination, enhancing charge transfer rate; (iii) the porosity and large surface area of MOFs provide lots of active sites for $\mathrm{OH}^{-}{ }^{-}$coordination and the ordered structure can retain stable in a long time. For example, the visiblelight-responsive ZIF-67 was utilized to synthesize ZnO@ Au@ZIF-67, which exhibited relatively high photoconversion efficiency up to $0.80 \%$ compared to $\mathrm{ZnO} @ \mathrm{Au}$ [29]. This was mainly ascribed to the visible-light adsorption of ZIF-67 and enhanced electron-hole separation. Upon irradiation, electrons were transferred from ZIF-67 shell to ZnO@ Au core. Recently, Natarajan et al. have synthesized a Co(II)-MOF with a suitable band gap of 2.2-2.4 eV [30]. Upon irradiation, holes were generated in the d-valence band of the transition metal Co and facilitated the coordination of $\mathrm{OH}^{-}$to the surface of MOF-based photoanode, accelerating charge transfer and water splitting. Notably, the crystal structure of photoconductive MOFs can affect the final $\mathrm{H}_{2}$ evolution activity. Two MOF compounds with different crystal structures were synthesized from 4'-(2,4-disulfophenyl)-3,2':6',3'-terpyridine $\left(\mathrm{H}_{2} \mathrm{DSPTP}\right)$ organic ligand and $\mathrm{CuSO}_{4} \cdot 5 \mathrm{H}_{2} \mathrm{O}$ [31]. Although the two compounds shared the same ligand and metal ion, they exhibited different PEC performances. The structure with more extensive $\pi-\pi$ interactions than the other facilitated photogenerated hole transfer and thus inhibited electron-hole recombination, enabling higher photoconversion efficiency. Therefore, crystal structure of photoconductive MOFs should also be taken into consideration for efficient photoelectrochemical $\mathrm{H}_{2}$ evolution.

\section{Photoluminescence}

\subsection{Types of Photoluminescent MOFs}

Recent years have seen tremendous progress in researches on MOFs with photoluminescent properties. In fact, many other materials such as lanthanide metals and molecule dyes also have been found to display photoluminescence. However, low absorption coefficient [32], aggregation-caused quenching (ACQ) [33], poor stability and other unavoidable defects prevent these traditional photoluminescent materials from large-scale applications in practical field. To overcome these defects, the most adopted strategy is to combine the exceptional porosity, stability and tunability of MOFs with the photoluminescence of conventional materials. The reported photoluminescence obtained in MOFs can be concluded as three types: linker-based luminescence, metal-centered luminescence and guest-induced luminescence.

\subsubsection{Liker-Based Luminescence}

Ligand-centered luminescence In some MOFs containing photoactive ligands, the photoluminescence is attributed to the intraligand emission or ligand-to-ligand charge or energy transfer, namely ligand-centered luminescence. In general, ligands with aromatic moieties possess more possibilities to realize photoluminescence because the conjugated $\pi$-electrons abundant in aromatic rings are easily excited to induce $\pi-\pi^{*}$ transition or facilitate charge transfer, which can lead to luminescent emission. Till now, many organic ligands have been investigated and most of them exhibit photoluminescence as expected, shown in Table 1.

It is proposed that the conformation of ligands mainly influences the emission band and that the luminescence intensity can be modulated by the distance between neighboring ligands. This was confirmed by the research on a series of $\mathrm{H}_{3}$ TTPCA-based Pb-MOFs that had different compositions of metal oxygen clusters $\left[\mathrm{Pb}_{7}(\mathrm{COO})_{12} \mathrm{X}_{2}\right](\mathrm{X}=\mathrm{Cl}$, $\mathrm{Br}$, or I) [34]. The emission spectrums of the three MOFs and free $\mathrm{H}_{3}$ TTPCA molecule under $371 \mathrm{~nm}$ excitation were compared. As shown in Fig. 6a, the emission band shifted from 440 for $\mathrm{H}_{3}$ TTPCA to $467 \mathrm{~nm}$ for Pb-MOFs, which was attributed to the increase in the conformation of the organic ligand from one in free $\mathrm{H}_{3}$ TTPCA to three in the MOFs. The effect of conformation of organic ligand was also confirmed by the red shift presented by Bi-MOF $\left[\mathrm{Bi}(\mathrm{BTC})\left(\mathrm{H}_{2} \mathrm{O}\right)\right] \cdot \mathrm{H}_{2} \mathrm{O}$ compared to $\mathrm{H}_{3}$ BTC [35]. Red-shifted luminescence band caused by increased ligand conformation may be due to the reduced molecule vibration and decreased loss of energy by radiationless decay. Furthermore, Fig. 6b shows that with an 
Table 1 Organic ligands that enable photoluminescence

\begin{tabular}{lll}
\hline Organic ligands & Abbreviation used in text & References \\
\hline 1,10-phenanthroline-5,6-dione & PHDI & {$[96]$} \\
2,5-dihydroxyl-1,4-terephthalic acid & DHTA & {$[96]$} \\
4, 40-bis(pyridyl)diphenyl ether & BPDPE & {$[39]$} \\
3-(3,5dicarboxylphenyl)-5-(4-carboxylphenyl)-1-H-1,2,4-triazole & $\mathrm{H}_{3}$ DBPT & {$[97]$} \\
1,1',1'-(1,3,5-triazine-2,4,6-triyl)tripiperidine-4-carboxylic acid & $\mathrm{H}_{3}$ TTPCA & {$[34]$} \\
Bismuth-1,3,5-benzenetricarboxylic acid & $\mathrm{H}_{3} \mathrm{BTC}$ & {$[35,98]$} \\
$N, N^{\prime}$-di(4-pyridyl)thiazolo-[5,4-d]thiazole & DPTTZ & {$[36]$} \\
3-(3',5'-dicarboxylphenoxy)phthalic acid & $\mathrm{H}_{4} \mathrm{~L}$ & {$[47]$} \\
para-terphenyl-3,30,5,50-tetracarboxylic acid & $\mathrm{H}_{4} \mathrm{TPTC}$ & {$[99]$} \\
\hline
\end{tabular}
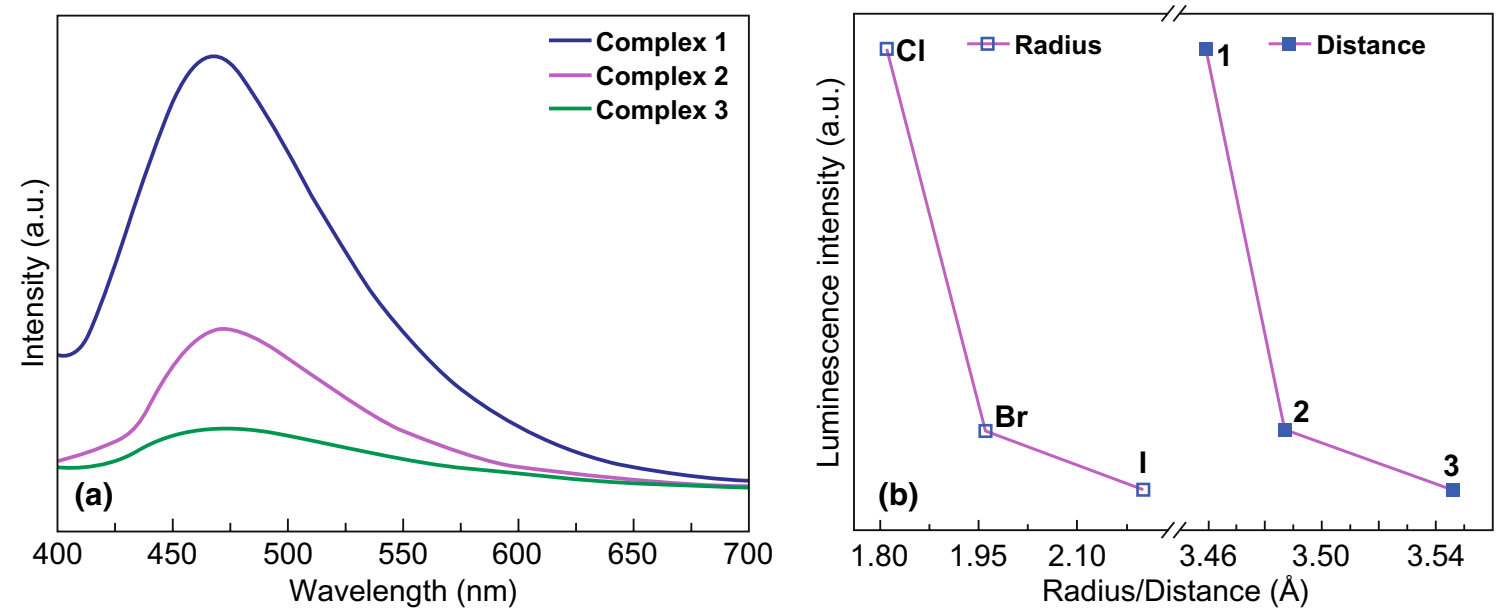

Fig. 6 a Luminescence spectra of the three Pb-MOFs. b Relationship among luminescence intensity, halogen atom radius, and distance between ligands in the three Pb-MOFs. Reprinted with permission from Ref. [34]. Copyright 2019, American Chemical Society

increase in the halogen atom radius in the three $\mathrm{Pb}-\mathrm{MOF}$, the distances of organic ligand in the three MOFs increased as well, which accounted for the decrease in the luminescence intensities at $467 \mathrm{~nm}$ of the three MOFs as observed in Fig. 6a. The photoluminescence of the three MOFs originated from $\pi^{*}-\pi$ transition of the organic ligand, and thus, an increase in ligand distance should negatively influence inter-ligand charge transfer and thereby result in lower luminescence intensity. Comparisons between the synthetic and activated (heated under vacuum at $100{ }^{\circ} \mathrm{C}$ for $4 \mathrm{~h}$ ) MOFs further evidenced the relationship between ligand distance and luminescence intensity. After activated, two MOFs exhibited increased ligand distance and decreased luminescence intensity, while the other exhibited decreased ligand distance and enhanced luminescence intensity.
Sometimes in order to enhance the luminescence intensity or fluorescence changes in MOFs for detection and sensing, another organic ligand is introduced as an antenna that absorbs more light and transfers the energy to the emissive ligand. For MOF $\mathrm{Zn}_{2}(\mathrm{NDC})_{2}$ (DPTTZ), naphthalene dicarboxylate (NDC) serves as an antenna and energy donor and $N, N^{\prime}$-di(4-pyridyl)thiazolo-[5,4-d]thiazole (DPTTZ) functions as energy acceptor and light emitter [36]. As shown in Fig. 7a, a good overlap between the adsorption spectra of NDC and the emission spectra of DPTTZ was observed, which was the prerequisite for Förster resonance energy transfer from NDC to DPTTZ. Figure $7 \mathrm{~b}$ shows the exclusively DPTTZ-centric emission in spite of excitation wavelengths, which was rarely observed in other photoluminescent MOFs. What is more, compared to free DPTTZ ligand, 

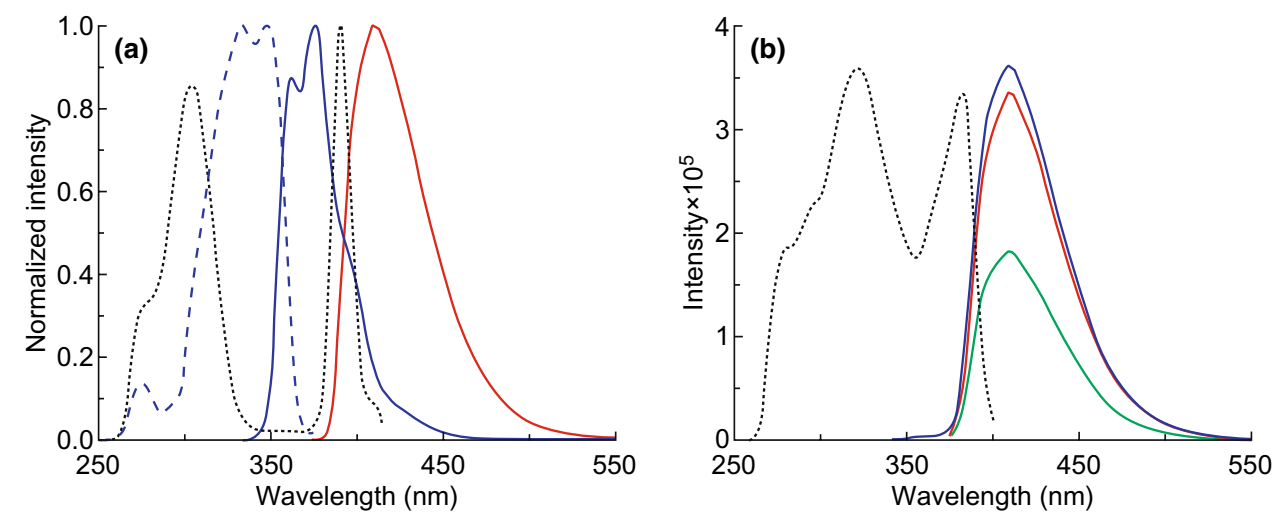

Fig. 7 a Excitation (dashed lines) and emission (solid lines) spectra of free NDC (blue) and DPTTZ (red) ligands showing the requisite spectral overlap for FRET. b Excitation (dashed black line) and emission spectra of $\mathrm{Zn}_{2}(\mathrm{NDC})_{2}(\mathrm{DPTTZ})$ showing exclusively DPTTZ-centric emission regardless of excitation wavelengths ( $\lambda_{\mathrm{Ex}}=320$ (blue), 350 (green), and $380 \mathrm{~nm}$ (red)). Reprinted with permission from Ref. [36]. Copyright 2019, American Chemical Society. (Color figure online)

$\mathrm{Zn}_{2}(\mathrm{NDC})_{2}(\mathrm{DPTTZ})$ exhibits more efficient fluorescence changes in the presence of $\mathrm{Hg}^{2+}$ under illumination at a wide wavelength region, making it a possible sensor for $\mathrm{Hg}^{2+}$.

Ligand-to-metal charge transfer As one of the possible ways to realize photoluminescence in MOFs, ligand-tometal charge transfer is due to the interactions between metal ions and organic ligands. It is typically observed in $\mathrm{Pb} / \mathrm{Zn} / \mathrm{Cu}$-based MOFs, where the metal center binds to $\mathrm{O}$ atoms of the organic ligand and charge transfer occurs from ligand to metal through metal-oxygen bonds. For example, $\left[\mathrm{Pb}\left(\mathrm{H}_{2} \mathrm{O}\right)(\gamma-\mathrm{CD})\right]\left(\mathrm{NO}_{3}\right)_{2} \cdot 11 \mathrm{H}_{2} \mathrm{O}(\gamma-\mathrm{CD}-\mathrm{Pb})$, obtained from $\gamma$-cyclodextrin and $\mathrm{Pb}^{2+}$, exhibited photoluminescence with maximum emission wavelength at $345 \mathrm{~nm}$ excited at $290 \mathrm{~nm}$ [37]. While cyclodextrins are non-aromatic ligands and lack photoluminescence, it was the presence of $\mathrm{Pb}$ (II) that induced charge transfer from ligand to metal center through $\mathrm{Pb}-\mathrm{O}$ bonds under irradiation and hence photoluminescence. In $\mathrm{Zn}_{3} \cdot \mathrm{BDC} \cdot 2 \mathrm{BTC} \cdot 2 \mathrm{NH}\left(\mathrm{CH}_{3}\right)_{2} \cdot 2 \mathrm{NH}_{2}\left(\mathrm{CH}_{3}\right)_{2}$, a new emission peak at $430 \mathrm{~nm}$ was attributed to charge transfer from $\mathrm{O}$ atoms of the ligands to the empty $4 \mathrm{~s}$ orbitals of $\mathrm{Zn}^{2+}$ [38]. The aforementioned photoconductive $\mathrm{ZnL}$ (DPE) $\left(\mathrm{H}_{2} \mathrm{O}\right) \cdot \mathrm{H}_{2} \mathrm{O}$ [15] also exhibited a weak photoluminescence band at $450 \mathrm{~nm}$ due to ligand-to-metal charge transfer in the presence of N-donor ligand DPE. However, the luminescence intensity of this MOF was much weaker than the free $\mathrm{H}_{2} \mathrm{~L}$ ligand, since the MOF exhibited reduced charge recombination which improved the photoconductivity but inhibited photoluminescence. Interestingly, ligand-to-metal charge transfer can also occur between the ligand of MOFs and metal ions in the environmental solutions. A new emission band was observed in $[\mathrm{CuI}(\mathrm{BPDPE})]_{\mathrm{n}}$ when treated with $\mathrm{Al}^{3+}$ solutions, making it a possible $\mathrm{Al}^{3+}$ sensor [39], which will be discussed in detail in the following.

Metal-to-ligand charge transfer Photoluminescence in some MOFs originates from metal-to-ligand charge transfer. Typically, metal-to-ligand charge transfer involves $\pi$-rich ligands which serve as effective electron acceptors in MOFs. The metal involved in metal-to-ligand charge transfer is mainly $\mathrm{d}^{10} \mathrm{Cu}(\mathrm{I})$, whose $\mathrm{d}$ electrons are right in the valence orbitals to facilitate charge transfer. The emissions of a series of $\mathrm{Cu}(\mathrm{I}) \mathrm{MOFs}$ of 2,2'-dipyridylamine derivatives, formulated as $\left[\mathrm{Cu}_{6}(\mathrm{tppa})\left(\mu_{3}-\mathrm{Br}\right)_{6}\right]_{\mathrm{n}},\left[\mathrm{Cu}_{2}(\mathrm{tppa})(\mu-\mathrm{CN})_{2}\right]_{\mathrm{n}}$, $[\mathrm{Cu}(\text { tpbpa }) \mathrm{Br}]_{\mathrm{n}},\left[\mathrm{Cu}_{4}(\text { tpbpa })_{2}(\mu-\mathrm{I})_{4}\right]_{\mathrm{n}},\left[\mathrm{Cu}_{4}(\text { tpbpa })(\mu-\mathrm{CN})_{4}\right]_{\mathrm{n}}$ and $\left[\mathrm{Cu}_{8}(\text { tpbpa })(\mu-\mathrm{CN})_{8}\right]_{\mathrm{n}} \cdot 2 \mathrm{nH}_{2} \mathrm{O}$, were all ascribed to metal-to-ligand charge transfer due to the presence of $\pi$-rich ligands with a lower energy of the $\pi^{*}$-orbital, which were more prone to induce metal-to-ligand charge transfer [40]. Compared to the corresponding free ligands, the emission bands of these MOFs were all red-shifted but in various degrees due to different ligand conformations, indicative of the influence of ligand conformations on the emission bands. For example, the tppa ligands in $\left[\mathrm{Cu}_{6}(\text { tppa })\left(\mu_{3}-\mathrm{Br}\right)_{6}\right]_{\mathrm{n}}$ and $\left[\mathrm{Cu}_{2}(\text { tppa })(\mu-\mathrm{CN})_{2}\right]_{\mathrm{n}}$ adopted inward- and trans-conformations, respectively, as shown in Fig. 8a. The emission bands of these two MOFs shown in Fig. 8b revealed different emission peaks at 569 and $573 \mathrm{~nm}$, respectively. 

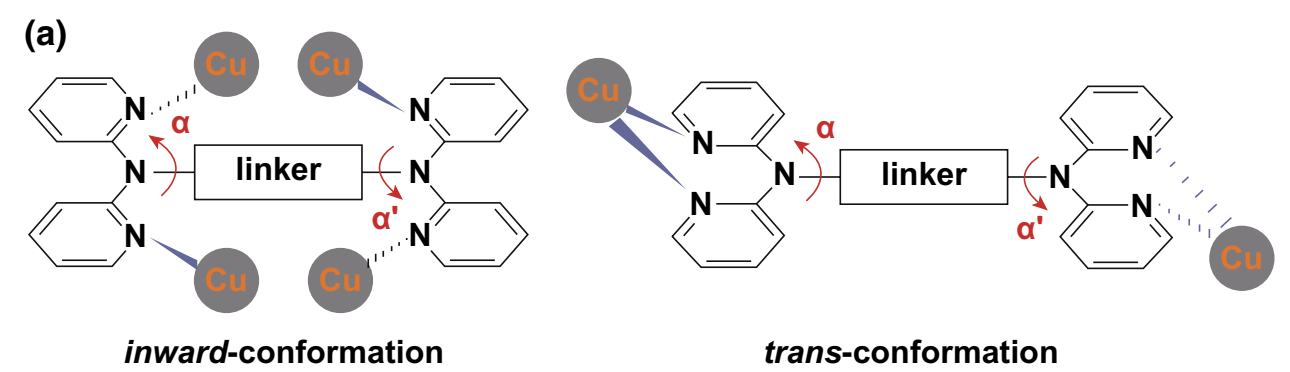

trans-conformation

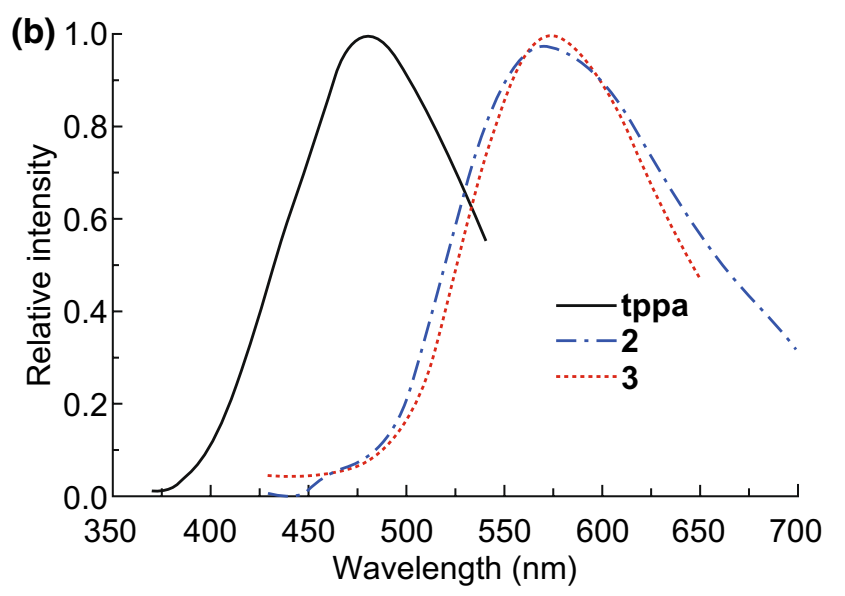

Fig. 8 a Inward- and trans-conformations of $\left[\mathrm{Cu}_{6}(\mathrm{tppa})\left(\mu_{3}-\mathrm{Br}\right)_{6}\right]_{\mathrm{n}}$ and $\left[\mathrm{Cu}_{2}(\mathrm{tppa})(\mu-\mathrm{CN})_{2}\right]_{\mathrm{n}}$,. b Emission spectra of free tppa ligand, $\left[\mathrm{Cu} \mathrm{t}_{6}(\mathrm{tppa})\right.$ $\left.\left(\mu_{3}-\mathrm{Br}\right)_{6}\right]_{\mathrm{n}}(2)$ and $\left[\mathrm{Cu}_{2}(\mathrm{tppa})(\mu-\mathrm{CN})_{2}\right]_{\mathrm{n}}(3)$. Reprinted with permission from Ref. [40]. Copyright 2012, Royal Society of Chemistry

\subsubsection{Metal-Centered Luminescence}

Lanthanide is well known to be a series of metals that exhibit exceptional photoluminescent properties such as large Stoke shift, extremely sharp emission and long life time, owing to the unique $f-f$ transitions between the $4 \mathrm{f}$ electrons. However, the low absorption coefficient of lanthanide metals hinders their wide applications in practical luminescent devices. One feasible strategy to overcome this defect is to combine lanthanide metals with MOFs, which afford effective energy donor organic ligands that serve as an antenna with excellent light absorption properties. Besides, some rare earth metals also exhibit photoluminescence under irradiation. Therefore, many metal-centered luminescent MOFs have been successfully synthesized by directly constructing frameworks with lanthanide or rare earth metals or by doping non-luminescent MOFs with lanthanide or rare earth metals, as shown in Table 2.

It should be noted that it is crucial to choose appropriate organic ligands for synthesis of metal-centered photoluminescent MOFs. Aromatic ligands with a $\pi$-conjugated system or a heterocyclic organic ligand are ideal ligands to this end, and to better improve their light adsorption capacity, carboxylic groups are extensively utilized to modify the ligands. In the synthesized MOFs, organic ligands function as antennas and sensitizers, which effectively adsorb light and transfer the energy to the metal center. $\mathrm{H}_{4} \mathrm{~L}^{+} \mathrm{Cl}^{-}$ligand, for example, was prepared by modifying $\mathrm{H}_{2} \mathrm{Bcpi}^{+} \mathrm{X}^{-}$ligand with imidazole and two aromatic carboxylic acids, as shown in Fig. 9 [41]. The as-synthesized $\mathrm{H}_{4} \mathrm{~L}^{+} \mathrm{Cl}^{-}$ligand exceptionally met the demand for antennas in photoluminescent MOFs. A series of LnMOFs formulated as $\left\{\left[\mathrm{Ln}(\mathrm{L})\left(\mathrm{H}_{2} \mathrm{O}\right)_{2}\right] \cdot 5 \mathrm{H}_{2} \mathrm{O}\right\}_{\mathrm{n}}$ $\left(\mathrm{Ln}=\mathrm{Eu}, \mathrm{Tb}, \mathrm{Gd}\right.$, and $\left.\mathrm{Eu}_{x} \mathrm{~Tb}_{1-x}\right)$ with superior photoluminescent properties were thus synthesized based on $\mathrm{H}_{4} \mathrm{~L}^{+} \mathrm{Cl}^{-}$ligand.

In general, metal-centered luminescent MOFs inherit the luminescent properties of the original metals, as both of them have the similar emission bands. Most of LnMOFs can emit light with several colors, corresponding to a number of different transitions from excitation state to ground 
Table 2 Metals involved in MOFs to induce photoluminescence

\begin{tabular}{|c|c|c|c|}
\hline Metal centers & Characteristic emissions & Synthesized MOFs & References \\
\hline \multirow[t]{7}{*}{$\mathrm{Tb}$} & \multirow{7}{*}{$\begin{array}{l}{ }^{5} \mathrm{D}_{4} \rightarrow{ }^{7} \mathrm{~F}_{6} 489 \mathrm{~nm} \\
{ }^{5} \mathrm{D}_{4} \rightarrow{ }^{7} \mathrm{~F}_{5} 543 \mathrm{~nm} \\
{ }^{5} \mathrm{D}_{4} \rightarrow{ }^{7} \mathrm{~F}_{4} 582 \mathrm{~nm} \\
{ }^{5} \mathrm{D}_{4} \rightarrow{ }^{7} \mathrm{~F}_{3} 623 \mathrm{~nm}\end{array}$} & $\begin{array}{l}\text { MR-MOF-Tb } \\
\text { WR-MOF-Tb }\end{array}$ & [42] \\
\hline & & Tb-SA & {$[32]$} \\
\hline & & $\left\{\left[\mathrm{Tb}(\mathrm{L})\left(\mathrm{H}_{2} \mathrm{O}\right)_{2}\right] \cdot 5 \mathrm{H}_{2} \mathrm{O}\right\}_{\mathrm{n}}$ & [41] \\
\hline & & {$\left[\mathrm{Tb}(\mathrm{TCBA})\left(\mathrm{H}_{2} \mathrm{O}\right)_{2}\right]_{2} \cdot \mathrm{DMF}$} & {$[100]$} \\
\hline & & $\left\{\left[\mathrm{Me}_{2} \mathrm{NH}_{2}^{+}\right]\left[\mathrm{Tb}(\mathrm{L})\left(\mathrm{H}_{2} \mathrm{O}\right)_{2}\right]\right\}_{\mathrm{n}}$ & [101] \\
\hline & & {$\left[\mathrm{TbL}_{2}\left(\mathrm{H}_{2} \mathrm{O}\right)_{4}\right]_{\mathrm{n}} \cdot \mathrm{nNO}_{3}$} & [102] \\
\hline & & TbTMA & {$[103]$} \\
\hline \multirow[t]{8}{*}{$\mathrm{Eu}$} & \multirow{8}{*}{$\begin{array}{l}{ }^{5} \mathrm{D}_{0} \rightarrow{ }^{7} \mathrm{~F}_{0} 579 \mathrm{~nm} \\
{ }^{5} \mathrm{D}_{0} \rightarrow{ }^{7} \mathrm{~F}_{1} 590 \mathrm{~nm} \\
{ }^{5} \mathrm{D}_{0} \rightarrow{ }^{7} \mathrm{~F}_{2} 614 \mathrm{~nm} \\
{ }^{5} \mathrm{D}_{0} \rightarrow{ }^{7} \mathrm{~F}_{3} 650 \mathrm{~nm} \\
{ }^{5} \mathrm{D}_{0} \rightarrow{ }^{7} \mathrm{~F}_{4} 697 \mathrm{~nm}\end{array}$} & $\begin{array}{l}\text { MR-MOF-Eu } \\
\text { WR-MOF-Eu }\end{array}$ & [42] \\
\hline & & Eu(Ln)@bio-MOF-1 & {$[52]$} \\
\hline & & $\left\{\left[\mathrm{Eu}(\mathrm{L})\left(\mathrm{H}_{2} \mathrm{O}\right)_{2}\right] \cdot 5 \mathrm{H}_{2} \mathrm{O}\right\}_{\mathrm{n}}$ & [41] \\
\hline & & {$\left[\mathrm{Eu}_{2}\left(\mathrm{SO}_{4}\right)_{2}\left(\mathrm{H}_{6} \mathrm{htp}\right)\left(\mathrm{H}_{2} \mathrm{O}\right)_{4}\right] \cdot 10 \mathrm{H}_{2} \mathrm{O}$} & [104] \\
\hline & & $\left\{\left[\mathrm{Eu}(2,5-\mathrm{FDA})_{0.5}(\mathrm{Glu})\left(\mathrm{H}_{2} \mathrm{O}\right)_{2}\right] \cdot \mathrm{xH}_{2} \mathrm{O}\right\}_{\mathrm{n}}$ & [105] \\
\hline & & $\mathrm{Zn}(\mathrm{BDC})(\mathrm{dpNDI}): 2 \% \mathrm{Eu}$ & {$[106]$} \\
\hline & & $\left\{\left(\mathrm{Me}_{2} \mathrm{NH}_{2}^{+}\right)\left[\mathrm{Eu}(\mathrm{L})\left(\mathrm{H}_{2} \mathrm{O}\right)_{2}\right]\right\}_{\mathrm{n}}$ & [101] \\
\hline & & {$\left[\mathrm{EuL}_{2}\left(\mathrm{H}_{2} \mathrm{O}\right)_{4}\right]_{\mathrm{n}} \cdot \mathrm{nNO}_{3}$} & {$[102]$} \\
\hline \multirow[t]{5}{*}{$\mathrm{Sm}$} & \multirow{5}{*}{$\begin{array}{l}{ }^{4} \mathrm{G}_{5 / 2} \rightarrow{ }^{6} \mathrm{~F}_{5 / 2} 561 \mathrm{~nm} \\
{ }^{4} \mathrm{G}_{5 / 2} \rightarrow{ }^{6} \mathrm{~F}_{7 / 2} 596 \mathrm{~nm} \\
{ }^{4} \mathrm{G}_{5 / 2} \rightarrow{ }^{6} \mathrm{~F}_{9 / 2} 644 \mathrm{~nm} \\
{ }^{4} \mathrm{G}_{5 / 2} \rightarrow{ }^{6} \mathrm{~F}_{11 / 2} 703 \mathrm{~nm}\end{array}$} & $\begin{array}{l}\text { MR-MOF-Sm } \\
\text { WR-MOF-Sm }\end{array}$ & {$[42]$} \\
\hline & & {$\left[\mathrm{Sm}_{2}\left(\mathrm{SO}_{4}\right)_{2}\left(\mathrm{H}_{6} \mathrm{htp}\right)\left(\mathrm{H}_{2} \mathrm{O}\right)_{4}\right] \cdot 10 \mathrm{H}_{2} \mathrm{O}$} & [104] \\
\hline & & $\left\{\left[\mathrm{Sm}(2,5-\mathrm{FDA})_{0.5}(\mathrm{Glu})\left(\mathrm{H}_{2} \mathrm{O}\right)_{2}\right] \cdot \mathrm{xH}_{2} \mathrm{O}\right\}_{\mathrm{n}}$ & [105] \\
\hline & & $\left\{\left(\mathrm{Me}_{2} \mathrm{NH}_{2}^{+}\right)\left[\mathrm{Sm}(\mathrm{L})\left(\mathrm{H}_{2} \mathrm{O}\right)_{2}\right]\right\}_{\mathrm{n}}$ & {$[101]$} \\
\hline & & {$\left[\mathrm{SmL}_{2}\left(\mathrm{H}_{2} \mathrm{O}\right)_{4}\right]_{\mathrm{n}} \cdot \mathrm{nNO}_{3}$} & {$[102]$} \\
\hline
\end{tabular}

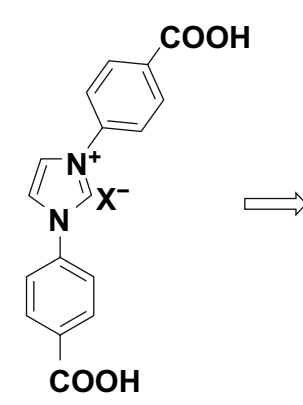

$\mathrm{X}^{-}=\mathrm{Cl}^{-}, \mathrm{Br}^{-} \quad \mathrm{H}_{2} \mathrm{Bcpi}^{+} \mathrm{X}^{-}$

Fig. 9 Modification of $\mathrm{H}_{2} \mathrm{Bcpi}^{+} \mathrm{X}^{-}$for $\mathrm{H}_{4} \mathrm{~L}^{+} \mathrm{Cl}^{-}$. Reprinted with permission from Ref. [41]. Copyright 2019, American Chemical Society

state characteristic of lanthanide metals. For example, two hybrids of MR-MOF-Eu and WR-MOF-Eu synthesized through assembly of MOFs based on Eu metal ions and 2-amino-1,4-benzendicarboxylic acid $\left(\mathrm{NH}_{2}\right.$-BDC) with two microsphere resins (Wang resin (WR) and Merrifield resin (MR)) exhibited similar emission bands at around 579, $590,614,650$, and $697 \mathrm{~nm}$ due to characteristic ${ }^{5} \mathrm{D}_{0} \rightarrow{ }^{7} \mathrm{~F}_{\mathrm{J}}$
$(\mathrm{J}=0-4)$ transitions of $\mathrm{Eu}^{3+}$, as shown in Fig. 10a, b [42]. $\left\{\left[\mathrm{Eu}(\mathrm{L})\left(\mathrm{H}_{2} \mathrm{O}\right)_{2}\right] \cdot 5 \mathrm{H}_{2} \mathrm{O}\right\}_{\mathrm{n}}$ based on the aforementioned $\mathrm{H}_{4} \mathrm{~L}^{+} \mathrm{Cl}^{-}$ligand [41] also presented similar emission bands at 579, 581, 617, 653, and $697 \mathrm{~nm}$, as shown in Fig. 11. Photoluminescent MOFs with the same lanthanide metal possess similar emission bands due to their characteristic state transitions. Notably, different lanthanide metals can be combined into one MOF to obtain a combination of different luminous colors. Modulation of the proportions can result in tunable colors and even white light emission, which will be discussed in detail in the following. The characteristic emission bands of commonly used lanthanide metals are listed in Table 3 along with recently synthesized MOFs.

\subsubsection{Guest-Induced Photoluminescence}

Many molecules are well photoluminescent but with poor stability and intrinsic aggregation-caused quenching effect, hindering their practical applications. Encapsulation of these molecules into the pores of MOFs, where the guest 

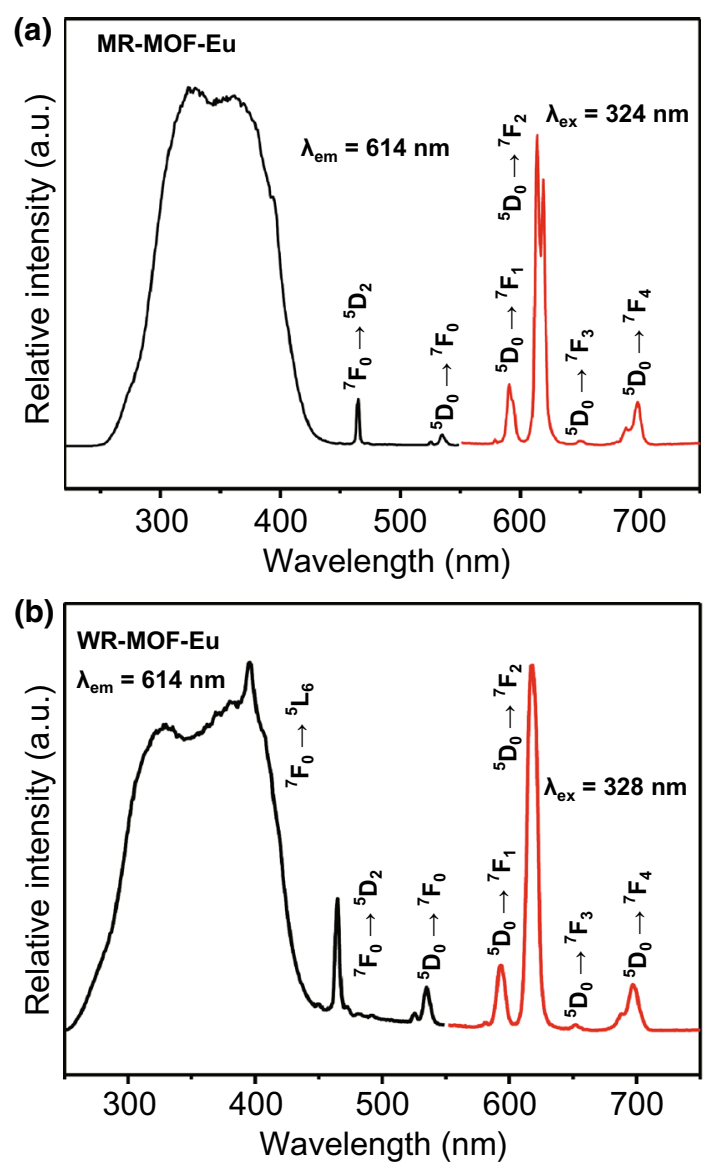

Fig. 10 Excitation (black line) and emission (red line) spectra of a MR-MOF-Eu and b WR-MOF-Eu hybrid materials. Reprinted with permission from Ref. [42]. Copyright 2020, Elsevier. (Color figure online)

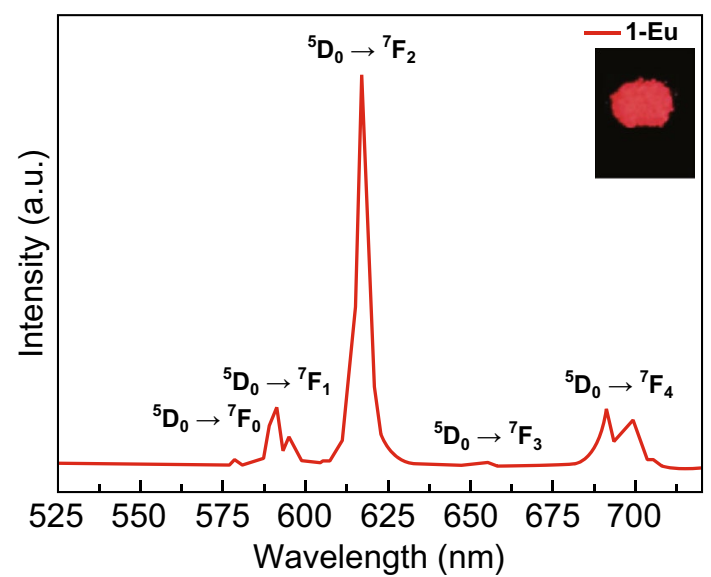

Fig. 11 Solid-state emission spectrum of $\left\{\left[\mathrm{Eu}(\mathrm{L})\left(\mathrm{H}_{2} \mathrm{O}\right)_{2}\right] \cdot 5 \mathrm{H}_{2} \mathrm{O}\right\}_{n}$ at $254 \mathrm{~nm}$ at room temperature. Reprinted with permission from Ref. [41]. Copyright 2019, American Chemical Society molecules are isolated from each other to avoid aggregation-caused quenching effect, has been adopted to obtain photoluminescent MOFs. The rigid structure of MOFs also provides protection for luminescent molecules and enhances the material stability. A large class of these guest molecules is organic dyes such as cyanine and rhodamines [33]. Others include perovskites like $\mathrm{MAPbBr}_{3}$ [43], quantum dots [44], and so forth.

A recent research conducted by Let et al. adopted rhodamine B (RhB) and Bio-MOF-1 to synthesize dye@MOF composite [33]. RhB was chosen because of its cationic nature, exceptional photoluminescence and abundant free carboxylic groups to interact with $\mathrm{Fe}^{3+}$. The anionic nature of Bio-MOF-1 framework facilitated effective bonds with cationic RhB molecules in an ion-exchange process. As shown in Fig. 12a, the PXRD profiles of as-synthesized Bio-MOF-1 and Bio-MOF-1@RhB exhibited minimal difference, indicating that the pristine MOF structure was nearly unaffected upon the encapsulation of $\mathrm{RhB}$ molecules. Figure 12b displays the TGA profiles of RhB, Bio-MOF-1 and Bio-MOF-1@RhB. While RhB molecules experienced substantial loss after $\sim 300{ }^{\circ} \mathrm{C}$, Bio-MOF-1@RhB showed no obvious loss up to $400{ }^{\circ} \mathrm{C}$, indicating that the confinement effect of MOF could significantly enhance the stability of $\mathrm{RhB}$, enabling its application in $\mathrm{Fe}^{3+}$ detection.

Quantum dots (QDs) are small particles with superior photoactive properties.PEG-ZnS QDs@ZIF-67 nanohybrids were synthesized through encapsulation of polyethylene glycol (PEG)-capped ZnS quantum dots into ZIF-67 [45]. The adsorption properties of ZIF-67 to capture and concentrate $\mathrm{Cu}^{2+}$ facilitated $\mathrm{ZnS}$ QDs to detect $\mathrm{Cu}^{2+}$ as selective luminescent sensor. Notably, compared to traditional QDs like $\mathrm{CdSe}$ and $\mathrm{PbSe}$, carbon quantum dots (C-QDs) possess more attractive advantages such as higher stability, lower toxicity and so forth. A C-QDs@UiO-66-(COOH $)_{2}$ composite film was fabricated through electrophoretic deposition and served as luminescent temperature sensor [46]. In addition to QDs, photoactive perovskites can not only improve photoconductivity in solar cells, but also promote photoluminescence in MOFs. However, the inherent instability inhibits their practical applications. For example, organic $\mathrm{MA}^{+}$cations of $\mathrm{MAPbX}_{3}\left(\mathrm{MA}=\mathrm{CH}_{3} \mathrm{NH}_{3}, \mathrm{X}=\mathrm{Cl}, \mathrm{Br}\right.$, I) undergo rapid degradation in polar solutions or high temperature. Encapsulating $\mathrm{MAPbX}_{3}$ into MOFs can greatly enhance its stability, and its application in information protection has been demonstrated [43]. QDs and perovskites as guest molecules 
Table 3 Photoluminescent sensors based on MOFs toward various analytes

\begin{tabular}{|c|c|c|c|c|}
\hline Target analyte & Luminescent MOFs as sensors & $K_{\mathrm{SV}}\left(\mathrm{M}^{-1}\right)$ & Limit of detection (LOD) & References \\
\hline \multirow[t]{8}{*}{$\mathrm{Fe}^{3+}$} & Bio-MOF-1@RhB & $5.5 \times 10^{4}$ & $1.1 \mathrm{ppm}$ & [33] \\
\hline & {$\left[\mathrm{Pb}_{1.5}(\mathrm{DBPT})\right]_{2} \cdot(\mathrm{DMA})_{3}\left(\mathrm{H}_{2} \mathrm{O}\right)_{4}$} & $1.2 \times 10^{5}$ & $2.5 \mathrm{ppm}$ & [97] \\
\hline & {$\left[\mathrm{Bi}(\mathrm{BTC})\left(\mathrm{H}_{2} \mathrm{O}\right)\right] \cdot \mathrm{H}_{2} \mathrm{O}$} & $2.02 \times 10^{4}$ & $1.59 \mu \mathrm{M}$ & [35] \\
\hline & $\left\{\left[\mathrm{Cd}_{1.5}(\mathrm{DBPT})(\mathrm{DiPyDz})\left(\mathrm{H}_{2} \mathrm{O}\right)\right] \cdot 3.5 \mathrm{H}_{2} \mathrm{O}\right\}_{\mathrm{n}}$ & $4.789 \times 10^{5}$ & $78 \mathrm{ppb}$ & {$[58]$} \\
\hline & {$[\mathrm{Cd}(\mathrm{L})(\mathrm{pda})]$} & $1.03 \times 10^{5}$ & $112 \mathrm{ppb}$ & {$[59]$} \\
\hline & $\left\{\left[\mathrm{Tb}(\mathrm{Cmdcp})\left(\mathrm{H}_{2} \mathrm{O}\right)_{3}\right]_{2}\left(\mathrm{NO}_{3}\right)_{2} \cdot 5 \mathrm{H}_{2} \mathrm{O}\right\}_{\mathrm{n}}$ & $5.532 \times 10^{3}$ & $4.0 \mu \mathrm{M}$ & {$[56]$} \\
\hline & {$\left[\mathrm{Zn}(1,6-\mathrm{NDS})(\mathrm{bbimb})_{1.5}\right] \cdot 2 \mathrm{H}_{2} \mathrm{O}$} & $7.17 \times 10^{3}$ & $1.76 \times 10^{-4} \mathrm{M}$ & [107] \\
\hline & {$\left[\mathrm{Cd}_{2}(1,6-\mathrm{NDS})_{2}(\mathrm{bbimb})_{3}\left(\mathrm{H}_{2} \mathrm{O}\right)_{4}\right] \cdot 2 \mathrm{H}_{2} \mathrm{O}$} & $1.01 \times 10^{4}$ & $1.80 \times 10^{-4} \mathrm{M}$ & [107] \\
\hline \multirow[t]{2}{*}{$\mathrm{Cu}^{2+}$} & $\mathrm{Tb}-\mathrm{SA}$ & $6.298 \times 10^{3}$ & $1 \times 10^{-4} \mathrm{M}$ & {$[32]$} \\
\hline & PEG-ZnS QDs@ZIF-67 & - & $0.96 \mathrm{nM}$ & [45] \\
\hline \multirow[t]{2}{*}{$\mathrm{Al}^{3+}$} & {$[\mathrm{CuI}(\mathrm{BPDPE})]_{\mathrm{n}}$} & $1.2560 \times 10^{4}$ & $2.1 \times 10^{-6} \mathrm{M}$ & [39] \\
\hline & {$\left[\mathrm{Pb}_{1.5}(\mathrm{DBPT})\right]_{2} \cdot(\mathrm{DMA})_{3}\left(\mathrm{H}_{2} \mathrm{O}\right)_{4}$} & $4.3 \times 10^{4}$ & - & {$[97]$} \\
\hline \multirow[t]{2}{*}{$\mathrm{Cr}_{2} \mathrm{O}_{7}^{2-}$} & {$\left[\mathrm{Bi}(\mathrm{BTC})\left(\mathrm{H}_{2} \mathrm{O}\right)\right] \cdot \mathrm{H}_{2} \mathrm{O}$} & $1.95 \times 10^{4}$ & $1.64 \mu \mathrm{M}$ & {$[35]$} \\
\hline & {$[\mathrm{Cd}(\mathrm{L})(\mathrm{pda})]$} & $1.01 \times 10^{5}$ & $126 \mathrm{ppb}$ & {$[59]$} \\
\hline $\mathrm{Zr}^{4+}$ & {$\left[\mathrm{Pb}_{1.5}(\mathrm{DBPT})\right]_{2} \cdot(\mathrm{DMA})_{3}\left(\mathrm{H}_{2} \mathrm{O}\right)_{4}$} & $1.6 \times 10^{5}$ & - & [97] \\
\hline $\mathrm{In}^{3+}$ & {$\left[\mathrm{Pb}_{1.5}(\mathrm{DBPT})\right]_{2} \cdot(\mathrm{DMA})_{3}\left(\mathrm{H}_{2} \mathrm{O}\right)_{4}$} & $1.6 \times 10^{5}$ & - & {$[97]$} \\
\hline $\mathrm{O}_{2}$ & MIL-100(In) つ Tb ${ }^{3+}$ & 7.59 & $0.4 \%$ & {$[108]$} \\
\hline TBBPA (tetrabromo-bisphenol A) & MOF-74(Zn)-en & - & $0.75 \mu \mathrm{g} \mathrm{L}^{-1}$ & {$[53]$} \\
\hline nitrobenzene & $\mathrm{Zn}_{3}(\mathrm{BTC})_{2}: 4 \% \mathrm{Eu}(\mathrm{III})$ & $3.957 \times 10^{3}$ & $0.97 \mathrm{ppm}$ & {$[51]$} \\
\hline NP(p-nitrophenol) & In-atp & - & $2 \times 10^{-3} \mathrm{U} \mathrm{L}^{-1}$ & [48] \\
\hline picric acid(TNP) & {$[\mathrm{CuI}(\mathrm{BPDPE})]_{\mathrm{n}}$} & $1.5 \times 10^{4}$ & $1.09 \times 10^{-6} \mathrm{M}$ & [39] \\
\hline 2,4-dinitrophenol & {$\left[\mathrm{Zn}\left(\mathrm{H}_{2} \mathrm{~L}\right)(2,2 \text {-bipy })\right]_{\mathrm{n}}$} & $1.83 \times 10^{4}$ & $7.08 \times 10^{-4} \mathrm{mM}$ & {$[47]$} \\
\hline acetone & $\left\{\left[\mathrm{Cd}_{1.5}(\mathrm{DBPT})(\mathrm{DiPyDz})\left(\mathrm{H}_{2} \mathrm{O}\right)\right] \cdot 3.5 \mathrm{H}_{2} \mathrm{O}\right\}_{\mathrm{n}}$ & - & $0.0013 \%(\mathrm{v} / \mathrm{v} \%)$ & {$[58]$} \\
\hline DMA ( $N, N$-dimethylacetamide) & {$\left[\mathrm{Pb}_{1.5}(\mathrm{DBPT})\right]_{2} \cdot(\mathrm{DMA})_{3}\left(\mathrm{H}_{2} \mathrm{O}\right)_{4}$} & - & - & {$[97]$} \\
\hline triiodothyronine hormone (T3) & $\mathrm{Cu}-\mathrm{MOF}-\mathrm{NPs}$ & - & $0.198 \mathrm{ng} \mathrm{dL}^{-1}$ & {$[50]$} \\
\hline L-cysteine & $\left\{\left[\mathrm{Ca}_{1.5}\left(\mu_{8}-\mathrm{HL}_{1}\right)(\mathrm{DMF})_{2}\right] \cdot \mathrm{DMF}\right\}_{\mathrm{n}}$ & - & $15 \mathrm{nM}$ & {$[109]$} \\
\hline Alpha-fetoprotein (AFP) & $\mathrm{Cu}-\mathrm{MOF}-\mathrm{NPs}$ & - & $1.18 \mathrm{ng} \mathrm{mL}^{-1}$ & [49] \\
\hline
\end{tabular}
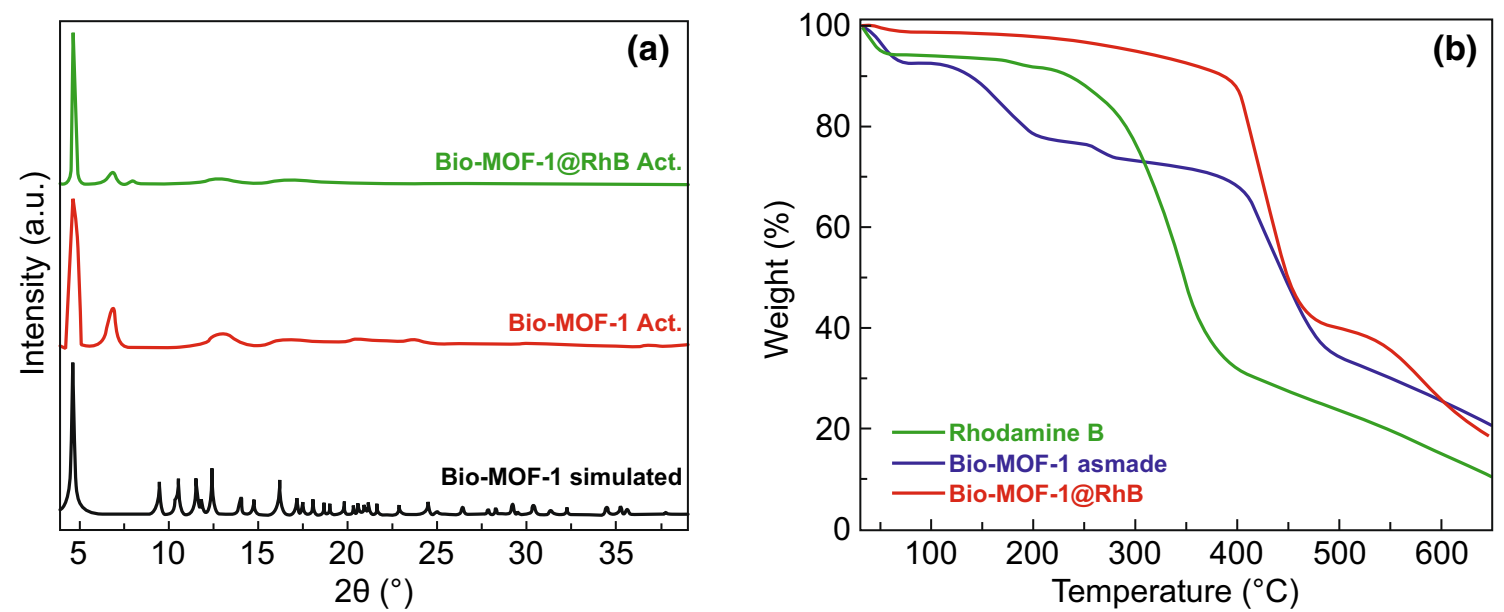

Fig. 12 a PXRD pattern of Bio-MOF-1 simulated (black), Bio-MOF activated (brown) \& Bio-MOF@RhB activated (green). b TGA profiles of as-made Bio-MOF-1 (blue), RhB (green) \& Bio-MOF@RhB (brown). Reprinted with permission from Ref. [33]. Copyright 2020, Elsevier. (Color figure online) 
to promote photoluminescent properties of MOFs for light emitting and optical information protection will be further discussed in the following part.

\subsection{Applications}

\subsubsection{Photoluminescent Sensors}

Photoluminescent MOFs as sensors are expected to play an important role in many fields such as industrial production, environmental protection and health care. Many photoluminescent MOFs exhibit high sensitivity toward specific metal ions or substances harmful to environment or even human body. Photoluminescent MOFs as sensors reported recently are shown in Table 3. In particular, nitro explosives (NEs) have been widely used in industrial production, but they can cause lots of problems, not only environmental pollution but also threat to human health and even country security. Effective NEs detections are in great demand, and photoluminescent MOFs have attracted much attention in this field. For example, $\left[\mathrm{Zn}\left(\mathrm{H}_{2} \mathrm{~L}\right)(2,2 \text {-bipy })\right]_{\mathrm{n}}$ based on $\mathrm{H}_{4} \mathrm{~L}$ ligand exhibited ligand-centered photoluminescence and was highly promising for detections of a series of nitroaromatic explosives, among which the detection of 2,4-dinitrophenol (2,4-DNP) could reach a high $K_{\mathrm{sv}}$ value of $1.83 \times 10^{4} \mathrm{M}^{-1}$ and a low detection limit of $7.08 \times 10^{-4} \mathrm{mM}$, as shown in Fig. 13 [47]. In addition, luminescent MOFs can also function as biosensors in biological field. For instance, the alkaline phosphatase (ALP) enzyme, as a signal for serious diseases, can be detected in human serum samples by In-atp [48]. Similarly, Cu-MOF-NPs can detect alpha-fetoprotein (AFP) for liver cancer diagnosis [49] as well as triiodothyronine hormone (T3) for thyroid disease diagnosis [50]. More recently reported luminescent MOF sensors toward various metal ions and organic molecules are listed in Table 3, and the mechanisms for luminescent sensing are discussed as following.

It has been widely observed that exposure to specific analytes can arise changes in the intensity of luminescence emitted by MOFs. The changes may be luminescence quenching (turned off) or enhancement (turned on) or sometimes even

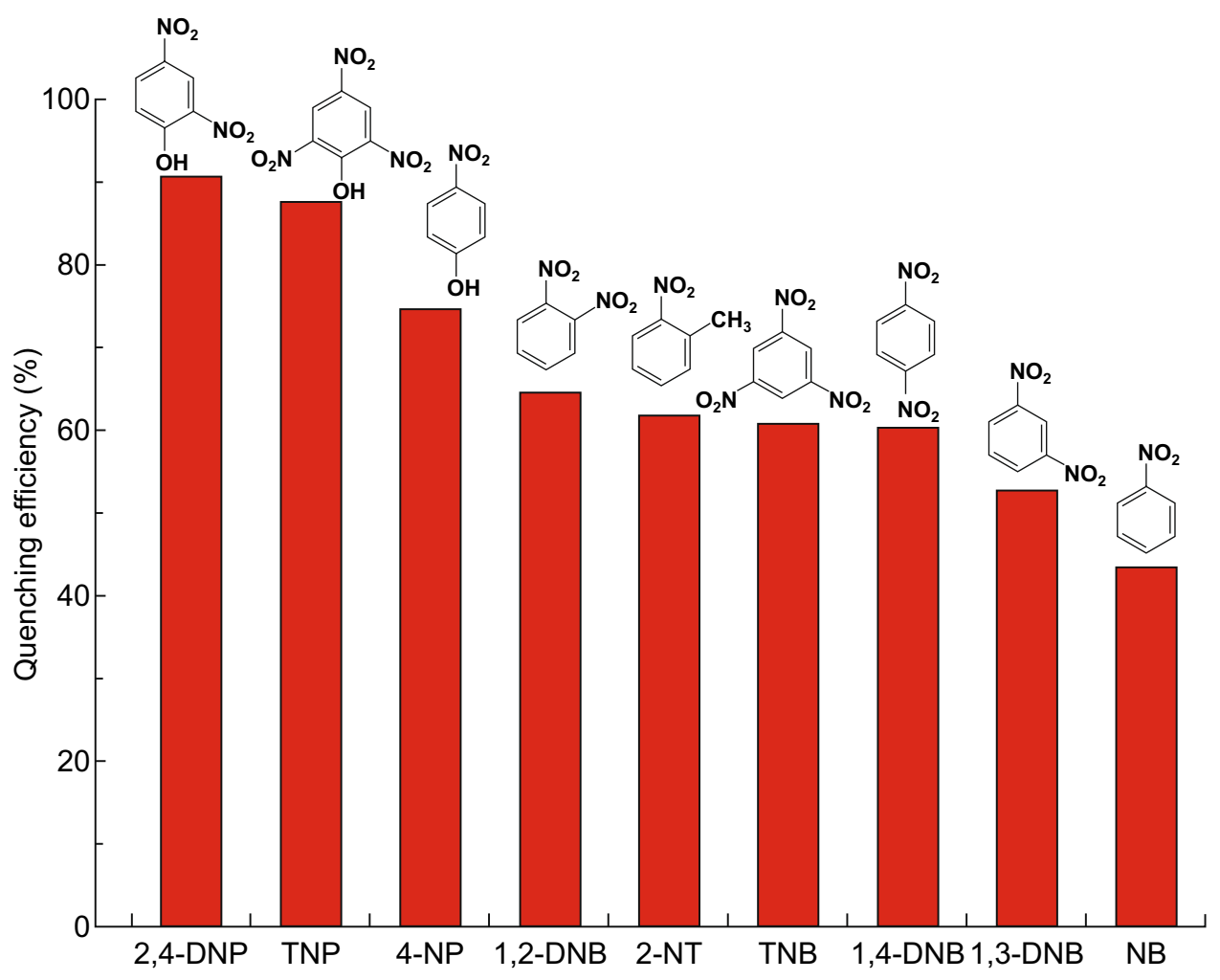

Fig. 13 The quenching percentage of $\left[\mathrm{Zn}\left(\mathrm{H}_{2} \mathrm{~L}\right)(2,2-\text { bipy })\right]_{\mathrm{n}}$ in DMF of NB, 2-NP, 4-NP, 1,2-DNB, 1,3-DNB, 1,4-DNB, 2,4-DNP, TNP and TNB at excitation of $278 \mathrm{~nm}$. Reprinted with permission from Ref. [47]. Copyright 2019, Royal Society of Chemistry 
both, which can be explained by the theory of charge and energy transfer. One typical example is the aforementioned $\mathrm{Cu}(\mathrm{I})-\mathrm{MOF}[\mathrm{CuI}(\mathrm{BPDPE})]_{\mathrm{n}}$, which presented an emission peak at $340 \mathrm{~nm}$ under excitation at $305 \mathrm{~nm}$ [39]. Treated with $\mathrm{Al}^{3+}$ of increasing concentration, the emission intensity at $340 \mathrm{~nm}$ gradually decreased and the intensity of a new emission peak at $420 \mathrm{~nm}$ gradually got stronger, as shown in Fig. 14. This phenomenon could be ascribed to the change of charge transfer from ligand-to-ligand (BPDPE-to-BPDPE) to ligand-to-metal (BPDPE-to- $\mathrm{Al}^{3+}$ ) as a result of $\mathrm{Al}-\mathrm{O}$ weak interactions in the presence of $\mathrm{Al}^{3+}$.

Many photoluminescent MOFs display luminescent quenching effect when exposed to external ions or

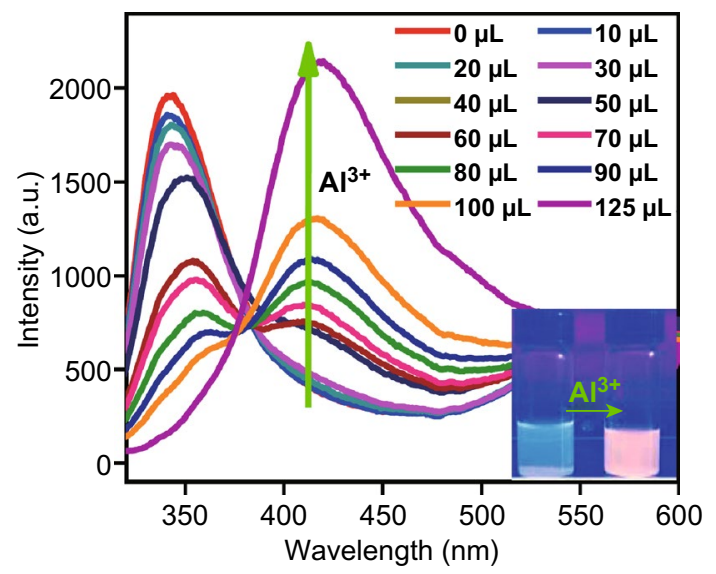

Fig. 14 Changes of emission intensities of $[\mathrm{CuI}(\mathrm{BPDPE})]_{\mathrm{n}}$ with incremental addition of $\mathrm{Al}^{3+}(1 \mathrm{mM})$. Reproduced with permission from Ref. [39]. Copyright 2020, Elsevier molecules. The quenching effect can be analyzed by the Stern-Völmer equation:

$I_{0} / I=1+K_{\mathrm{SV}}[M]$

where $I_{0}$ refers to the pristine luminescence intensity of MOFs, $I$ is the luminescence intensity of MOFs after being treated with external analytes, $[M]$ denotes the concentration of the external analytes, and $K_{\mathrm{SV}}$ is the quenching constant of MOFs. In terms of the quenching process, luminescent quenching can be divided into two parts: dynamic quenching and static quenching. While for some luminescence quenching only one type of process either dynamic or static is involved, most quenching processes include both, such as the coexistence of dynamic and static quenching when an $\mathrm{Eu}$ (III)-doped $\mathrm{Zn}-\mathrm{MOF}, \mathrm{Zn}_{3}(\mathrm{BTC})_{2}: 4 \% \mathrm{Eu}(\mathrm{III})$, was exposed to nitrobenzene (NB) [51].

Dynamic quenching originates from the interactions between the energy donor and quencher. For example, the sensing mechanism of $\mathrm{Eu}(\mathrm{Ln}) @$ bio-MOF-1 toward $\mathrm{O}_{2}$ was confirmed as the $\mathrm{O}_{2}$ quenching on long-range energy rollback from ligand triplet state to bio-MOF-1, as depicted in Fig. 15 [52]. Upon irradiation, the bio-MOF-1 matrix absorbed photons and transferred the energy to the organic diamine ligands of Eu(III) complexes, which further transferred the energy to emissive Eu(III) ions, resulting in strong red emission. There was supposed to be an energy roll-back procedure from ligand to bio-MOF-1. Due to the fully matched multiplicity, ${ }^{3} \mathrm{O}_{2}$ could quench the energy roll-back procedure, accompanied by the release of ${ }^{1} \mathrm{O}_{2}$, leading to the quenching effect of luminescence of Eu(Ln)@bio-MOF-1.
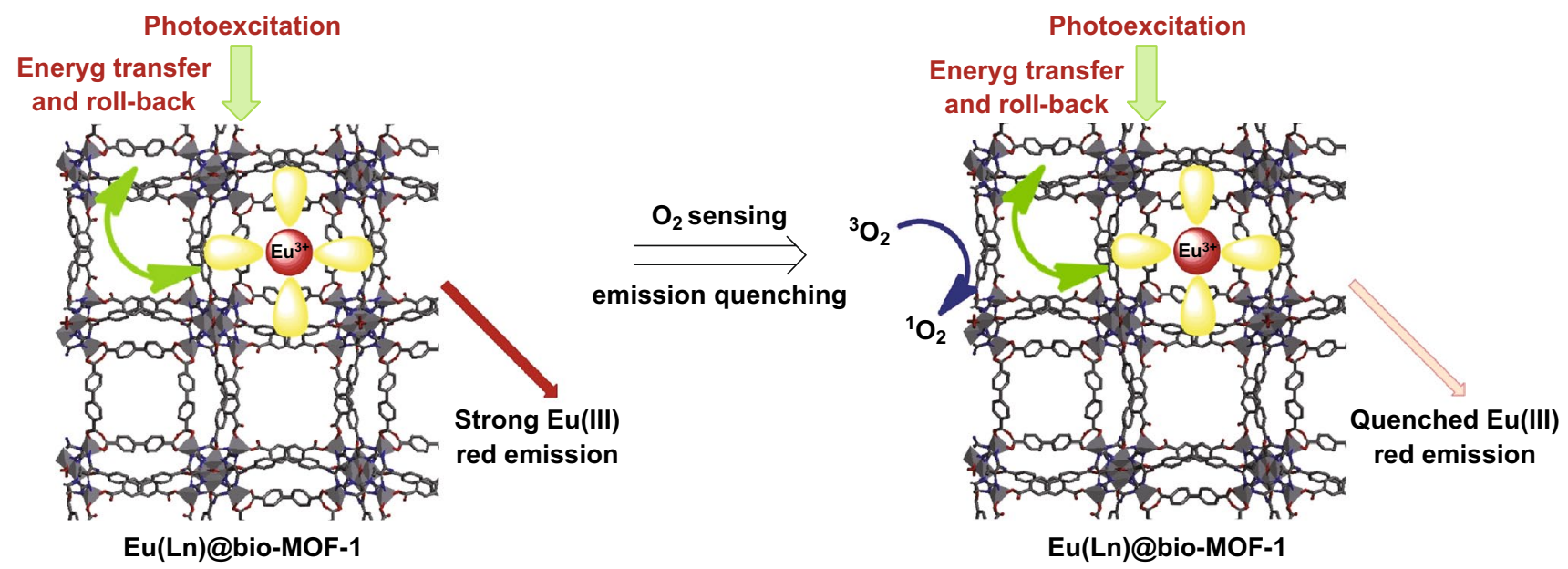

Fig. 15 Sensing mechanism of Eu(Ln)@bio-MOF-1 composite samples toward $\mathrm{O}_{2}$. Reproduced with permission from Ref. [52]. Copyright 2019, Elsevier 
In contrast, static quenching results from the generation of non-luminescent complexes between the fluorophore and quencher, diminishing the energy transfer between the fluorophore and energy donor. A LnMOF thin film of terbiumsuccinate (Tb-SA) was fabricated through cathodic electrodeposition and showed highly eye-detectable luminescent response as a photoluminescent sensor for $\mathrm{Cu}^{2+}$ in aqueous environment as well as high sensitivity, selectivity and stability [32]. The bright green light at $545 \mathrm{~nm}$ emitted from the film excited by laser at $303 \mathrm{~nm}$ could be quenched as a result of static quenching induced by non-luminescent complex of $\mathrm{Cu}^{2+}$ and succinic acid due to possible ion-exchange between $\mathrm{Cu}^{2+}$ and $\mathrm{Tb}^{3+}$, which inhibited the energy transfer in $\mathrm{Tb}$-SA composite.

There are two ways to distinguish static and dynamic quenching: through the luminescence lifetime or through $K_{\mathrm{SV}}$ response toward temperature change. On the one hand, luminescence lifetime retains nearly unchanged after static quenching, while in the case of dynamic quenching, increase in concentration of quencher gives rise to decrease in luminescence lifetime. The aforementioned $\mathrm{Tb}-\mathrm{SA}$ exhibited static quenching in the presence of $\mathrm{Cu}^{2+}$ since the luminescence lifetimes calculated with and without $\mathrm{Cu}^{2+}$ were nearly equal to each other, as shown in Fig. 16 [32]. The dynamic quenching of $\mathrm{Eu}(\mathrm{Ln}) @$ bio-MOF-1 toward $\mathrm{O}_{2}$ was confirmed by the fact that the lifetime of $\mathrm{Eu}(\mathrm{III})$ emission obviously decreased when $\mathrm{O}_{2}$ concentrations increased from 0 to $100 \%$ [52]. On the other hand, in dynamic quenching the $\mathrm{K}_{\mathrm{SV}}$ value increases with increased temperature, and for static quenching, the converse is true. For instance, the

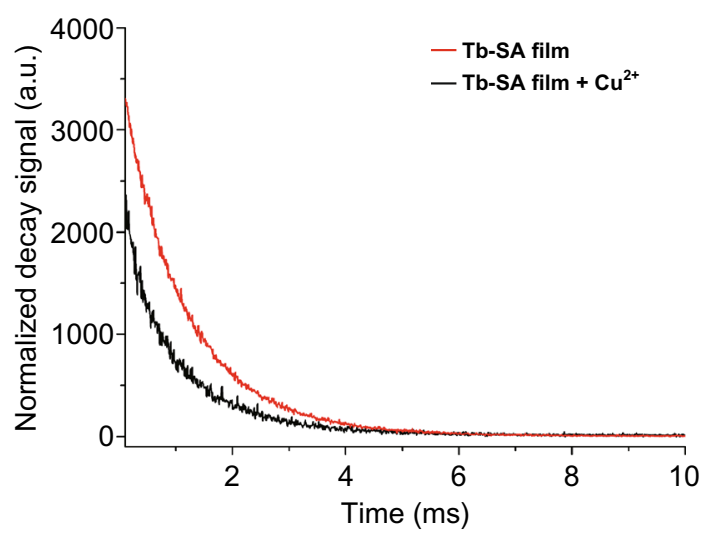

Fig. 16 Luminescence decay curves of Tb-SA films with and without the addition of $\mathrm{Cu}^{2+}$. Reproduced with permission from Ref. [32]. Copyright 2015, Elsevier luminescence quenching induced by triiodothyronine hormone (T3) in Cu-MOF-NPs investigated by Sheta et al. was ascribed to dynamic quenching because the $K_{\mathrm{SV}}$ value was positively proportional to the temperature, as shown in Fig. 17, where the slopes of simulated lines stand for the $K_{\mathrm{SV}}$ values [50].

While many luminescent sensors are fabricated based on quenching effect, others are based on the phenomenon of luminescence enhancement or generation of a new emission band. MOF-74(Zn)-en could act as a highly selective sensor for TBBPA [53]. Increases of both the concentration of TBBPA and interaction time resulted in enhanced fluorescence intensity of MOF-74(Zn)-en. The results shown in Fig. 18 revealed that the optimal contact time for TBBPA detection was around $40 \mathrm{~min}$ and the simulated Stern-Völmer equation was $F / F_{0}=0.004\left[C_{\mathrm{TBBPA}}\right]+1$ $\left(R^{2}=0.998\right)$. The possible mechanism could be attributed to Förster resonance energy transfer from MOF-74(Zn)en to TBBPA as TBBPA could interact with amino groups in MOF-74( $\mathrm{Zn}$ )-en and an overlap between the adsorption spectrum of MOF-74(Zn)-en and the emission spectrum of TBBPA was observed, enabling fluorescence enhancement. As for highly luminescent $\mathrm{Zn}_{2}$ (bpdc) ${ }_{2}$ (bpee) MOF $\left(\mathrm{H}_{2}(\mathrm{bpdc})=4,4^{\prime}\right.$-biphenyldicarboxylic acid and bpee $=1,2$-bipyridylethene), exposure to subppm amines turned on a new absorption band and a new luminescence band due to the release of bpee molecules exchanged by amines, enabling sensing functions [54].

Overall, to realize photoluminescence quenching or enhancement in MOFs for fabrication of practical

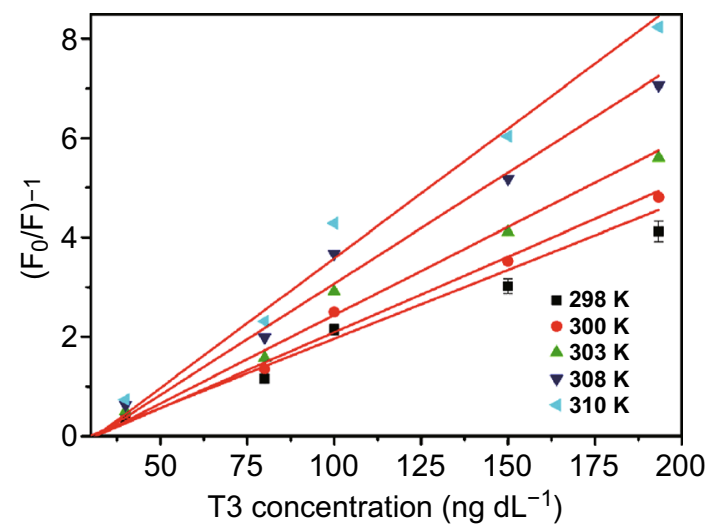

Fig. 17 The Stern-Völmer plots for PL quenching of Cu-MOF-NPs by $\mathrm{T} 3$ hormone at different five temperatures. Reproduced with permission from Ref. [50]. Copyright 2019, John Wiley \& Sons 

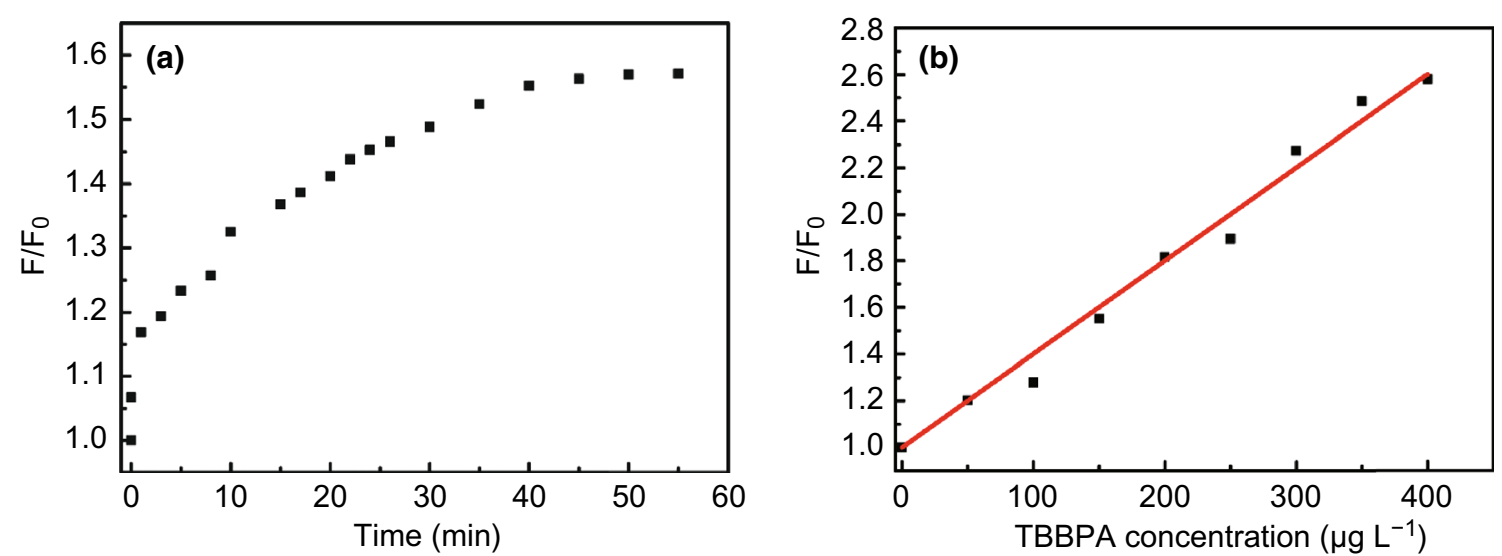

Fig. 18 a Photoluminescence enhancement ratio of MOF-74(Zn)-en in the presence of TBBPA (150 $\left.\mu \mathrm{g} \mathrm{L}^{-1}\right)$ at different incubation time. b Calibration curves of photoluminescence enhancement ratios of MOF-74( $\mathrm{Zn}$ )-en in the presence of different concentrations of TBBPA $\left(0-400 \mu \mathrm{g} \mathrm{L}^{-1}\right)$. Reproduced with permission from Ref. [53]. Copyright 2019, Elsevier

luminescent sensors toward different kinds of target analytes, five possibilities are usually taken into consideration: (1) structural transitions of MOFs induced by target analyte; (2) ion-exchange or ligand-exchange induced by target analyte; (3) interactions between target analyte and the fluorophore in MOFs; (4) the overlap between the absorption spectrum and of the target analyte and the excitation spectrum of the MOFs; (5) the overlap between the absorption spectrum of the MOFs and the emission spectrum of the target analyte. The first possibility was demonstrated in $\mathrm{Zn}_{2}(\mathrm{bdc})_{2}(\mathrm{dpNDI})$ (PCP-Zn) [55]. Adsorption of benzene molecules into PCP-Zn would cause considerable transformation of the
PCP-Zn

(a)

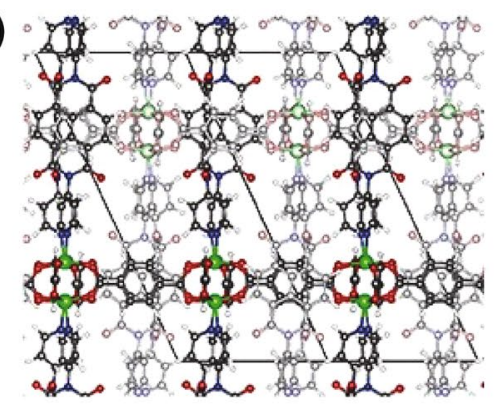

(d)

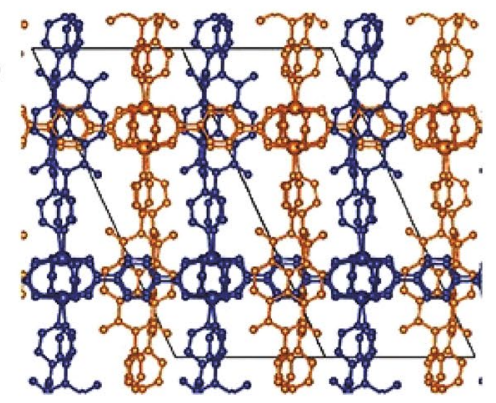

$P C P^{*}-Z n$

(b)

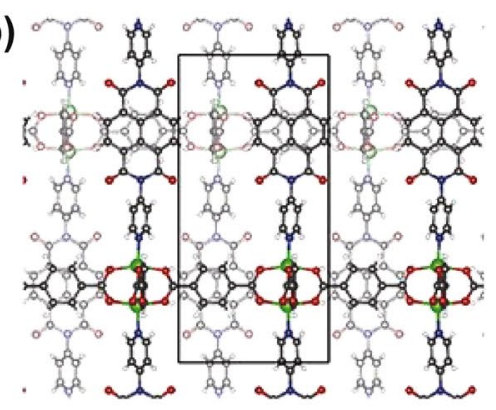

(e)

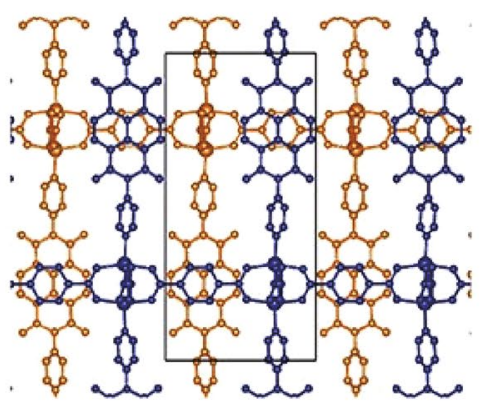

\section{$\mathrm{Bz}+\mathrm{PCP}-\mathrm{Zn}$}

(c)

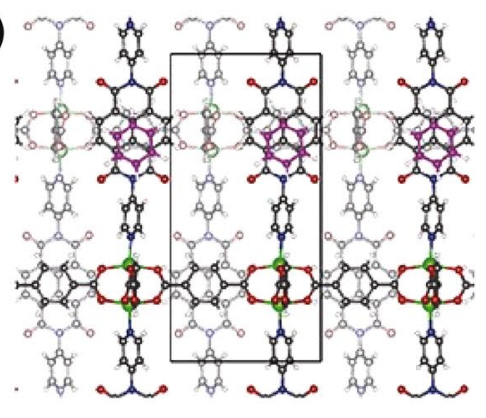

(f)

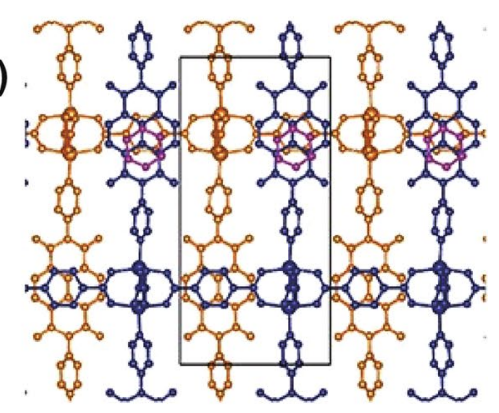

Fig. 19 a PCP-Zn: Structure of pristine MOF before guest molecule introduction. b PCP*-Zn: Structure after guest-molecule-induced structural change, but without guest molecule. $\mathbf{c}$ Bz+PCP-Zn: Structure after adsorption of benzene in the MOF. d-f The same structures as a-c with subframeworks colored as blue (subframework 1) and orange (subframework 2) and the hydrogens removed for clarity. Reproduced with permission from Ref. [55]. Copyright 2019, American Chemical Society 
framework structure (Fig. 19), which significantly decreased the distance between $\mathrm{HOMO}_{\mathrm{PCP}^{*} \text {-Zn }}$ and $\mathrm{LUMO}_{\mathrm{PCP}^{*} \text {-Zn }}$ and localized the orbitals, increasing the oscillator strengths and rendering the pristine non-luminescent PCP-Zn strong photoluminescence. The luminescence enhancement made PCP-Zn a promising sensor for benzene detection. Examples for the second and third possibilities include $\mathrm{Zn}_{2}$ (bpdc) $)_{2}$ (bpee) [54] and Tb-SA [32], respectively, which have been discussed before. As for the fourth possibility, a typical example is $\left\{\left[\mathrm{Tb}(\mathrm{Cmdcp})\left(\mathrm{H}_{2} \mathrm{O}\right)_{3}\right]_{2}\left(\mathrm{NO}_{3}\right)_{2} \cdot 5 \mathrm{H}_{2} \mathrm{O}\right\}_{\mathrm{n}}$ $\left(\mathrm{H}_{3} \mathrm{CmdcpBr}=\mathrm{N}\right.$-carboxymethyl-(3,5-dicarboxyl)pyridinium bromide) as sensor toward $\mathrm{Fe}^{3+}[56]$. As shown in Fig. 20, there was an obvious overlap between the adsorption spectrum of $\mathrm{Fe}^{3+}$ and the excitation spectrum of the MOF, which was not observed for other metal ions. The overlap revealed that $\mathrm{Fe}^{3+}$ would compete with the MOF to adsorb light energy, disabling the MOF to adsorb enough light to be excited and emit photoluminescence, leading to a quenching effect. The fifth possibility usually occurs between photoadsorptive MOFs and emissive target analyte, such as the aforementioned MOF-74(Zn)-en for TBBPA detection [53]. Notably, for the design of luminescent MOFs as sensors, Lewis acidic/basic active sites are often involved. In particular, Lewis basic sites have a strong chelating ability to Lewis acidic ions like $\mathrm{Cu}^{2+}, \mathrm{Zn}^{2+}, \mathrm{La}^{2+}[57], \mathrm{Fe}^{3+}$ [58] and so forth, hence promoting the sensitivity of sensors toward these metal ions. For example, $\left\{\left[\mathrm{Cd}_{1.5}(\mathrm{DBPT})(\mathrm{DiPyDz})\right.\right.$ $\left.\left.\left(\mathrm{H}_{2} \mathrm{O}\right)\right] \cdot 3.5 \mathrm{H}_{2} \mathrm{O}\right\}_{n}$ possess $\mathrm{H}_{3}$ DBPT ligand that has open Lewis basic triazolyl groups, which can effectively bind to

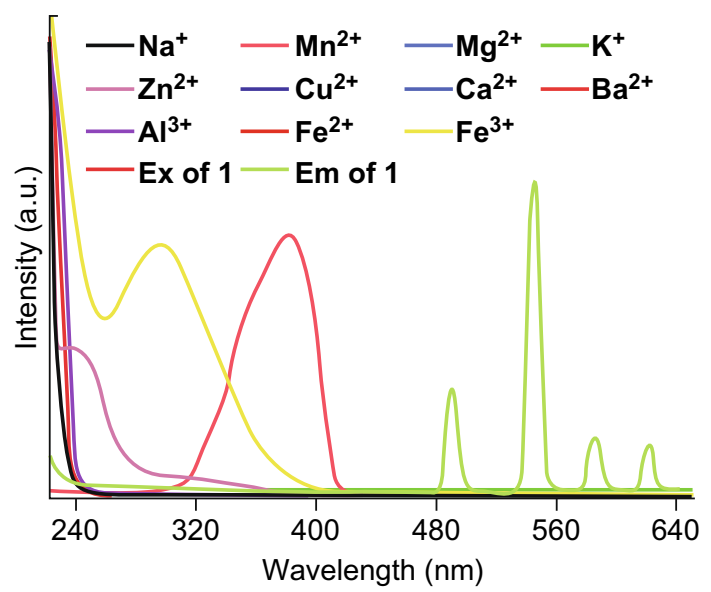

Fig. 20 The emission $\left(\lambda_{\mathrm{ex}}=380 \mathrm{~nm}\right)$ and excitation $\left(\lambda_{\mathrm{em}}=545 \mathrm{~nm}\right)$ spectra of $\left\{\left[\mathrm{Tb}(\mathrm{Cmdcp})\left(\mathrm{H}_{2} \mathrm{O}\right)_{3}\right]_{2}\left(\mathrm{NO}_{3}\right)_{2} \cdot 5 \mathrm{H}_{2} \mathrm{O}\right\}_{\mathrm{n}}$, as well as the absorption spectra of different metal ions. Reproduced with permission from Ref. [56]. Copyright 2019, Royal Society of Chemistry
$\mathrm{Fe}^{3+}$ ions [58]. The limit of detection of this MOF toward $\mathrm{Fe}^{3+}$ can reach as low as $78 \mathrm{ppb}$, much lower than $112 \mathrm{ppb}$ for $[\mathrm{Cd}(\mathrm{L})(\mathrm{pda})][59]$.

\subsubsection{Light Emitting}

More and more attention is being paid to the possible application of luminescent MOFs in lighting devices. Notably, based on the superior compositional tunability and diversity of MOFs, usually two or more emissive ions or molecules are involved in the construction of MOFs or guest@MOF hybrids to combine each emission color of each emissive component in order to obtain various high-quality colors. For example, a series of $\mathrm{H}_{4} \mathrm{~L}^{+} \mathrm{Cl}^{-}$-based $\left\{\left[\mathrm{Eu}_{x} \mathrm{~Tb}_{1-x}(\mathrm{~L})\right.\right.$ $\left.\left.\left(\mathrm{H}_{2} \mathrm{O}\right)_{2}\right] \cdot 5 \mathrm{H}_{2} \mathrm{O}\right\}_{\mathrm{n}}$ with both $\mathrm{Eu}^{3+}$ and $\mathrm{Tb}^{3+}$ ions were synthesized [41]. Dual emission of $\mathrm{Eu}^{3+}$ and $\mathrm{Tb}^{3+}$ was observed under excitation at $302 \mathrm{~nm}$. As the molar ratio of $\mathrm{Eu}^{3+}$ increased from 5 to $90 \%$, the luminescence intensity of $\mathrm{Tb}^{3+}$ at $544 \mathrm{~nm}$ gradually weakened and the luminescence intensity of $\mathrm{Eu}^{3+}$ at $617 \mathrm{~nm}$ gradually enhanced, as shown in Fig. 21a. This phenomenon was ascribed to enhanced energy transfer from $\mathrm{Tb}^{3+}$ to $\mathrm{Eu}^{3+}$ as molar ratio of $\mathrm{Eu}^{3+}$ increased, which gradually quenched the photoluminescence of $\mathrm{Tb}^{3+}$. Specifically, under irradiation at $254 \mathrm{~nm}$, the luminescence colors of the MOF smoothly changed from yellow-green, yellow, orange, orange-red to red as the molar ratio of $\mathrm{Eu}^{3+}$ increased from 5 to $90 \%$ due to the synergy of $\mathrm{Tb}^{3+}$ and $\mathrm{Eu}^{3+}$ emissions, as shown in Fig. 21b. Multicolor emissions can be realized by modulating the molar ratio of different emissive components in one MOFs. In particular, based on three-primary colors theory, this dual emission mechanism has been widely applied in white-light-emitting field. The Commission International deI'Eclairage (CIE) color coordinates are used to assess the quality of white light emitted by various materials. The closer the CIE of MOFs is to the standardized coordinate for pure white light $(0.3333$, 0.3333), the higher the quality and purity of emitted white light are. And the different emissive components commonly used for synthesis of white-light-emitting MOFs with exceptional color quality and quantum yield are lanthanide metal ions, guest molecules and organic ligands.

Mixed-LnMOFs synthesized from two or more types of lanthanide metals are promising candidates for white light emission. A series of mixed-LnMOFs $\left[\left(\mathrm{Eu}_{x} \mathrm{~Tb}_{1-x}\right)_{2}(\mathrm{TDC}\right.$ )$\left._{3}\left(\mathrm{CH}_{3} \mathrm{OH}\right)_{2} \cdot\left(\mathrm{CH}_{3} \mathrm{OH}\right)\right]$, abbreviated as $\mathrm{Eu}_{x} \mathrm{~Tb}_{1-x}-\mathrm{MOFs}$, 
(a)

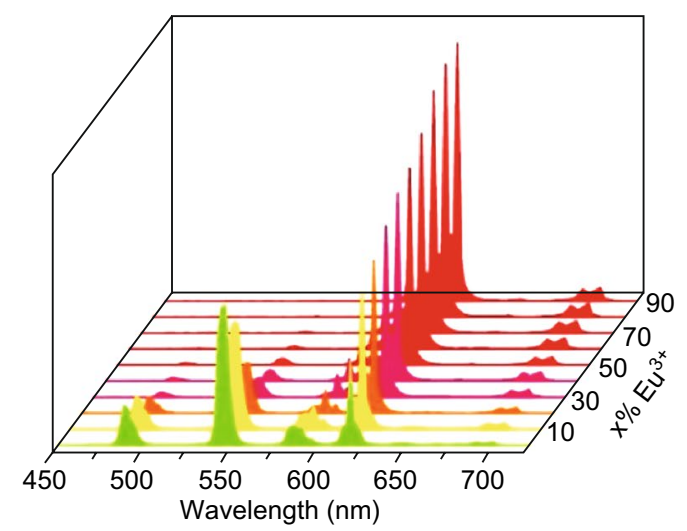

(b)

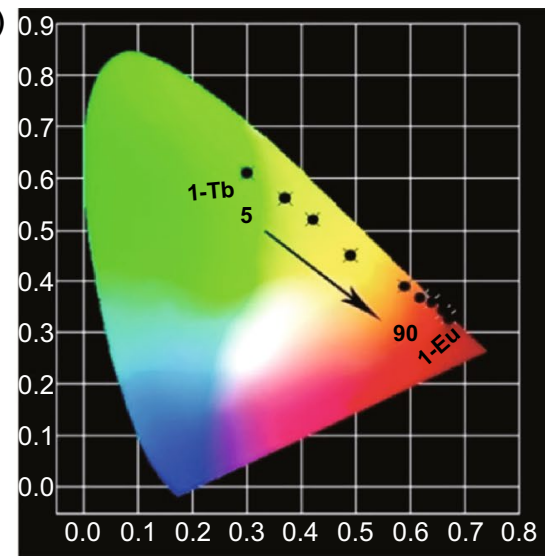

Fig. 21 a Solid-state emission spectra of $\left\{\left[\mathrm{Eu}_{x} \mathrm{~Tb}_{1-x}(\mathrm{~L})\left(\mathrm{H}_{2} \mathrm{O}\right)_{2}\right] \cdot 5 \mathrm{H}_{2} \mathrm{O}\right\}_{\mathrm{n}}$ with different molar ratios of Eu ${ }^{3+}$ under excitation of $302 \mathrm{~nm}$. b CIE chromaticity diagram of $\left\{\left[\mathrm{Eu}_{x} \mathrm{~Tb}_{1-x}(\mathrm{~L})\left(\mathrm{H}_{2} \mathrm{O}\right)_{2}\right] \cdot 5 \mathrm{H}_{2} \mathrm{O}\right\}_{\mathrm{n}}$. Reprinted with permission from Ref. [41]. Copyright 2019, American Chemical Society

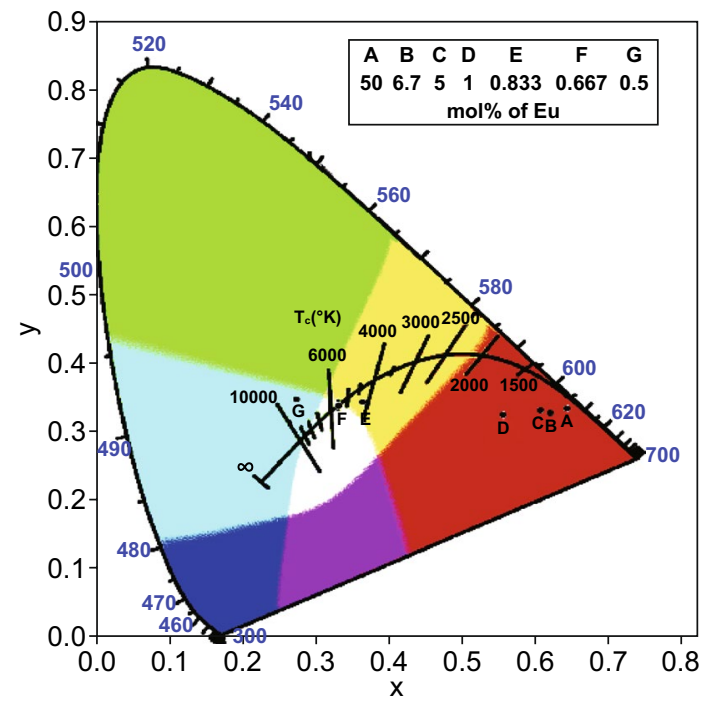

Fig. 22 CIE chromaticity diagram of mixed $\mathrm{Eu}_{x} \mathrm{~Tb}_{1-x}-\mathrm{MOF}$ with different $\mathrm{Eu}$ ratios and excitation wavelengths. Reprinted with permission from Ref. [60]. Copyright 2019, Elsevier

were investigated with $x=0.5,0.067,0.05,0.01,0.00833$, 0.00667 , and 0.005 [60]. The CIE chromaticity diagram of MOFs with different Eu ratios is depicted in Fig. 22. It was found that only $\mathrm{Eu}_{0.00667} \mathrm{~Tb}_{0.99333}$-MOF emitted white light under $350 \mathrm{~nm}$ excitation, with the CIE coordination of $(0.3333,0.3394)$ very close to that of pure white light. This research reveals that carefully tuning the ratio of different lanthanide metal ions in MOFs is a promising strategy to generate pure white light emission.
Dual emission for white light can be realized through introduction of luminescent guest molecules as well. The reported luminescent materials encapsulated into MOFs include iridium complex [61], fluorescent proteins (FPs) [62], carbon dots (CDs) [63], quantum dots (QDs), organic dyes and so on, as shown in Table 4. With optimal amount of guest molecules and excitation wavelengths, white light emission can be observed in the synthesized guest@MOF hybrids. As shown in Fig. 23, different amounts of bluelight-emitting carbon dots (CDs) were encapsulated into a mixed-LnMOF which emitted yellow luminescence and the final hybrids exhibited different luminescence colors upon irradiation [63]. For CDs-3@LnMOF with 3 mL CDs, different CIE coordinates were obtained under various wavelengths in range of 360-380 $\mathrm{nm}$ and the best CIE coordinate could reach up to $(0.334,0.334)$ when CDs-3@LnMOF was irradiated under $370 \mathrm{~nm}$. This revealed that the CIE coordinates can be modulated through careful selections of guest molecule concentration and excitation wavelength. It should be noted that sometimes the luminescence bands of guest molecules will be influenced and changed upon encapsulation into MOFs. For example, R-phycoerythrin (R-PE) proteins were denatured after embedded into HSB-W1 framework, which inhibited their pristine orange luminescence at $578 \mathrm{~nm}$ and aroused new green $(518 \mathrm{~nm})$ and red (600, $647 \mathrm{~nm}$ ) luminescence [62]. Synergy of emissions from R-PE and blue-light-emitting HSB-W1 finally resulted in high-quality white light emission with CIE of $(0.33,0.34)$. 
Table 4 Photoluminescent MOFs for white-light emission

\begin{tabular}{|c|c|c|c|c|}
\hline MOFs & Guest molecules & Excitation $(\mathrm{nm})$ & CIE & References \\
\hline HSB-W1 & R-phycoerythrin (R-PE) & 405 & $(0.33,0.34)$ & {$[62]$} \\
\hline Cd-MOF (CP1) & CdTe QDs & 330 & $(0.33,0.32)$ & [110] \\
\hline$\left[\mathrm{Eu}_{1.22} \mathrm{~Tb}_{0.78}(1,4-\mathrm{phda})_{3}\left(\mathrm{H}_{2} \mathrm{O}\right)\right]\left(\mathrm{H}_{2} \mathrm{O}\right)_{2}$ & CDs-3 & 370 & $(0.334,0.334)$ & {$[63]$} \\
\hline $\begin{array}{l}{\left[\left(\mathrm{CH}_{3}\right)_{2} \mathrm{NH}_{2}\right]_{15}\left[\left(\mathrm{Cd}_{2} \mathrm{Cl}\right)_{3}(\mathrm{TATPT})_{4}\right] \cdot 12 \mathrm{DMF} .} \\
\quad 18 \mathrm{H}_{2} \mathrm{O}\end{array}$ & {$\left[\operatorname{Ir}(\text { ppy })_{2}(\text { bpy })\right]^{+}$} & 370 & $(0.31,0.33)$ & {$[61]$} \\
\hline \multirow[t]{3}{*}{ ZIF- $8^{2}$} & $\mathrm{C}-151$ & 365 & $(0.16,0.12)$ & [111] \\
\hline & $\mathrm{F}$ & & $(0.26,0.58)$ & \\
\hline & RB & & $(0.57,0.43)$ & \\
\hline$\left[\mathrm{Eu}(\mathrm{MCTCA})_{1.5}\left(\mathrm{H}_{2} \mathrm{O}\right)_{2}\right] \cdot 1.75 \mathrm{H}_{2} \mathrm{O}$ & $\mathrm{H}_{4}$ TBAPy & 350 & $(0.3482,0.3301)$ & [112] \\
\hline$\left[\mathrm{Me}_{2} \mathrm{NH}_{2}\right][\operatorname{In}(\mathrm{bptc})]$ & safranin $\mathrm{O}$ & 380 & $(0.32,0.33)$ & [113] \\
\hline ZJU-28 & Cou-6/R6G/R101 & 460 & $(0.36,0.34)$ & [114] \\
\hline \multirow[t]{2}{*}[\mathrm{Eu}_{0.05}(\mathrm{H}_{2}\mathrm{O})_{4}(\mathrm{pdc})]{$\left._{4} \mathrm{SiMo}_{12} \mathrm{O}_{40}\right] \cdot 2 \mathrm{H}_{2} \mathrm{O}$} & $\mathrm{Eu}^{3+}$ & 295 & $(0.3425,0.2548)$ & {$[92]$} \\
\hline & $\mathrm{Eu}^{3+} / \mathrm{Tb}^{3+}$ & & $(0.3857,0.3377)$ & \\
\hline$\left[\mathrm{Zn}_{4} \mathrm{OL}_{2} \cdot \mathrm{xDMF}\right]_{\mathrm{n}}$ & DCM/C6 & 365 & $(0.32,0.31)$ & [115] \\
\hline $\mathrm{Zr}-\mathrm{MOF}$ & CDs & 365 & $(0.31,0.34)$ & [116] \\
\hline
\end{tabular}

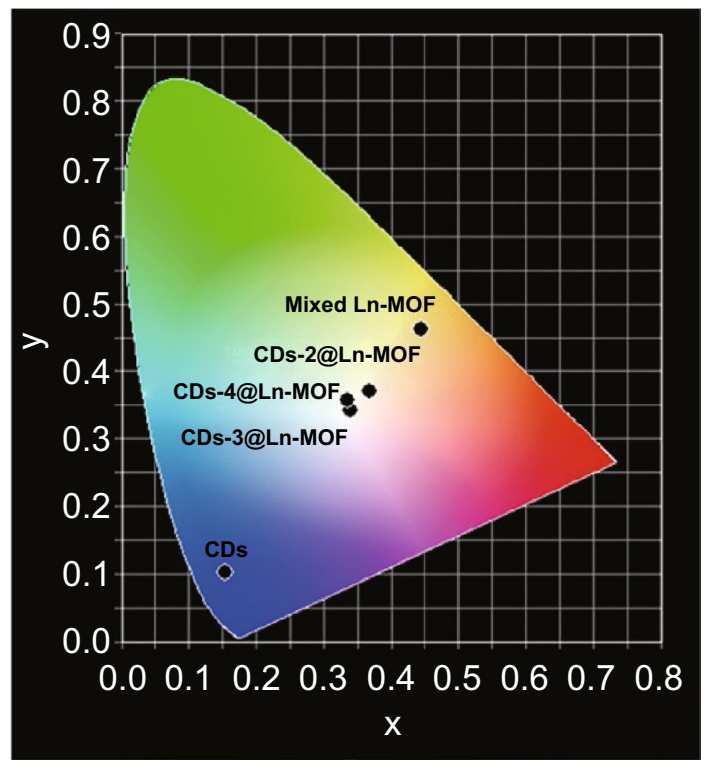

Fig. 23 CIE chromatic diagram of CDs, mixed-LnMOF, and CDs@ LnMOF hybrids. CDs-2, CDs-3, and CDs-4 refer to 2, 3, and $4 \mathrm{~mL}$ of CDs encapsulated into MOFs, respectively. Reprinted with permission from Ref. [63]. Copyright 2019, American Chemical Society

What is more, some LnMOFs with photoactive ligands can also generate dual emissions from Ln metal ions and organic ligands. In this case, the ligand-centered emission needs to be resensitized by dopant metal ions. For example, while the MOF [Eu(3-TPyMNTB) $)_{2}$ ] $\left(\mathrm{ClO}_{4}\right)_{3} \cdot 2.5 \mathrm{MeCN}$ emitted characteristic red luminescence, the Ag-doped MOF [ $\left.\operatorname{EuAg}_{3}(3-\mathrm{TPyMNTB})_{2}\left(\mathrm{H}_{2} \mathrm{O}\right)(\mathrm{MeCN})\right]$

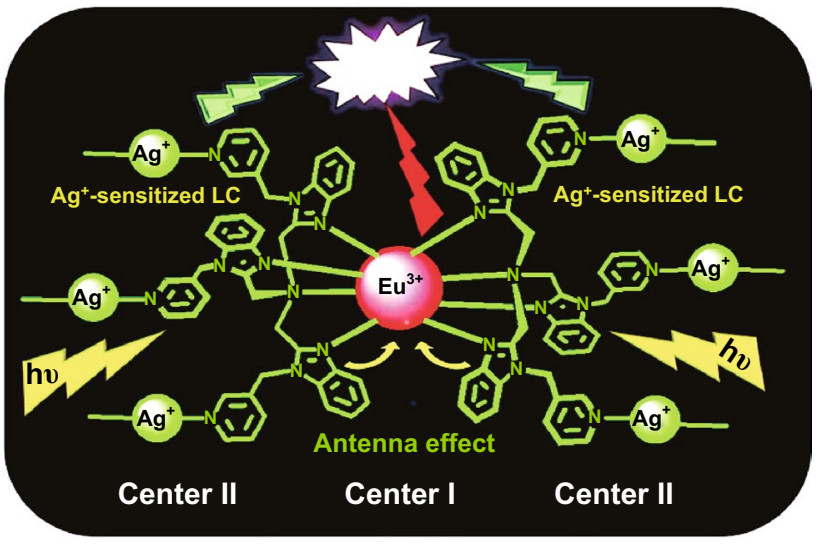

Fig. 24 Dual-emitting pathways in the Ag-doped MOF generating white-light emission. Reprinted with permission from Ref. [64]. Copyright 2012, American Chemical Society

$\left(\mathrm{ClO}_{4}\right)_{6} \cdot 4 \mathrm{MeCN}$ directly emitted white light due to the ligand-centered emission of TPyMNTB resensitized by doped $\mathrm{Ag}^{+}$, as depicted in Fig. 24 [64].

One crucial challenge to light-emitting devices is the accompanying generated thermal energy. Under irradiation, a considerable amount of light energy absorbed by the device is converted to thermal energy, which diffuses into the surrounding environment and is hard to reuse, lowering the overall efficiency of the lighting device. What's worse, the generated thermal energy will increase device temperature, which will probably decrease the device luminescence lifetime or even directly damage the device. Interestingly, 
an effective solution toward this challenge was proposed. Carbon quantum dot (CQD) and stearic acid (SA) molecules were simultaneously incorporated into Cr-MIL-101- $\mathrm{NH}_{2}$ to synthesize novel phase change materials (PCMs) [44]. As superior photoluminescent particles, CQD was utilized to render the composite light-emitting properties. Stearic acid functioned as thermal energy guest, which constantly adsorbed the generated heat in the process of photoluminescence, enabling thermal energy recycling and maintaining a relatively low temperature, hence improving luminescence efficiency and device lifetime. This PCMs system provides exciting improvement for lighting devices and is supposed to attract more and more attention.

\subsubsection{Luminescent Thermometer}

Compared to traditional thermometers, such as liquidfilled thermometers, transistors, and thermocouples, which need direct physical contact with the tested environment, luminescent thermometers have attracted much attention due to their non-contact real-time temperature-sensing properties and can be applied in fast-moving samples and in strong magnetic or electronic situations. Excitingly, another promising application of photoluminescent MOFs is self-calibrating luminescent thermometer based on fluorescence intensity ratio (FIR) technique. In this case, dual emissions are required and the intensities of emissions at different wavelengths response to the temperature change differently. The intensity ratio of emissions at two wavelengths is the basis to measure temperature. One example is $\mathrm{CsPbBr}_{3} @ \mathrm{Eu}-\mathrm{BTC}$ which has been investigated in the temperature range of $20-100{ }^{\circ} \mathrm{C}$ and served as a reliable and stable thermometer with a high relative sensitivity $\left(\mathrm{S}_{\mathrm{r}}\right)$ of $3.9 \% /{ }^{\circ} \mathrm{C}$ at $20{ }^{\circ} \mathrm{C}$ and excellent temperature resolution of $0.004{ }^{\circ} \mathrm{C}$ [65]. As temperature increased, the photoluminescence at $528 \mathrm{~nm}$ from $\mathrm{CsPbBr}_{3}$ QDs got weaker, whereas the emission of $\mathrm{Eu}^{3+}$ at $618 \mathrm{~nm}$ became stronger, as shown in Fig. 25. Other luminescent MOFs with potential for temperature sensing based on FIR technique include the aforementioned $\left[\left(\mathrm{Eu}_{0.0069} \mathrm{~Tb}_{0.9931}\right)_{2}(\mathrm{TDC})_{3}\left(\mathrm{CH}_{3} \mathrm{OH}\right)_{2} \cdot\left(\mathrm{CH}_{3} \mathrm{OH}\right)\right]$ in the range of 288-353 $\mathrm{K}$ [60], $\mathrm{Eu}_{0.0069} \mathrm{~Tb}_{0.9931}$-DMBDC (DMBDC $=2,5$-dimethoxy-1,4-benzenedicarboxylate) in the range of 10-300 K [66], and so on. In addition, changes in the single-luminescence intensity at single wavelength of MOFs at different temperatures can also provide reference

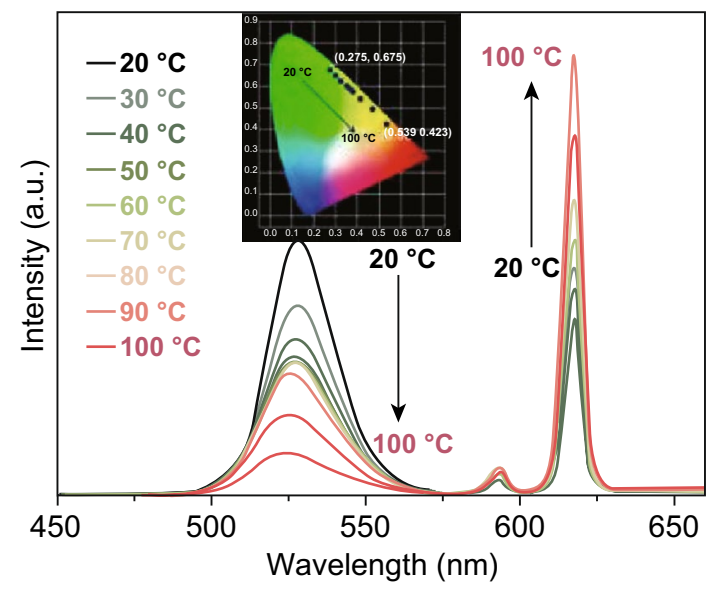

Fig. 25 Temperature-dependent PL spectra of $\mathrm{CsPbBr}_{3} @ \mathrm{Eu}-\mathrm{BTC}$ in the temperature range of $20-100{ }^{\circ} \mathrm{C}$ excited at $339 \mathrm{~nm}$ (inset: the CIE $(x, y)$ coordinate diagram of emission colors at various temperatures). Reprinted with permission from Ref. [65]. Copyright 2020, American Chemical Society

for temperature sensing. C-QDs @UiO-6-(COOH $)_{2}$ [46] film can detect temperature change in the range of 97-297 K with the $\mathrm{S}_{\mathrm{r}}$ value up to $1.3 \% \mathrm{~K}^{-1}$ at $297 \mathrm{~K}$. Luminescence intensities of C-QDs@UiO-6-(COOH $)_{2}$ at different temperatures are shown in Fig. 26a, and the relation between intensity and temperature is linear simulated in Fig. 26b.

\subsubsection{Optical Information Protection}

Based on the quenching and recovery of luminescence, the potential of MOFs for information encryption and decryption has also been investigated. $\mathrm{MAPbBr}_{3} @ \mathrm{UiO}-66$, synthesized by simply encapsulating the conventional luminescent $\mathrm{MAPbBr}{ }_{3}$ perovskite into the MOF UiO-66, was such stable material that it was used for information protection and anticounterfeiting because $\mathrm{MAPbBr}_{3}$ could be converted into $\mathrm{PbBr}_{2}$ by water and would recover when treated with $\mathrm{MABr}$ solution, as shown in Fig. 27 [43]. The single and bimetallic MOFs $\left[\mathrm{Eu}_{x} \mathrm{~Tb}_{2-x}(1,4-\text { phda })_{3}\left(\mathrm{H}_{2} \mathrm{O}\right)\right]\left(\mathrm{H}_{2} \mathrm{O}\right)_{2}(x=0,0.73,1.22$, $1.57,1.94$, and 2 ) have also been demonstrated to serve as luminescent security inks [63]. In this case, special information storage boxes were utilized, which were transparent under daylight but could be excited to emit luminescence under UV light. Letters were written on box by MOF ink that emitted the same luminescence color as the box. Addition of styrene could quench the luminescence of the MOF due to energy transfer from the MOF to styrene, enabling decoding 

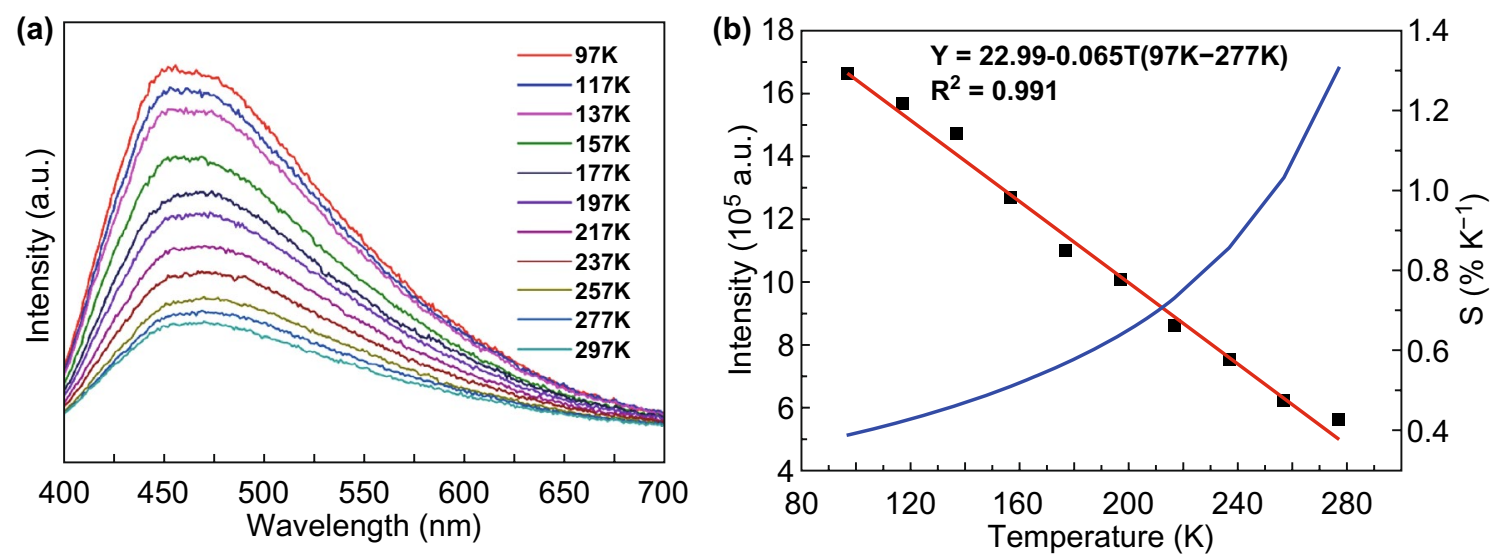

Fig. 26 a PL emission spectra of C-QDs@UiO-66-(COOH $)_{2}$ film in the temperature range of 97-297 K. b Emission intensity of the C-QDs@ UiO-66- $(\mathrm{COOH})_{2}$ film as a function of temperature (black squares, left axis) with the fitting curve (red line, $\mathrm{R}^{2}=0.991$ ) and the relative sensitivity curve (blue line, right axis). Reprinted with permission from Ref. [46]. Copyright 2018, American Chemical Society

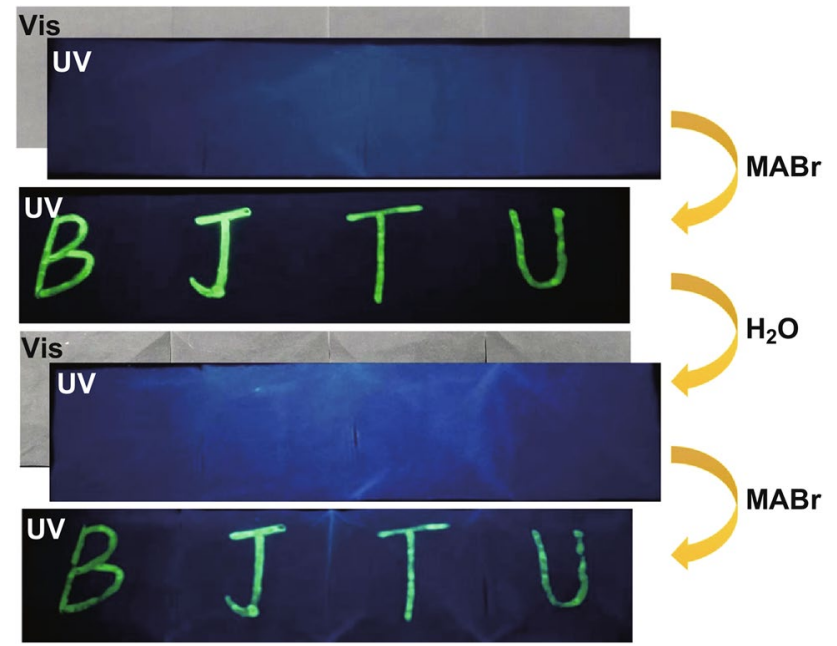

Fig. 27 Reversible fluorescence switching of the BJTU pattern written on the paper at different stages under ambient and $365 \mathrm{~nm}$ UV light. Reprinted with permission from Ref. [43]. Copyright 2019, Elsevier

of the letters under UV light. Besides, styrene could easily evaporate in air, making it possible to erase and rewrite the letters.

\section{Deposition of MOF Thin Films}

For device integration, it is required that MOFs possess enough physical contacts with other materials and to meet this requirement, MOFs are often prepared in forms of thin films. It is of great significance to master how to fabricate high-quality MOF thin films with precise control over the thickness, morphology, density, crystallinity, roughness, and orientation, which determine the device performance of MOFs [67]. For conductive MOFs, it has been demonstrated that thickness [68] and orientation [69] of thin films can affect the electrical conductivity. For photoluminescent MOFs, thin films possess advantages over powders, such as more binding sites for analyte molecules or ions, easy separation from solutions, less crystal defects and so forth. Many methods have been developed for deposition of MOF thin films, some of which have been demonstrated to exhibit flexibility toward various MOFs.

\subsection{Electrochemical Deposition}

Electrochemical deposition, including cathodic and anodic deposition, is a rapid method to fabricate MOF thin films and allows for mechanical and electrical contact between the MOF and substrate. For cathodic deposition, precursor metal ions and ligands are both required in electrolyte and the MOF thin film deposits on the surface of cathode. For instance, as shown in Fig. 28, with a graphite rod as the anode and the fluorine-doped tin oxide (FTO) conductive glass as the cathode, the Eu-HBPTC thin film appeared on the cathode when the two electrodes were immersed into the mixed solution of benzophe-none-3,30,4,40-tetracarboxylic dianhydride (BTDA), DMF and $\mathrm{Eu}\left(\mathrm{NO}_{3}\right)_{3} \cdot 6 \mathrm{H}_{2} \mathrm{O}$ and a constant current was applied [70]. The thus synthesized Eu-HBPTC thin film presented the similar emission spectra to $\mathrm{Eu}^{3+}$ ions 


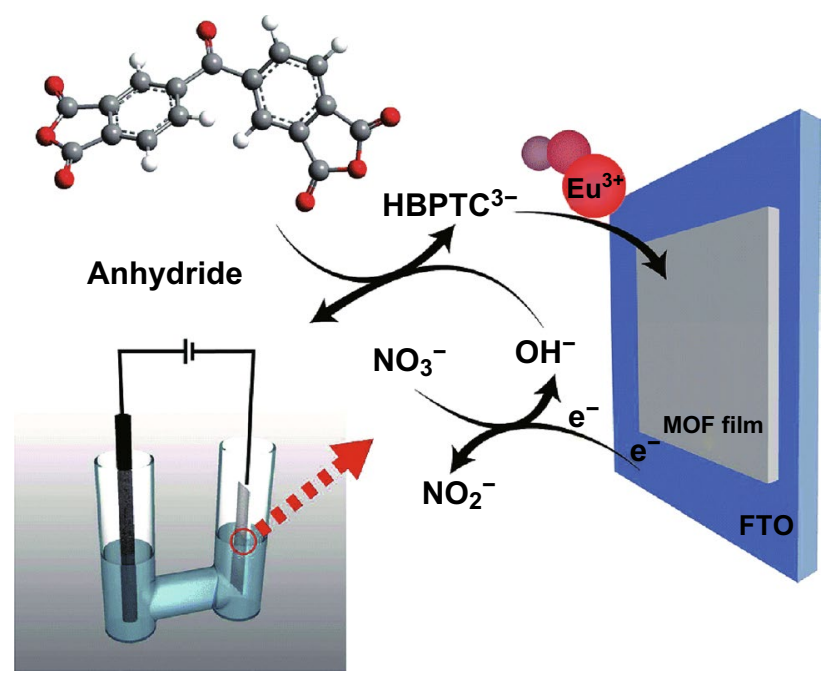

Fig. 28 Cathodic deposition of Eu-HBPTC thin film. Reprinted with permission from Ref. [70]. Copyright 2014, Royal Society of Chemistry

and could be used as a highly selective sensor for carbonate in aqueous solution even with the $\mathrm{CO}_{3}{ }^{2-}$ concentration down to $10^{-4} \mathrm{M}$. Similarly, this method has succeeded in fabrication of the aforementioned MOF terbium-succinate (Tb-SA) thin film as a sensor for $\mathrm{Cu}^{2+}$ [32]. Furthermore, using the same method, white-light-emitting thin films of LnCPs, formulated as $\left[\operatorname{Ln}_{6}(\mathrm{HMA})_{6}\left(\mathrm{H}_{2} \mathrm{O}\right)_{16}\right] \cdot 17 \mathrm{H}_{2} \mathrm{O}$ (HMA$\mathrm{Ln}, \mathrm{Ln}=\mathrm{Eu}^{3+}, \mathrm{Gd}^{3+}, \mathrm{Tb}^{3+} ; \mathrm{H}_{3} \mathrm{HMA}=$ hemimellitic acid), were fabricated and exhibited satisfactory CIE coordinates reaching $(0.33,0.34)$ [71].

However, for anodic deposition, the MOF thin film deposits on the anode and the electrolyte only contains the precursor organic ligands because metal ions for MOF construction come from the anode. A series of MOFs were deposited on indium tin oxide (ITO) glass previously coated by corresponding metallic films through anodic deposition, which proved to be a promising strategy for integration of MOFs with electronic devices, and attempts of involving more conductive MOFs in this processing are under way [72].

The difference between anodic deposition and cathodic deposition was investigated by comparing the anodic deposition of $\mathrm{Cu}-\mathrm{INA}, \mathrm{Cu}-\mathrm{INA}(\mathrm{Cl})$, and $\mathrm{Cu}-\mathrm{INA}(\mathrm{F})$ with the cathodic deposition of HKUST-1 [73]. It was demonstrated that the anodic deposition consists of four phases: initial nucleation, growth of MOF islands, intergrowth, and crystal detachment, as shown in Fig. 29. A lag time is needed for

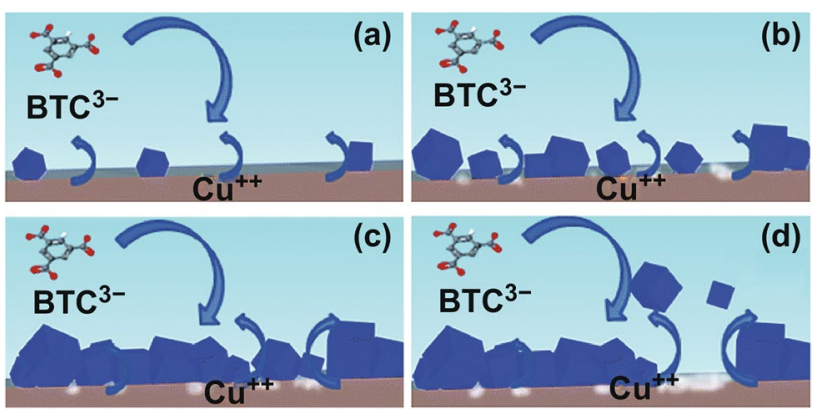

Fig. 29 Four phases of anodic deposition: a initial nucleation, b growth of MOF islands, $\mathbf{c}$ intergrowth, and $\mathbf{d}$ crystal detachment. Reprinted with permission from Ref. [73]. Copyright 2016, Royal Society of Chemistry

anodic deposition depending on the applied current and the metal-ion concentration threshold for MOF nucleation, while cathodic deposition can start at potentials less cathodic. However, anodic deposition facilitates better manipulation of the film characteristics like film thickness, crystal size, and morphology by varying synthesis parameters like voltage and current density, concentrations of ligands and conduction salt and temperature [72]. Though anodic deposition has been widely adopted to fabricate films with excellent electrocatalytic and proton-conductive properties [74, 75], investigations on MOF films with photophysical properties as luminescent sensors or photoconductive electrodes fabricated through anodic deposition are still limited.

\subsection{Electrophoretic Deposition}

Electrophoretic deposition is based on the fact that the suspended MOFs possess a surface charge. By immersing two identical conductive electrodes into the colloidal MOF suspension and applying a fixed voltage between the two electrodes, the MOF particles will move toward the oppositely charged electrode driven by the electric field and hence form a thin film. Interestingly, this method enables MOF particles to deposit on predefined positions and form micropatterned films. Take the fabrication of NU-1000 thin films on FTO for example: bare FTO platform was firstly modified with an insulating photoresist layer, and then photolithography was applied to create certain micropatterns of the photoresist layer; with NU-1000 deposited only on the exposed sections of FTO through electrophoretic deposition, followed by the 
removal of photoresist materials by immersing the platform in acetone, a micropatterned NU-1000 thin film was thus formed [76].

Through electrophoretic deposition, continuous and dense thin films of a series of photoluminescent LnMOFs were successfully fabricated on unmodified low-cost substrates including zinc plate, ITO and FTO glasses, rapidly in 5 min [77]. In particular, as-synthesized Tb-BTC films exhibited exceptional performances in the detection of nitrobenzene (NB) and $\mathrm{Cr}^{3+}$ in solution and trinitrotoluene (TNT) and NB in gas phases. In addition, for the sake of ratiometric temperature-sensing thin films, two dual-emitting Ln@UiO-66-Hybrid MOFs, with lanthanide metals and luminescent ligand integrated in a UiO-66-type structure, were deposited on FTO substrates through electrophoretic deposition where the charges from uncoordinated carboxylic groups played a critical role [78]. The thus synthesized Tb@UiO-66-Hybrid film was able to measure temperatures in range of 303-353 K with a relative sensitivity of $2.76 \% \mathrm{~K}^{-1}$, while the temperature range and relative sensitivity for Eu@UiO-66-Hybrid film were $303-403 \mathrm{~K}$ and $4.26 \% \mathrm{~K}^{-1}$, respectively. Later on, the same group used the same electrophoretic deposition methodology to fabricate C-QDs@UiO-66-(COOH $)_{2}$ composite thin film as a temperature sensor in range of 97-297 $\mathrm{K}$ with a relative sensitivity of up to $1.3 \% \mathrm{~K}^{-1}$ [46]. The film exhibited better temperature-sensing performances than non-film-state C-QDs@UiO-66-(COOH $)_{2}$ composites, which to some extent corroborated the more excellent capacities of thin films.

\subsection{Layer-by-Layer Assembly}

Layer-by-layer assembled method relies on the in situ growth of MOFs on different substrates. In general, the process includes repeating growth cycles of stepwise immersion of the substrate into solution of metal ions and then solution of organic ligands. The substrate is usually modified with a self-assembled monolayer (SAM) such as an organic linking molecular or metal-oxide film, to facilitate the strong adhesion of MOFs to the substrate during crystal growth and better control the interface of the bottom substrate and the MOF films. It has been validated that the SAM surface can affect the nucleation and further influence the crystal growth [79]. The film thickness can be well controlled by the number of growth cycles.
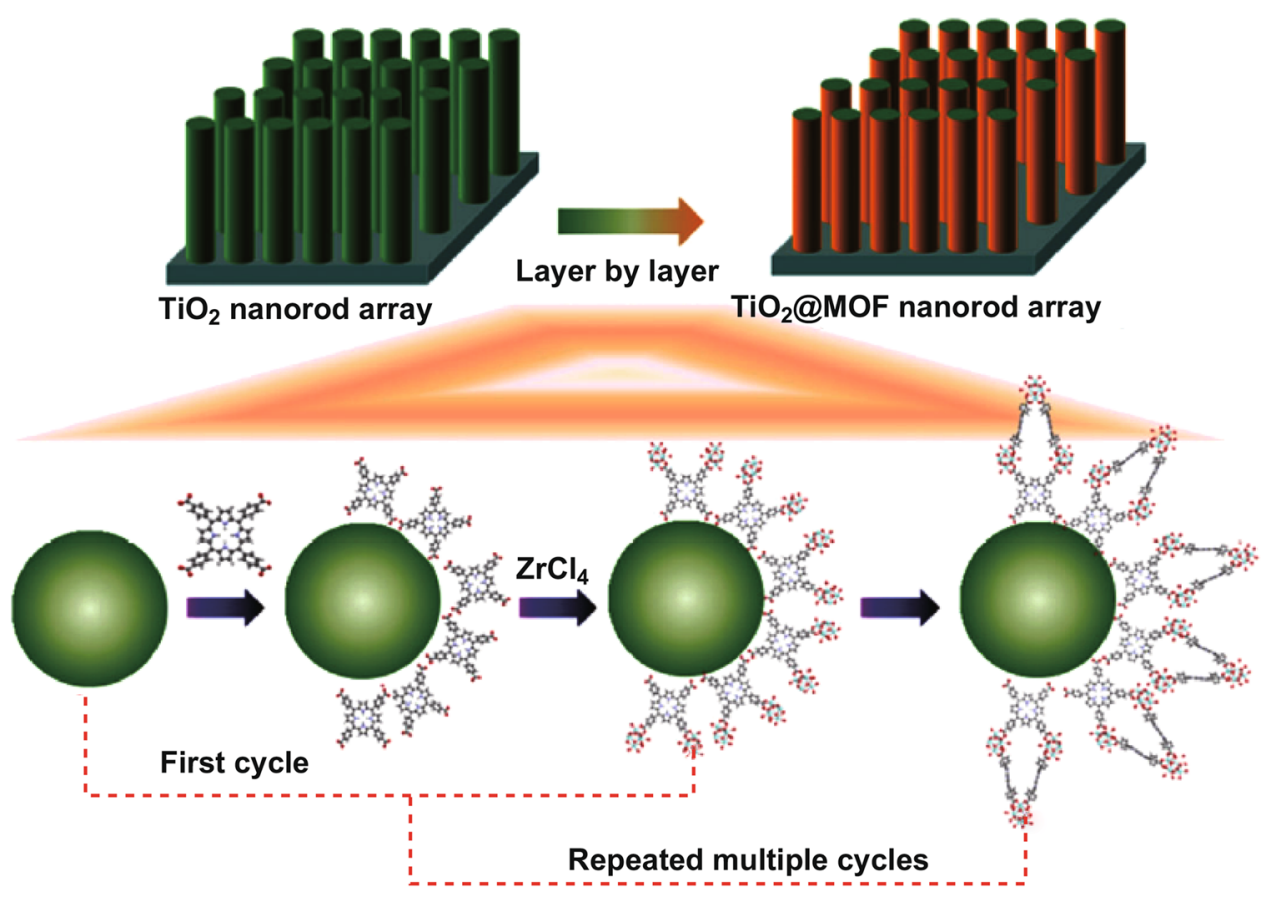

Fig. 30 Synthesis of $\mathrm{TiO}_{2} @ \mathrm{MOF}$ nanorod array photoanode through layer-by-layer method. Reprinted with permission from Ref. [28]. Copyright 2018, Springer Nature 
A p-n heterojunction photoanode for solar water splitting was fabricated by coating a porphyrin-based MOF PCN-225 layer on a vertically aligned $\mathrm{TiO}_{2}$ nanorod array through layer-by-layer self-assembly [28]. The specific processing is shown in Fig. 30. The $\mathrm{TiO}_{2}$ nanorod arrays were alternately soaked into a $0.5 \mathrm{mM}$ TCPP in ethanol solution and into a $2 \mathrm{mM} \mathrm{ZrCl}_{4}$ in ethanol solution at $40{ }^{\circ} \mathrm{C}$ with intervals set as $10 \mathrm{~min}$. The above treatments were repeated for 5 cycles to obtain PCN-225 films with ideal thickness, and subsequently, the $\mathrm{TiO}_{2} @ \mathrm{MOF}$ samples were heated at $150{ }^{\circ} \mathrm{C}$ under an $\mathrm{N}_{2}$ gas environment to strengthen the contact between the $\mathrm{MOF}$ and $\mathrm{TiO}_{2}$. The thus synthesized $\mathrm{TiO}_{2} @$ Co-MOF photoanode presented a photocurrent density of up to $2.93 \mathrm{~mA} \mathrm{~cm}^{-2}$ at $1.23 \mathrm{~V}$ (vs. RHE).

Interestingly, through layer-by-layer assembly method, Eu-SURMOF was deposited on top of Tb-SURMOF to form a hetero-multilayer architecture, which suppressed direct energy transfer from $\mathrm{Tb}(\mathrm{III})$ to $\mathrm{Eu}(\mathrm{III})$ and thereby made the modulation of the emission color easier [80]. An Eu-NDC@ HPNA thin film was also fabricated through this method and served as a luminescent sensor for formaldehyde, an illegal preservative in aquatic product, indicating that luminescent MOFs could play a significant role in food industry and our health [81].

While layer-by-layer assembly method has many advantages such as well-controlled thickness and mild reaction condition at room temperature, there are still some disadvantages like tedious repeating operations, long reaction times, and so on. Therefore, some improved methods have been developed. A promising alternative method is to use the metal oxide itself as a template for MOF growth by sequential exposure to the metal cation and then the organic linker. With aluminum-doped zinc oxide (AZO) as a seed layer, copper benzene-1,3,5-tricarboxylate (Cu-BTC) MOF growth occurs rapidly only on the AZO surface and it is found that $\mathrm{Cu}$-BTC morphology can be optimized through careful choice of the $\mathrm{Cu}$ salt, solvent system, and $\mathrm{pH}$ [82]. It was also found that zeolite imidazolate framework-8 (ZIF8 ) can directly assemble on gold surfaces when modified by cysteamine in colloidal suspensions, without the need to pretreat the substrate with SAM [83]. One of the challenges that block wide applications of layer-by-layer assembly in fabrication of electronic or optoelectronic devices lies in that it commonly relies on insulating SAMs to control the thin-film orientation, which could impede charge transportation. Inspired by these investigations, more convenient preparations of MOF thin films for high-performance photoelectronic and photoluminescent devices through better improved layer-by-layer assembly method should be included in future researches.

\subsection{Solvothermal Deposition}

The solvothermal growth of MOF films is a facile, efficient, and low-cost deposition method and thus has been widely adopted. Upon heating, MOFs growth occurs rapidly on the substrate surface. In general, this method allows for direct and oriented deposition of MOF particles on semiconducting metal-oxide-coated electrodes, which thereby makes it more attractive for production of electronic and optoelectronic devices.

Under solvothermal conditions, pillared porphyrin framework-11 (PPF-11) featuring Zn-tetrakis(4-carboxyphenyl) porphyrin (ZnTCPP) and 2,2'-dimethyl-4,4'bipyridine was deposited on $\mathrm{ZnO}$-coated FTO electrodes to form precisely [100]-oriented films, as shown in Fig. 31 [84]. DMF/EtOH solutions of $\mathrm{Zn}\left(\mathrm{NO}_{3}\right)_{2} \cdot 6 \mathrm{H}_{2} \mathrm{O}$, TCPP, DMBPY and $1 \mathrm{M}$ $\mathrm{HNO}_{3} / \mathrm{EtOH}$ were heated at $80{ }^{\circ} \mathrm{C}$ for $2 \mathrm{~h}$, followed by the immersion of annealed $\mathrm{ZnO}-\mathrm{FTO}$ slides into the above precursor solutions at upright positions at $80{ }^{\circ} \mathrm{C}$ for $30 \mathrm{~min}$, which led to spontaneous formation of uniform crystalline films. Solar cells based on the as-synthesized PPF-11/ ZnO-FTO photoanode exhibited superior photovoltaic response with power conversion efficiency up to $0.86 \%$, which was significantly linked to the covalent attachment to $\mathrm{ZnO}$ surface and [100] orientation of PPF-11 films.

Solvothermal deposition has also been utilized to generate MOF thin films as efficient luminescent sensors [85-87]. MOF-5 was deposited on ZnO-coated FTO substrate

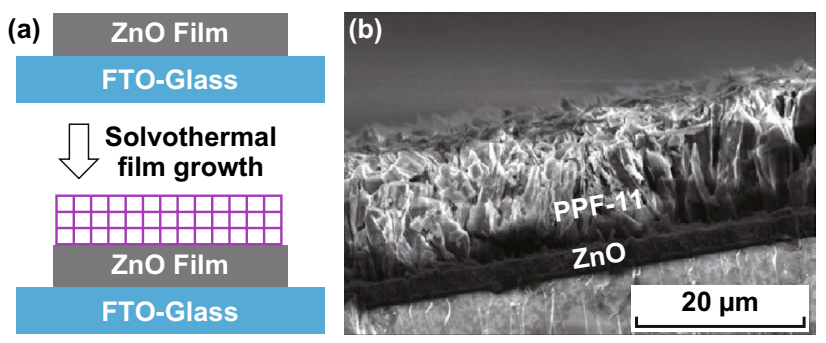

Fig. 31 a Schematic diagram of the solvothermal growth of PPF-11 film. b Cross-sectional-SEM images of solvothermally grown $10 \mu \mathrm{m}$ thick PPF-11 film on $\mathrm{ZnO}$ layer. Reprinted with permission from Ref. [84]. Copyright 2019, American Chemical Society 
solvothermally, followed by postsynthetic introduction of $\mathrm{Tb}^{3+}$ [85]. Tb(III)@MOF-5/ZnO was demonstrated to detect acetone molecules with high selectivity due to the luminescence response of $\mathrm{Tb}^{3+}$ ions. In this study, the failure of MOF-5 deposition on bare FTO revealed that $\mathrm{ZnO}$ coating was necessary for MOF-5 growth. Similarly, MIL-124@ $\mathrm{Eu}^{3+}$ film was deposited on porous $\mathrm{a}-\mathrm{Al}_{2} \mathrm{O}_{3}$ plate as ammonia sensor with the limit of detection of $26.2 \mathrm{ppm}$ [87].

\subsection{Liquid-Liquid Interfacial Method}

Liquid-liquid interfacial method is another facile and rapid method to obtain MOF thin films. Typically, it starts with the preparation of two immiscible liquid systems, which dissolve metal-ion salts and organic ligands, respectively. Then, by simply layering one of the liquid systems onto another, the MOF thin film appears at the liquid-liquid interface and can be observed through eyes [68, 88]. Further improvement of this method combines the spray technique by spraying the atomized solution of metal ions onto solutions of ligands $[89,90]$. Since thin films form at liquid-liquid interface and can be easily separated from the liquid, this method is promising for fabricating free-standing MOF thin films without substrates. The main challenge of this method lies in the careful selection of immiscible solvents to dissolve metal ions and ligands, respectively. However, with its facile, convenient and time-saving advantages, liquid-liquid interfacial method holds a bright prospect for integration of MOF thin films with optical devices and should attract more attention.

\subsection{Ultrasonic Spray Deposition}

Ultrasonic spray deposition is a novel strategy for MOF thin-film fabrication. The process of this technique is shown in Fig. 32. Two precursor solutions of metal ions and organic ligands are held in two separated ultrasonic nebulizers to generate corresponding ultrafine mists, which are then transported through a gas flux and mixed on the heated substrate surface, where solvents evaporate and MOFs crystalize to form matrix-free thin films. Following the above processing, $\mathrm{Tb}_{2}(\mathrm{BDC})_{3}(\mathrm{BDC}=1$,4-benzenedicarboxylate) MOF films were deposited on various substrates and exhibited photoluminescent properties [91]. It was revealed that the temperature of the substrate played

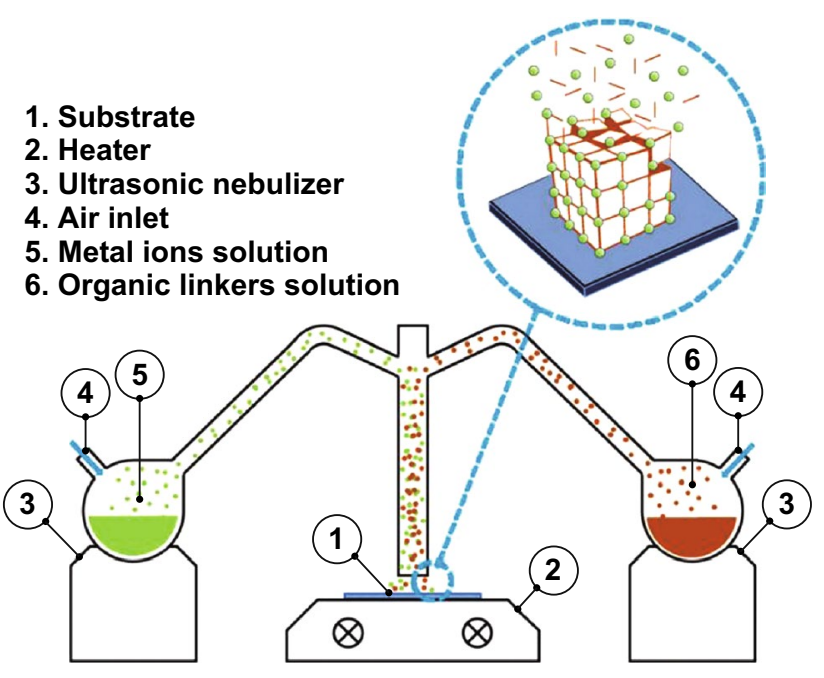

Fig. 32 Scheme of the ultrasonic spray deposition system. Reprinted with permission from Ref. [91] Copyright 2019, Elsevier

a crucial role in the structures, morphologies, and luminescence properties of the as-synthesized films and low temperatures tended to generate films with higher luminescence intensities. As a time-saving, low-cost, and scalable new route for fabrication of luminescent MOF films, ultrasonic spray deposition can be considered a breakthrough for integration of MOFs in future optical devices.

\subsection{Other Methods}

Apart from the aforementioned methods, many other methods have also been developed to fabricate various MOF thin films with excellent photophysical properties. Spin coating, for example, has proved to be successful in the fabrication of white-light-emitting $\mathrm{Ln}^{3+}$-functionalized $\left[\mathrm{La}\left(\mathrm{H}_{2} \mathrm{O}\right)_{4}(\mathrm{pdc})\right]_{4}\left[\mathrm{SiMo}_{12} \mathrm{O}_{40}\right] \cdot 2 \mathrm{H}_{2} \mathrm{O}$ thin films [92] as well as white-light-emitting Sm ${ }^{3+} @ \mathrm{NENU}-5$ and $\mathrm{Eu}^{3+} / \mathrm{Tb}^{3+} @$ NENU-5 thin films [93]. Besides, Langmuir-Blodgett method was utilized to fabricate semiconducting $\mathrm{Cu}-\mathrm{PPF}$ thin films for photoelectric conversion [94]. It should be noted that films of the same MOF fabricated through different methods usually differ in morphologies, surface coverage rate, and hence device performances. A research pointed out that luminescent MOF-76(Tb) films fabricated through hydrothermal, microwave-assisted, and layer-bylayer methods presented pillar-like, sedimentary-rock-like, 
and needle-like crystal morphology, respectively, and layer-by-layer method achieved the highest surface coverage rate due to promoted metal-ion anchoring [95]. Sometimes, more than one method will be adopted to combine advantages of each method to fabricate better MOF films.

\section{Conclusion and Outlook}

In summary, conductive MOFs with photoconductive and photoluminescent properties have been widely investigated. Compared to conventional energy such as fossil fuels and natural gas that is limited in nature and contaminates our environment, light energy possesses superior advantages such as renewability and eco-friendliness. For effective utilization of light energy, many novel materials have been developed and MOFs with excellent photophysical properties provide another possibility to this end. Photoconductive MOFs are promising materials for solar cells and water splitting with superior light adsorption capacity, high stability, low cost, and many other advantages. Photoluminescent MOFs exhibit a bright prospect in many interesting fields such as luminescent analyte sensing, temperature sensing, light emitting, and optical information protection. In addition, thin films based on these photoconductive and photoluminescent MOFs have been reported, making it possible to integrate these MOFs with practical devices.

However, still there are challenges for further development of these MOFs and more efforts should be done in many future works. For example, to date most of photoconductive MOFs actually exhibit relatively low electrical conductivity despite their superior light adsorption capacity, which to some extent restrains their application in solar cells. Attempts should be continued to synthesize MOFs with higher electrical conductivity and higher photoelectric conversion efficiency. Also, most of the reported methods to fabricate MOF thin films are only applicable to some specific MOFs, and therefore, it is of great significance to search for more facile and more flexible methods for MOF thin-film fabrication. It is believed that these advances will definitely extend the applications of MOFs to electronic and optoelectronic devices and probably arise impactful innovation in the field of materials.
Acknowledgements This work was supported by the National Natural Science Foundation of China (Grant No. 51603052) and the FRF for the Central Universities (18lgjc66).

Open Access This article is licensed under a Creative Commons Attribution 4.0 International License, which permits use, sharing, adaptation, distribution and reproduction in any medium or format, as long as you give appropriate credit to the original author(s) and the source, provide a link to the Creative Commons licence, and indicate if changes were made. The images or other third party material in this article are included in the article's Creative Commons licence, unless indicated otherwise in a credit line to the material. If material is not included in the article's Creative Commons licence and your intended use is not permitted by statutory regulation or exceeds the permitted use, you will need to obtain permission directly from the copyright holder. To view a copy of this licence, visit http://creativecommons.org/licenses/by/4.0/.

\section{References}

1. H.C. Zhou, J.R. Long, O.M. Yaghi, Introduction to metalorganic frameworks. Chem. Rev. 112(2), 673-674 (2012). https://doi.org/10.1021/cr300014x

2. J. Zheng, X. Cui, Q. Yang, Q. Ren, Y. Yang, H. Xing, Shaping of ultrahigh-loading mof pellet with a strongly anti-tearing binder for gas separation and storage. Chem. Eng. J. 354, 1075-1082 (2018). https://doi.org/10.1016/j.cej.2018.08.119

3. A.H. Chughtai, N. Ahmad, H.A. Younus, A. Laypkov, F. Verpoort, Metal-organic frameworks: versatile heterogeneous catalysts for efficient catalytic organic transformations. Chem. Soc. Rev. 44(19), 6804-6849 (2015). https://doi. org/10.1039/C4CS00395K

4. C. Wang, F.F. Liu, Z. Tan, Y.M. Chen, W.C. Hu, X.H. Xia, Fabrication of bio-inspired 2d mofs/paa hybrid membrane for asymmetric ion transport. Adv. Funct. Mater. 30(9), 1908804 (2019). https://doi.org/10.1002/adfm.201908804

5. M. Ko, L. Mendecki, K.A. Mirica, Conductive two-dimensional metal-organic frameworks as multifunctional materials. Chem. Commun. 54(57), 7873-7891 (2018). https://doi. org/10.1039/C8CC02871K

6. P.I. Scheurle, A. Mahringer, A.C. Jakowetz, P. Hosseini, A.F. Richter, G. Wittstock, D.D. Medina, T. Bein, A highly crystalline anthracene-based mof-74 series featuring electrical conductivity and luminescence. Nanoscale 11(43), 2094920955 (2019). https://doi.org/10.1039/C9NR05431F

7. V. Stavila, A.A. Talin, M.D. Allendorf, Mof-based electronic and opto-electronic devices. Chem. Soc. Rev. 43(16), 5994 6010 (2014). https://doi.org/10.1039/C4CS00096J

8. X. Deng, J.Y. Hu, J. Luo, W.M. Liao, J. He, Conductive metal-organic frameworks: Mechanisms, design strategies 
and recent advances. Top Curr. Chem. 378(2), 27 (2020). https://doi.org/10.1007/s41061-020-0289-5

9. C.W. Kung, P.C. Han, C.H. Chuang, K.C.W. Wu, Electronically conductive metal-organic framework-based materials. APL Mater. 7(11), 110902 (2019). https://doi. org/10.1063/1.5125487

10. S.K. Bhardwaj, N. Bhardwaj, R. Kaur, J. Mehta, A.L. Sharma, K.H. Kim, A. Deep, An overview of different strategies to introduce conductivity in metal-organic frameworks and miscellaneous applications thereof. J. Mater. Chem. A 6(31), 14992-15009 (2018). https://doi.org/10.1039/C8TA04220A

11. P. Li, B. Wang, Recent development and application of conductive mofs. Isr. J. Chem. 58(9-10), 1010-1018 (2018). https://doi.org/10.1002/ijch.201800078

12. E. Castaldelli, K.D.G. Imalka Jayawardena, D.C. Cox, G.J. Clarkson, R.I. Walton, L. Le-Quang, J. Chauvin, S.R.P. Silva, G.J. Demets, Electrical semiconduction modulated by light in a cobalt and naphthalene diimide metal-organic framework. Nat. Commun. 8(1), 2139 (2017). https://doi.org/10.1038/ s41467-017-02215-7

13. Z.L. Wu, C.H. Wang, B. Zhao, J. Dong, F. Lu et al., A semi-conductive copper-organic framework with two types of photocatalytic activity. Angew. Chem. Int. Ed. 55(16), 4938-4942 (2016). https://doi.org/10.1002/anie.201508325

14. X. Liu, M. Kozlowska, T. Okkali, D. Wagner, T. Higashino et al., Photoconductivity in metal-organic framework (MOF) thin films. Angew. Chem. Int. Ed. 58(28), 95909595 (2019). https://doi.org/10.1002/anie.201904475

15. X. Yan, X. Qiu, Z. Yan, H. Li, Y. Gong, J. Lin, Configurations, band structures and photocurrent responses of 4-(4-oxopyridin-1(4 h)-yl)phthalic acid and its metalorganic frameworks. J. Solid State Chem. 237, 313-322 (2016). https://doi.org/10.1016/j.jssc.2016.02.041

16. K. Leong, M.E. Foster, B.M. Wong, E.D. Spoerke, D. Van Gough, J.C. Deaton, M.D. Allendorf, Energy and charge transfer by donor-acceptor pairs confined in a metalorganic framework: a spectroscopic and computational investigation. J Mater. Chem. A 2(10), 3389-3398 (2014). https://doi.org/10.1039/C3TA14328G

17. S. Wang, T. Kitao, N. Guillou, M. Wahiduzzaman, C. Martineau-Corcos et al., A phase transformable ultrastable titanium-carboxylate framework for photoconduction. Nat. Commun. 9(1), 1660 (2018). https://doi.org/10.1038/s4146 7-018-04034-w

18. A. Mohammadpour, S. Farsinezhad, B.D. Wiltshire, K. Shankar, Majority carrier transport in single crystal rutile nanowire arrays. Phys. Status Solidi (RRL) Rapid Res. Lett. 8(6), 512-516 (2014). https://doi.org/10.1002/ pssr.201308296

19. C.C. Chueh, C.I. Chen, Y.A. Su, H. Konnerth, Y.J. Gu, C.W. Kung, K.C.W. Wu, Harnessing mof materials in photovoltaic devices: recent advances, challenges, and perspectives. J. Mater. Chem. A 7(29), 17079-17095 (2019). https ://doi.org/10.1039/C9TA03595H

20. R. Kaur, A. Rana, R.K. Singh, V.A. Chhabra, K.H. Kim, A. Deep, Efficient photocatalytic and photovoltaic applications with nanocomposites between CdTe QDs and an NTU-9 MOF. RSC Adv. 7(46), 29015-29024 (2017). https://doi. org/10.1039/C7RA04125J

21. W. Zhang, W. Li, X. He, L. Zhao, H. Chen et al., Dendritic Fe-based polyoxometalates @ metal-organic framework (MOFs) combined with $\mathrm{ZnO}$ as a novel photoanode in solar cells. J. Mater. Sci.: Mater. Electron. 29(2), 1623-1629 (2017). https://doi.org/10.1007/s10854-017-8073-1

22. R. Kaur, K.H. Kim, A. Deep, A convenient electrolytic assembly of graphene-mof composite thin film and its photoanodic application. Appl. Surf. Sci. 396, 1303-1309 (2017). https://doi.org/10.1016/j.apsusc.2016.11.150

23. J. Liu, W. Zhou, J. Liu, I. Howard, G. Kilibarda et al., Photoinduced charge-carrier generation in epitaxial mof thin films: high efficiency as a result of an indirect electronic band gap? Angew. Chem. Int. Ed. 54(25), 7441-7445 (2015). https://doi.org/10.1002/anie.201501862

24. L. Li, H. Zhang, C. Liu, P. Liang, N. Mitsuzaki, Z. Chen, Effect of co-based metal-organic framework prepared by an in situ growth method on the photoelectrochemical performance of electrodeposited hematite photoanode. Energy Technol. 7(5), 1801069 (2019). https://doi.org/10.1002/ ente. 201801069

25. Z. Jiao, J. Zheng, C. Feng, Z. Wang, X. Wang, G. Lu, Y. $\mathrm{Bi}, \mathrm{Fe} / \mathrm{w}$ co-doped $\mathrm{BiVO}_{4}$ photoanodes with a metal-organic framework cocatalyst for improved photoelectrochemical stability and activity. Chemsuschem 9(19), 2824-2831 (2016). https://doi.org/10.1002/cssc.201600761

26. W. Zhang, R. Li, X. Zhao, Z. Chen, A.W. Law, K. Zhou, A cobalt-based metal-organic framework as cocatalyst on bivo4 photoanode for enhanced photoelectrochemical water oxidation. Chemsuschem 11(16), 2710-2716 (2018). https://doi. org/10.1002/cssc.201801162

27. Q. Zhanga, H. Wanga, Y. Donga, J. Yana, X. Keb, Q. Wua, $\mathrm{S}$. Xue, In situ growth of ultrathin co-mof nanosheets on $\alpha-\mathrm{Fe}_{2} \mathrm{O}_{3}$ hematite nanorods for efficient photoelectrochemical water oxidation. Sol. Energy 171, 388-396 (2018). https ://doi.org/10.1016/j.solener.2018.06.086

28. H. Yang, J. Bright, S. Kasani, P. Zheng, T. Musho, B. Chen, L. Huang, N. Wu, Metal-organic framework coated titanium dioxide nanorod array $\mathrm{p}-\mathrm{n}$ heterojunction photoanode for solar water-splitting. Nano Res. 12(3), 643-650 (2018). https ://doi.org/10.1007/s12274-019-2272-4

29. Y. Dou, J. Zhou, A. Zhou, J.R. Li, Z. Nie, Visible-light responsive mof encapsulation of noble-metal-sensitized semiconductors for high-performance photoelectrochemical water splitting. J. Mater. Chem. A 5(36), 19491-19498 (2017). https://doi.org/10.1039/C7TA06443H

30. K. Natarajan, A.K. Gupta, S.N. Ansari, M. Saraf, S.M. Mobin, Mixed-ligand-architected 2d Co(ii)-MOF expressing a novel topology for an efficient photoanode for water oxidation using visible light. ACS Appl. Mater. Interfaces 11(14), 13295-13303 (2019). https://doi.org/10.1021/acsam i.9b01754

31. T. Song, L. Zhang, P. Zhang, J. Zeng, T. Wang, A. Alia, H. Zeng, Stable and improved visible-light photocatalytic 
hydrogen evolution using copper(ii)-organic frameworks: engineering the crystal structures. J. Mater. Chem. A 5, 6013-6018 (2017). https://doi.org/10.1039/C7TA00095B

32. Z. Wang, H. Liu, S. Wang, Z. Rao, Y. Yang, A luminescent terbium-succinate mof thin film fabricated by electrodeposition for sensing of $\mathrm{Cu} 2+$ in aqueous environment. Sens. Actuator B 220, 779-787 (2015). https://doi.org/10.1016/j. snb.2015.05.129

33. S. Let, P. Samanta, S. Dutta, S.K. Ghosh, A dye@MOF composite as luminescent sensory material for selective and sensitive recognition of Fe(iii) ions in water. Inorg. Chim. Acta 500, 119205 (2020). https://doi.org/10.1016/j. ica.2019.119205

34. K.Y. Zhang, G. Zeng, L.X. Sun, Y.H. Xing, F.Y. Bai, Triazine poly(carboxylic acid) metal-organic frameworks and the fluorescent response with lead oxygen clusters: $\left[\mathrm{Pb}_{7}(\mathrm{COO})_{12} \mathrm{X}_{2}\right]$ by halogen tuning $(\mathrm{X}=\mathrm{Cl}, \mathrm{Br}$, or I). Inorg. Chem. 58(23), 15898-15908 (2019). https://doi.org/10.1021/acs.inorg chem.9b02365

35. Y. Sun, N. Zhang, Q.L. Guan, C.H. Liu, B. Li et al., Sensing of $\mathrm{Fe}^{3+}$ and $\mathrm{Cr}_{2} \mathrm{O}_{7}{ }^{2-}$ in water and white light: synthesis, characterization, and fluorescence properties of a crystalline bismuth-1,3,5-benzenetricarboxylic acid framework. Cryst. Growth Des. 19(12), 7217-7229 (2019). https://doi. org/10.1021/acs.cgd.9b01098

36. A. Khatun, D.K. Panda, N. Sayresmith, M.G. Walter, S. Saha, Thiazolothiazole-based luminescent metal-organic frameworks with ligand-to-ligand energy transfer and $\mathrm{Hg}(2+)$-sensing capabilities. Inorg. Chem. 58(19), 1270712715 (2019). https://doi.org/10.1021/acs.inorgchem.9b015 95

37. E.I. Koshevoy, D.G. Samsonenko, A.S. Berezin, V.P. Fedin, Metal-organic coordination polymers formed from $\gamma$-cyclodextrin and divalent metal ions. Eur. J. Inorg. Chem. 2019(39-40), 4321-4327 (2019). https://doi.org/10.1002/ ejic. 201900398

38. W. Chen, J.Y. Wang, C. Chen, Q. Yue, H.M. Yuan, J.S. Chen, S.N. Wang, Photoluminescent metal-organic polymer constructed from trimetallic clusters and mixed carboxylates. Inorg. Chem. 42, 944-946 (2002). https://doi. org/10.1021/ic025871j

39. K. Wu, J. Hu, X. Cheng, J. Li, C. Zhou, A superior luminescent metal-organic framework sensor for sensing trace $\mathrm{Al}^{3+}$ and picric acid via disparate charge transfer behaviors. J. Lumines. 219, 116908 (2020). https://doi.org/10.1016/j. jlumin.2019.116908

40. J. Ni, K.J. Wei, Y. Min, Y. Chen, S. Zhan, D. Li, Y. Liu, Copper(i) coordination polymers of 2,2'-dipyridylamine derivatives: syntheses, structures, and luminescence. Dalton Trans. 41(17), 5280-5293 (2012). https://doi. org/10.1039/c2dt12032a

41. P.F. Zhang, G.P. Yang, G.P. Li, F. Yang, W.N. Liu, J.Y. Li, Y.Y. Wang, Series of water-stable lanthanide metal-organic frameworks based on carboxylic acid imidazolium chloride: tunable luminescent emission and sensing. Inorg. Chem.
58(20), 13969-13978 (2019). https://doi.org/10.1021/acs. inorgchem.9b01954

42. J. Ma, L.M. Zhao, C.Y. Jin, B. Yan, Luminescence responsive composites of rare earth metal-organic frameworks covalently linking microsphere resin. Dyes Pigm. 173, 107883 (2020). https://doi.org/10.1016/j.dyepi g.2019.107883

43. L. Shi, J. Wang, L. Zhou, Y. Chen, J. Yan, C. Dai, Facile in situ preparation of MAPbBr 3@UiO-66 composites for information encryption and decryption. J. Solid State Chem. 282, 121062 (2020). https://doi.org/10.1016/j. jssc.2019.121062

44. X. Chen, H. Gao, M. Yang, L. Xing, W. Dong, A. Li, H. Zheng, G. Wang, Smart integration of carbon quantum dots in metal-organic frameworks for fluorescence-functionalized phase change materials. Energy Storage Mater. 18, 349-355 (2019). https://doi.org/10.1016/j.ensm.2018.08.015

45. F. Asadi, S.N. Azizi, M.J. Chaichi, Green synthesis of fluorescent PEG-ZnS QDs encapsulated into co-MOFs as an effective sensor for ultrasensitive detection of copper ions in tap water. Mater. Sci. Eng. C 105, 110058 (2019). https://doi. org/10.1016/j.msec.2019.110058

46. J.F. Feng, S.Y. Gao, J. Shi, T.F. Liu, R. Cao, C-QDs@UiO$66-(\mathrm{COOH})_{2}$ composite film via electrophoretic deposition for temperature sensing. Inorg. Chem. 57(5), 2447-2454 (2018). https://doi.org/10.1021/acs.inorgchem.7b02595

47. L.N. Wang, Y.H. Zhang, S. Jiang, Z.Z. Liu, Three coordination polymers based on 3-(3',5'-dicarboxylphenoxy)phthalic acid and auxiliary n-donor ligands: syntheses, structures, and highly selective sensing for nitro explosives and $\mathrm{Fe}^{3+}$ ions. CrystEngComm 21(31), 4557-4567 (2019). https://doi. org/10.1039/C9CE00542K

48. X.Y. Yao, Q. Wang, Q. Liu, M. Pang, X.M. Du, B. Zhao, Y. Li, W.J. Ruan, Ultrasensitive assay of alkaline phosphatase based on the fluorescent response difference of the metalorganic framework sensor. ACS Omega 5(1), 712-717 (2020). https://doi.org/10.1021/acsomega.9b03337

49. S.M. Sheta, S.M. El-Sheikh, M.M. Abd-Elzaher, S.R. Salem, H.A. Moussa, R.M. Mohamed, I.A. Mkhalid, A novel biosensor for early diagnosis of liver cancer cases using smart nanomagnetic metal-organic framework. Appl. Organomet. Chem. 33(12), e5249 (2019). https://doi.org/10.1002/aoc.5249

50. S.M. Sheta, S.M. El-Sheikh, M.M. Abd-Elzaher, Promising photoluminescence optical approach for triiodothyronine hormone determination based on smart copper metal-organic framework nanoparticles. Appl. Organomet. Chem. 33(9), e5069 (2019). https://doi.org/10.1002/aoc.5069

51. S. Xian, H.L. Chen, W.L. Feng, X.Z. Yang, Y.Q. Wang, B.X. Li, Eu(iii) doped zinc metal organic framework material and its sensing detection for nitrobenzene. J. Solid State Chem. 280, 120984 (2019). https://doi.org/10.1016/j. jssc.2019.120984

52. X. Qiao, Z. Ma, L. Si, W. Ding, G. Xu, Doping metal-organic framework with a series of europium-antenna cations: obviously improved spectral response for $\mathrm{O}_{2}$ gas via long-range 
energy roll-back procedure. Sens. Actuator B 299, 126978 (2019). https://doi.org/10.1016/j.snb.2019.126978

53. X.L. Zhang, S.M. Li, S. Chen, F. Feng, J.Q. Bai, J.R. Li, Ammoniated MOF-74(Zn) derivatives as luminescent sensor for highly selective detection of tetrabromobisphenol a. Ecotox. Environ. Safe. 187, 109821 (2020). https://doi. org/10.1016/j.ecoenv.2019.109821

54. A. Sousaraei, C. Queiros, F.G. Moscoso, T. Lopes-Costa, J.M. Pedrosa, A.M.G. Silva, L. Cunha-Silva, J. CabanillasGonzalez, Subppm amine detection via absorption and luminescence turn-on caused by ligand exchange in metal organic frameworks. Anal. Chem. 91(24), 15853-15859 (2019). https ://doi.org/10.1021/acs.analchem.9b04291

55. S. Jensen, K. Tan, W.P. Lustig, D.S. Kilin, J. Li, Y.J. Chabal, T. Thonhauser, Structure-driven photoluminescence enhancement in a Zn-based metal-organic framework. Chem. Mater. 31(19), 7933-7940 (2019). https://doi.org/10.1021/acs. chemmater.9b02056

56. K.Y. Wu, L. Qin, C. Fan, S.L. Cai, T.T. Zhang, W.H. Chen, X.Y. Tang, J.X. Chen, Sequential and recyclable sensing of $\mathrm{Fe}(3+)$ and ascorbic acid in water with a terbium(iii)-based metal-organic framework. Dalton Trans. 48(24), 8911-8919 (2019). https://doi.org/10.1039/C9DT00871C

57. W. Hua, T. Zhang, M. Wang, Y. Zhu, X. Wang, Hierarchically structural PAN/UiO-66-(COOH $)_{2}$ nanofibrous membranes for effective recovery of terbium(iii) and europium(iii) ions and their photoluminescence performances. Chem. Eng. J. 370, 729-741 (2019). https://doi.org/10.1016/j.cej.2019.03.255

58. T. Gao, B.X. Dong, Y. Sun, W.L. Liu, Y.L. Teng, Fabrication of a water-stable luminescent mof with an open lewis basic triazolyl group for the high-performance sensing of acetone and $\mathrm{Fe}^{3+}$ ions. J. Mater. Sci. 54(15), 10644-10655 (2019). https://doi.org/10.1007/s10853-019-03638-x

59. Z.Q. Liu, Y. Zhao, X.H. Liu, X.D. Zhang, Y. Liu, W.Y. Sun, Synthesis, crystal structure and fluorescent sensing property of metal-organic frameworks with 1,3-di( 1 h-imidazol-4-yl $)$ benzene and 1,4-phenylenediacetate. Polyhedron 167, 33-38 (2019). https://doi.org/10.1016/j.poly.2019.04.007

60. F. Zhang, J. Li, Z. Zhao, F. Wang, Y. Pu, H. Cheng, Mixedlnmofs with tunable color and white light emission together with multi-functional fluorescence detection. J. Solid State Chem. 280, 120972 (2019). https://doi.org/10.1016/j. jssc.2019.120972

61. C.Y. Sun, X.L. Wang, X. Zhang, C. Qin, P. Li et al., Efficient and tunable white-light emission of metal-organic frameworks by iridium-complex encapsulation. Nat. Commun. 4, 2717 (2013). https://doi.org/10.1038/ncomms3717

62. X. Wang, Z. Li, W. Ying, D. Chen, P. Li, Z. Deng, X. Peng, Blue metal-organic framework encapsulated denatured r-phycoerythrin proteins for a white-light-emitting thin film. J. Mater. Chem. C 8(1), 240-246 (2020). https://doi. org/10.1039/C9TC05342E

63. J. Othong, J. Boonmak, V. Promarak, F. Kielar, S. Youngme, Sonochemical synthesis of carbon dots/lanthanoid mofs hybrids for white light-emitting diodes with high color rendering. ACS Appl. Mater. Interfaces 11(47), 44421-44429 (2019). https://doi.org/10.1021/acsami.9b13814

64. Y. Liu, M. Pan, Q.Y. Yang, L. Fu, K. Li, S.C. Wei, C.Y. Su, Dual-emission from a single-phase $\mathrm{Eu}-\mathrm{Ag}$ metal-organic framework: an alternative way to get white-light phosphor. Chem. Mater. 24(10), 1954-1960 (2012). https://doi. org/10.1021/cm3008254

65. J. Liu, Y. Zhao, X. Li, J. Wu, Y. Han, X. Zhang, Y. Xu, Dualemissive CsPbBr3@Eu-BTC composite for self-calibrating temperature sensing application. Cryst. Growth Des. 20(1), 454-459 (2019). https://doi.org/10.1021/acs.cgd.9b01374

66. Y. Cui, H. Xu, Y. Yue, Z. Guo, J. Yu et al., A luminescent mixed-lanthanide metal-organic framework thermometer. J. Am. Chem. Soc. 134(9), 3979-3982 (2012). https://doi. org/10.1021/ja2108036

67. V. Rubio-Gimenez, S. Tatay, F. Volatron, F.J. Martinez-Casado, C. Marti-Gastaldo, E. Coronado, High-quality metalorganic framework ultrathin films for electronically active interfaces. J. Am. Chem. Soc. 138(8), 2576-2584 (2016). https://doi.org/10.1021/jacs.5b09784

68. I.F. Chen, C.F. Lu, W.F. Su, Highly conductive 2D metalorganic framework thin film fabricated by liquid-liquid interfacial reaction using one-pot-synthesized benzenehexathiol. Langmuir 34(51), 15754-15762 (2018). https://doi. org/10.1021/acs.langmuir.8b03938

69. S. Goswami, I. Hod, J.D. Duan, C.W. Kung, M. Rimoldi et al., Anisotropic redox conductivity within a metal-organic framework material. J. Am. Chem. Soc. 141(44), 1769617702 (2019). https://doi.org/10.1021/jacs.9b07658

70. H. Liu, H. Wang, T. Chu, M. Yu, Y. Yang, An electrodeposited lanthanide mof thin film as a luminescent sensor for carbonate detection in aqueous solution. J. Mater. Chem. C 2(41), 8683-8690 (2014). https://doi.org/10.1039/C4TC0 $1551 \mathrm{G}$

71. H. Liu, T. Chu, Z. Rao, S. Wang, Y. Yang, W.T. Wong, The tunable white-light and multicolor emission in an electrodeposited thin film of mixed lanthanide coordination polymers. Adv. Opt. Mater. 3(11), 1545-1550 (2015). https://doi. org/10.1002/adom.201500203

72. J.L. Hauser, M. Tso, K. Fitchmun, S.R.J. Oliver, Anodic electrodeposition of several metal organic framework thin films on indium tin oxide glass. Cryst. Growth Des. 19(4), 2358-2365 (2019). https://doi.org/10.1021/acs.cgd.9b00054

73. N. Campagnol, T.R.C. Van Assche, M. Li, L. Stappers, M. Dincă et al., On the electrochemical deposition of metalorganic frameworks. J. Mater. Chem. A 4(10), 3914-3925 (2016). https://doi.org/10.1039/C5TA10782B

74. E. Shi, X. Zou, J. Liu, H. Lin, F. Zhang et al., Electrochemical fabrication of copper-containing metal-organic framework films as amperometric detectors for bromate determination. Dalton Trans. 45(18), 7728-7736 (2016). https://doi. org/10.1039/C5DT04229A

75. F. Zhang, T. Zhang, X. Zou, X. Liang, G. Zhu, F. Qu, Electrochemical synthesis of metal organic framework films with 
proton conductive property. Solid State Ionics 301, 125-132 (2017). https://doi.org/10.1016/j.ssi.2017.01.022

76. I. Hod, W. Bury, D.M. Karlin, P. Deria, C.W. Kung et al., Directed growth of electroactive metal-organic framework thin films using electrophoretic deposition. Adv. Mater. 26(36), 6295-6300 (2014). https://doi.org/10.1002/ adma.201401940

77. J.F. Feng, X. Yang, S.Y. Gao, J. Shi, R. Cao, Facile and rapid growth of nanostructured ln-BTC metal-organic framework films by electrophoretic deposition for explosives sensing in gas and $\mathrm{Cr}(3+)$ detection in solution. Langmuir 33(50), 14238-14243 (2017). https://doi.org/10.1021/acs.langm uir. $7 \mathrm{~b} 03170$

78. J.F. Feng, S.Y. Gao, T.F. Liu, J. Shi, R. Cao, Preparation of dual-emitting ln@UiO-66-hybrid films via electrophoretic deposition for ratiometric temperature sensing. ACS Appl. Mater. Interfaces 10(6), 6014-6023 (2018). https://doi. org/10.1021/acsami.7b17947

79. S. Li, W. Shi, G. Lu, S. Li, S.C. Loo, F. Huo, Unconventional nucleation and oriented growth of ZIF-8 crystals on nonpolar surface. Adv. Mater. 24(44), 5954-5958 (2012). https ://doi.org/10.1002/adma.201201996

80. D.H. Chen, R. Haldar, B.L. Neumeier, Z.H. Fu, C. Feldmann, C. Wöll, E. Redel, Tunable emission in heteroepitaxial lnsurmofs. Adv. Funct. Mater. 29(37), 1903086 (2019). https ://doi.org/10.1002/adfm.201903086

81. Y. Wang, G. Zhang, F. Zhang, T. Chu, Y. Yang, A novel lanthanide mof thin film: the highly performance self-calibrating luminescent sensor for detecting formaldehyde as an illegal preservative in aquatic product. Sens. Actuator B 251, 667-673 (2017). https://doi.org/10.1016/j.snb.2017.05.063

82. S.E. Crawford, K.J. Kim, Y. Yu, P.R. Ohodnicki, Rapid, selective, ambient growth and optimization of copper benzene-1,3,5-tricarboxylate (Cu-BTC) metal-organic framework thin films on a conductive metal oxide. Cryst. Growth Des. 18(5), 2924-2931 (2018). https://doi.org/10.1021/acs. cgd.8b00016

83. G.M. Segovia, J.S. Tuninetti, S. Moya, A.S. Picco, M.R. Ceolín, O. Azzaroni, M. Rafti, Cysteamine-modified ZIF-8 colloidal building blocks: direct assembly of nanoparticulate mof films on gold surfaces via thiol chemistry. Mater. Today Chem. 8, 29-35 (2018). https://doi.org/10.1016/j.mtche m.2018.02.002

84. M.A. Gordillo, D.K. Panda, S. Saha, Efficient mof-sensitized solar cells featuring solvothermally grown [100]-oriented pillared porphyrin framework-11 films on zno/fto surfaces. ACS Appl. Mater. Interfaces 11(3), 3196-3206 (2019). https://doi. org/10.1021/acsami.8b17807

85. Y. Wang, F. Zhang, Z. Fang, M. Yu, Y. Yang, K.L. Wong, $\mathrm{Tb}$ (iii) postsynthetic functional coordination polymer coatings on $\mathrm{ZnO}$ micronanoarrays and their application in small molecule sensing. J. Mater. Chem. C 4(36), 8466-8472 (2016). https://doi.org/10.1039/C6TC01511E

86. Y.M. Zhu, C.H. Zeng, T.S. Chu, H.M. Wang, Y.Y. Yang, Y.X. Tong, C.Y. Su, W.T. Wong, A novel highly luminescent lnmof film: a convenient sensor for $\mathrm{Hg}^{2+}$ detecting. J. Mater. Chem.
A 1(37), 11312-11319 (2013). https://doi.org/10.1039/c3ta1 $1925 d$

87. J. Zhang, D. Yue, T. Xia, Y. Cui, Y. Yang, G. Qian, A luminescent metal-organic framework film fabricated on porous $\mathrm{Al}_{2} \mathrm{O}_{3}$ substrate for sensitive detecting ammonia. Microporous Mesoporous Mat. 253, 146-150 (2017). https://doi. org/10.1016/j.micromeso.2017.06.053

88. V. Rubio-Giménez, M. Galbiati, J. Castells-Gil, N. AlmoraBarrios, J. Navarro-Sánchez et al., Bottom-up fabrication of semiconductive metal-organic framework ultrathin films. Adv. Mater. 30(10), 1704291 (2018). https://doi.org/10.1002/ adma.201704291

89. Y.N. Li, S. Wang, Y. Zhou, X.J. Bai, G.S. Song et al., Fabrication of metal-organic framework and infinite coordination polymer nanosheets by the spray technique. Langmuir 33(4), 1060-1065 (2017). https://doi.org/10.1021/acs.langm uir.6b04353

90. X.J. Bai, D. Chen, L.L. Li, L. Shao, W.X. He et al., Fabrication of mof thin films at miscible liquid-liquid interface by spray method. ACS Appl. Mater. Interfaces 10(31), 25960 25966 (2018). https://doi.org/10.1021/acsami.8b09812

91. J.U. Balderas, D. Navarro, V. Vargas, M.M. Tellez-Cruz, S. Carmona, C. Falcony, Ultrasonic spray deposition as a new route to luminescent MOF film synthesis. J. Lumines. 212, 322-327 (2019). https://doi.org/10.1016/j.jlumi n.2019.04.051

92. B.H. Wang, B. Yan, Tunable multi-color luminescence and white emission in lanthanide ion functionalized polyoxometalate-based metal-organic frameworks hybrids and fabricated thin films. J. Alloy. Compd. 777, 415-422 (2019). https://doi.org/10.1016/j.jallcom.2018.10.406

93. B.H. Wang, B. Yan, Polyoxometalate-based metal-organic framework nenu-5 hybrid materials for photoluminescence tuning by introducing lanthanide ions and their functionalized soft ionogel/thin film. CrystEngComm 21(7), 11861192 (2019). https://doi.org/10.1039/C8CE01979G

94. K.M. Ishihara, F. Tian, Semiconducting langmuir-blodgett films of porphyrin paddle-wheel frameworks for photoelectric conversion. Langmuir 34(51), 15689-15699 (2018). https://doi.org/10.1021/acs.langmuir.8b03236

95. J. Li, X. Yuan, Y.N. Wu, X. Ma, F. Li, B. Zhang, Y. Wang, Z. Lei, Z. Zhang, From powder to cloth: facile fabrication of dense MOF-76( $\mathrm{Tb})$ coating onto natural silk fiber for feasible detection of copper ions. Chem. Eng. J. 350, 637-644 (2018). https://doi.org/10.1016/j.cej.2018.05.144

96. H. Wang, S. Han, J. Wang, L. Dun, B. Zhang, X. Chen, W. Li, C. Li, Crystal structure, thermal behavior and luminescence of a new manganese(ii) coordination polymer constructed with 1, 10-phenanthroline-5, 6-dione and 2, 5-dihydroxyl-1, 4-terephthalic acid. J. Mol. Struct. 1204, 127466 (2020). https://doi.org/10.1016/j.molst ruc. 2019.127466

97. Y. Sun, B.X. Dong, W.L. Liu, An adjustable dual-emission fluorescent metal-organic framework: effective detection of multiple metal ions, nitro-based molecules and DMA. 
Spectrochim. Acta A 223, 117283 (2019). https://doi. org/10.1016/j.saa.2019.117283

98. R.Q. Miao, Q.Q. Zhou, S.Q. Wang, X.Y. Cheng, D.F. Wang, R.B. Huang, Solvent-induced $\mathrm{Zn}$ (ii) coordination polymers with 1, 3, 5-benzenetricarboxylic acid. J. Mol. Struct. 1184, 219-224 (2019). https://doi.org/10.1016/j. molstruc.2019.02.015

99. X. Liu, B. Fu, L. Li, Y.F. Jian, S. Shu, Synthesis, crystal structure and photoluminescence of a three-dimensional zinc coordination compound with nbo-type topology. Acta Crystallogr. C 75(Pt 3), 277-282 (2019). https://doi. org/10.1107/S205322961900189X

100. W. Xu, H. Chen, Z. Xia, C. Ren, J. Han et al., A robust $\mathrm{Tb}$ (iii)-MOF for ultrasensitive detection of trinitrophenol: matched channel dimensions and strong host-guest interactions. Inorg. Chem. 58(12), 8198-8207 (2019). https://doi. org/10.1021/acs.inorgchem.9b01008

101. X. Shi, Y. Fan, J. Xu, H. Qi, J. Chai et al., Layer-structured lanthanide coordination polymers constructed from 3,5-bis(3,5-dicarboxylphenyl)-pyridine ligand as fluorescent probe for nitroaromatics and metal ions. Inorg. Chim. Acta 483, 473-479 (2018). https://doi.org/10.1016/j. ica.2018.08.050

102. L.N. Zheng, F.H. Wei, H.M. Hu, C. Bai, X.L. Yang, X. Wang, G. Xue, Lanthanide coordination polymers constructed from the asymmetrical n-heterocyclic rigid carboxylate: synthesis, crystal structures, luminescence properties and magnetic properties. Polyhedron 161, 47-55 (2019). https://doi.org/10.1016/j.poly.2018.12.030

103. R.R.F. Fonseca, R.D.L. Gaspar, I.M. Raimundo, P.P. Luz, Photoluminescent $\mathrm{Tb}^{3+}$-based metal-organic framework as a sensor for detection of methanol in ethanol fuel. J. Rare Earths 37(3), 225-231 (2019). https://doi.org/10.1016/j. jre.2018.07.006

104. R.F. Mendes, D. Ananias, L.D. Carlos, J. Rocha, F.A.A. Paz, Photoluminescent lanthanide-organic framework based on a tetraphosphonic acid linker. Cryst. Growth Des. 17(10), 5191-5199 (2017). https://doi.org/10.1021/acs.cgd.7b00667

105. M. Kumar, L.H. Wu, M. Kariem, A. Franconetti, H.N. Sheikh, S.J. Liu, S.C. Sahoo, A. Frontera, A series of lanthanide-based metal-organic frameworks derived from furan-2,5-dicarboxylate and glutarate: structure-corroborated density functional theory study, magnetocaloric effect, slow relaxation of magnetization, and luminescent properties. Inorg. Chem. 58(12), 7760-7774 (2019). https://doi. org/10.1021/acs.inorgchem.9b00219

106. S.G.F. de Assis, G.C. Santos, A.B.S. Santos, E.H.L. Falcão, R. da Silva Viana, S.A. Junior, Design of new europiumdoped luminescent mofs for UV radiation dosimetric sensing. J. Solid State Chem. 276, 309-318 (2019). https://doi. org/10.1016/j.jssc.2019.05.008

107. F.H. Zhao, W.Y. Guo, S.Y. Li, Z.L. Li, X.Q. Yan, X.M. Jia, L.W. Huang, J.M. You, Two entangled photoluminescent mofs of naphthalenedisulfonate and bis(benzimidazole) ligands for selective sensing of $\mathrm{Fe}^{3+}$. J. Solid State Chem. 278, 120926 (2019). https://doi.org/10.1016/j.jssc.2019.120926

108. Z. Dou, J. Yu, Y. Cui, Y. Yang, Z. Wang, D. Yang, G. Qian, Luminescent metal-organic framework films as highly sensitive and fast-response oxygen sensors. J. Am. Chem. Soc. 136(15), 5527-5530 (2014). https://doi.org/10.1021/ja411 $224 \mathrm{j}$

109. B. Yang, X. Li, J. An, H. Zhang, M. Liu, Y. Cheng, B. Ding, Y. Li, Designing an "off-on" fluorescence sensor based on cluster-based $\mathrm{Ca}$ (ii)-metal-organic frameworks for detection of L-cysteine in biological fluids. Langmuir 35(30), 98859895 (2019). https://doi.org/10.1021/acs.langmuir.9b01479

110. T. Mondal, D. Haldar, A. Ghosh, U.K. Ghorai, S.K. Saha, A MOF functionalized with CdTe quantum dots as an efficient white light emitting phosphor material for applications in displays. New J. Chem. 44(1), 55-63 (2020). https://doi. org/10.1039/C9NJ04304G

111. X.Y. Liu, K. Xing, Y. Li, C.K. Tsung, J. Li, Three models to encapsulate multicomponent dyes into nanocrystal pores: a new strategy for generating high-quality white light. J. Am. Chem. Soc. 141(37), 14807-14813 (2019). https://doi. org/10.1021/jacs.9b07236

112. J.X. Li, Q.L. Guan, Y. Wang, Z.X. You, Y.H. Xing, F.Y. Bai, L.X. Sun, A lanthanide-organic crystalline framework material encapsulating 1,3,6,8-tetrakis(p-benzoic acid)pyrene: selective sensing of $\mathrm{Fe}^{3+}, \mathrm{Cr}_{2} \mathrm{O}_{7}{ }^{2-}$ and colchicine and whitelight emission. New J. Chem. 44(4), 1446-1454 (2020). https ://doi.org/10.1039/C9NJ05175A

113. Y.H. Luo, A.D. Xie, W.C. Chen, D. Shen, D.E. Zhang, Z.W. Tong, C.S. Lee, Multifunctional anionic indium-organic frameworks for organic dye separation, white-light emission and dual-emitting $\mathrm{Fe}^{3+}$ sensing. J. Mater. Chem. C 7(47), 14897-14903 (2019). https://doi.org/10.1039/C9TC05113A

114. Y. Tang, T. Xia, T. Song, Y. Cui, Y. Yang, G. Qian, Efficient energy transfer within dyes encapsulated metal-organic frameworks to achieve high performance white light-emitting diodes. Adv. Opt. Mater. 6(24), 1800968 (2018). https://doi. org/10.1002/adom.201800968

115. Y.P. Xia, C.X. Wang, L.C. An, D.S. Zhang, T.L. Hu, J. Xu, Z. Chang, X.H. Bu, Utilizing an effective framework to dye energy transfer in a carbazole-based metal-organic framework for high performance white light emission tuning. Inorg. Chem. Front. 5(11), 2868-2874 (2018). https://doi. org/10.1039/C8QI00747K

116. A. Wang, Y.L. Hou, F. Kang, F. Lyu, Y. Xiong et al., Rare earth-free composites of carbon dots/metal-organic frameworks as white light emitting phosphors. J. Mater. Chem. C 7(8), 2207-2211 (2019). https://doi.org/10.1039/C8TC0 $4171 \mathrm{G}$ 